\title{
Fission Product Plateout and Liftoff in the MHTGR Primary System: A Review
}

Manuscript Completed: January 1991

Date Published: April 1991

Prepared by

R. P. Wichner

Oak Ridge National Laboratory

Operated by Martin Marietta Energy Systems, Inc.

Oak Ridge National Laboratory

Oak Ridge, TN 37831-6285

\section{DISCLAIMER}

This report was prepared as an account of work sponsored by an agency of the United States Government. Neither the United States Government nor any agency thereof, nor any of their employees, makes any warranty, express or implied, or assumes any legal liability or responsi-

Prepared for

Division of Regulatory Applications

Office of Nuclear Regulatory Research

U.S. Nuclear Regulatory Commission

Washington, DC 20555

NRC FIN A9477

Under Contract No. DE-ACO5-840R21400 bility for the accuracy, completeness, or usefulness of any information, apparatus, product, or process disclosed, or represents that its use would not infringe privately owned rights. Reference herein to any specific commercial product, process, or service by trade name, trademark, manufacturer, or otherwise does not necessarily constitute or imply its endorsement, recommendation, or favoring by the United States Government or any agency thereof. The views and opinions of authors expressed herein do not necessarily state or reflect those of the United States Government or any agency thereof.

\section{"IASTER \\ dro}




\section{DISCLAIMER}

This report was prepared as an account of work sponsored by an agency of the United States Government. Neither the United States Government nor any agency Thereof, nor any of their employees, makes any warranty, express or implied, or assumes any legal liability or responsibility for the accuracy, completeness, or usefulness of any information, apparatus, product, or process disclosed, or represents that its use would not infringe privately owned rights. Reference herein to any specific commercial product, process, or service by trade name, trademark, manufacturer, or otherwise does not necessarily constitute or imply its endorsement, recommendation, or favoring by the United States Government or any agency thereof. The views and opinions of authors expressed herein do not necessarily state or reflect those of the United States Government or any agency thereof. 


\section{DISCLAIMER}

Portions of this document may be illegible in electronic image products. Images are produced from the best available original document. 
a. 


\begin{abstract}
A review is presented of the technical basis for predicting radioactivity release resulting from depressurization of an MHTGR primary system. Consideration is restricted to so called dry events with no involvement of the steam system. The various types of deposition mechanisms effective for iodine, cesium, strontium, and silver are discussed in terms of their chemical characteristics and the nature of the materials in the primary system. Emphasis is given to iodine behavior, including means for estimating the quantity available for release, the types of "plateout" locations in the primary system, and the effect of dust on distribution and release. The behavior of fission products cesium, strontium, and silver in such accidents is presented qualitatively.

A major part of the review deals with expected dust levels, types, and transport. Available information on the level and nature of dust in the HTGR primary system is reviewed. A summary is presented of dust deposition and liftoff mechanisms. It was concluded that recent approaches to dust liftoff modeling, based on turbulent burst concepts for removal from surfaces, probably offer advantages over the current shear ratio approach.

This study concludes that iodine releases from dry depressurization events are likely to be extremely low, on the order of millicuries, due to a predictably low degree of chemical desorption, a low degree of dust liftoff, and a low involvement of iodine with dust. It was also concluded that deposition mechanisms controlling the distribution of fission product material in the primary system, and hence also controlling the degree of liftoff, depend strongly on the chemical nature of the individual elements. Therefore contrary to the current practice, both plateout and liftoff models should reflect those unique chemical and physical properties.
\end{abstract}


ABSTRACT

LIST OF FIGURES

vii

LIST OF TABLES

ix

ABBREVIATIONS

$\mathrm{xi}$

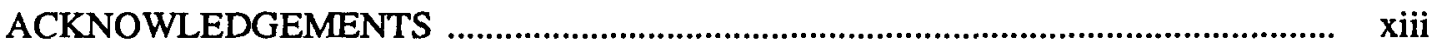

1. INTRODUCTION

1.1 OBJECTIVES AND SCOPE

1.2 FISSION PRODUCT CATEGORIES …....................................................... 1

1.3 FP FORMATION AND ABUNDANCE ................................................. 3

1.4 FP RELEASE FROM FUEL ................................................................. 5

1.5 FP DEPOSITION LOCATIONS AND MECHANISMS................................ 14

2. CHEMICAL ENVIRONMENT ........................................................................ 17

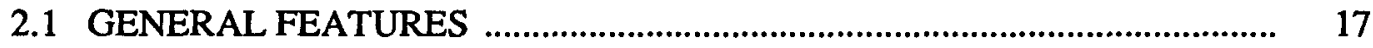

2.2 IMPURITY SOURCES AND EFFECTS ................................................... 17

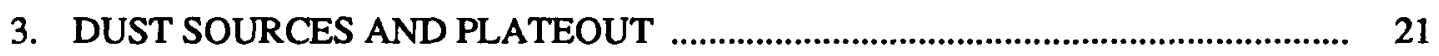

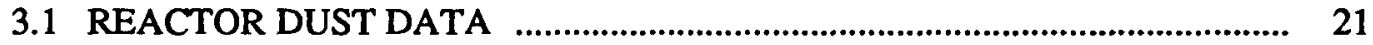

3.2 DUST PLATEOUT MODELS …................................................................. $\quad 30$

3.3 PREDICTED DEPOSITION RATES …................................................. 37

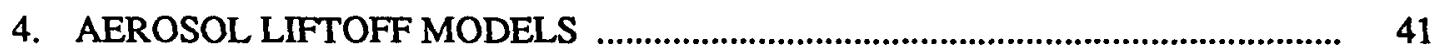

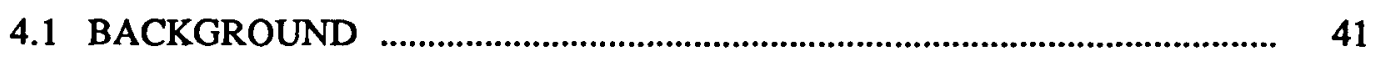

4.2 FORCES ON A PLATED PARTICLE ........................................................ 44

4.3 LIFTOFF BASED ON FORCE RATIO .................................................... 49

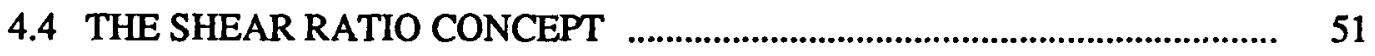

4.5 TURBULENT BURST CONCEPTS OF CLEAVER AND YATES …................................................................................... 53

4.6 PARTICLE “DESORPTION” MODEL ….................................................. 53

4.7 TURBULENT ENERGY THEORY OF WEEKS AND

4.8 CONCLUSIONS REGARDING THE STATUS OF LIFTOFF

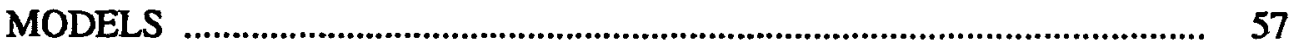

5. IODINE PLATEOUT AND LIFTOFF ESTIMATE .......................................... 59

5.1 IODINE RELEASE FROM FUEL .......................................................... 60

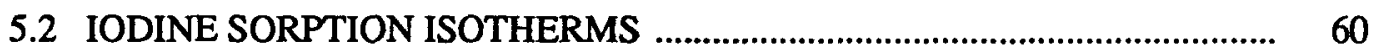

5.3 IODINE DISTRIBUTION APPROXIMATIONS …........................................ 67

5.4 AMOUNT OF IODINE IN THE PS UNDER NORMAL
OPERATING CONDITIONS

5.5 QUANTITY OF IODINE IN THE PRIMARY SYSTEM

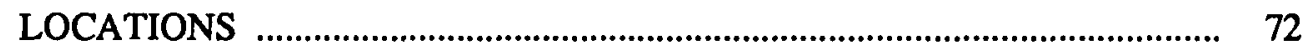


5.6 RELEASE OF IODINE DUE TO DEPRESSURIZATION ................................ 74

5.7 SUMMARY OF IODINE "LIFTOFF" ........................................................ 78

6. CESIUM, STRONTIUM AND SILVER "LIFTOFF": QUALITATIVE

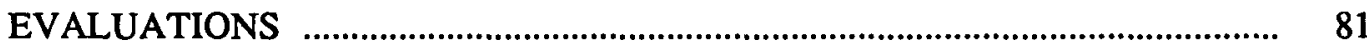

6.1 CESIUM PLATEOUT AND LIFTOFF …………................................... 81

6.2 SILVER PLATEOUT AND LIFTOFF ................................................. 83

6.3 STRONTIUM PLATEOUT AND LIFTOFF ……....................................... 85

7. DOE PLATEOUT AND LIFTOFF PROGRAM ……………………………........ 86

8. SUMMARY AND CONCLUSIONS ............................................................. 89

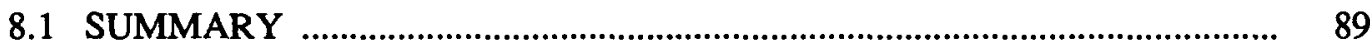

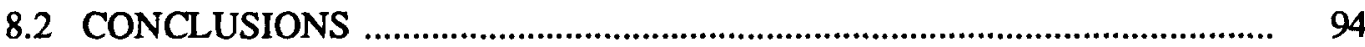

9. REFERENCES ……................................................................................ 96

APPENDIX A. FORMATION DIAGRAMS FOR THE PRINCIPAL IODINE, CESIUM, STRONTIUM, AND SILVER NUCLIDES ........................ 99

APPENDIX B. DUST PLATEOUT AND CALCULATIONAL METHOD ……....................................................................... 105

APPENDIX C. DERIVATION OF THE FORCE RATIO LIFTOFF

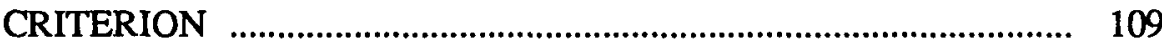

APPENDIX D. MODEL FOR CHEMISORPTIVE DESORPTION ............................. 113 


\section{LIST OF FIGURES}

Figure

Page

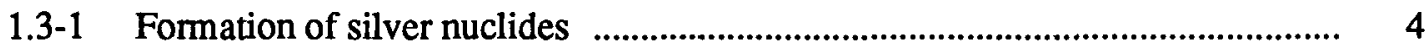

1.4-1 Fission gas release from contamination ...................................................... 8

1.5-1 Fission product plateout mechanisms ............................................................ 14

2.2-1 Influences on the chemical environment in the primary system ...................... 18

3.1-1 Circulating dust concentrations, Peach Bottom HTGR Core 2

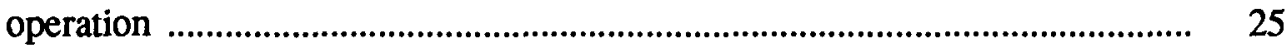

3.2-1 Particle sticking fractions vs Stokes No. and particle size, for hard particles and surfaces ...................................................................................... 32

3.2-2 Diffusion and thermophoretic deposition velocities for typical steam generator conditions ..................................................................................... 36

3.2-3 Impact fraction of particles in cross-flow to a cylinder .................................. 36

3.3-1 Dust deposition in the steam generator-comparison of mechanisms for "soot" particles ................................................................................................... 38

3.3-2 Dust deposition in the steam generator-comparison of mechanisms for "rust" particles .................................................................................................. 39

4.1-1 Liftoff velocity vs particle diameter for high and low adhesive force estimates (based on force ratio model) ........................................................... 42

4.1-2 Representative dust plateout configurations and factors affecting particle liftoff

4.2-1 Idealized situation used for Force Ratio model ….......................................... 47

5.2-1 Iodine sorption isotherms for low alloy steel (T-22) ........................................ 63

5.2-2 Assumed Langmuir isotherm for iodine on $\mathrm{H} 451$ graphite at $400^{\circ} \mathrm{C}$................. 64

5.6-1 Shear ratios in the steam generator predicted by RATSAM .......................... 76

A.1 Formation of iodine nuclides ................................................................. 100

A.2 Formation of cesium nuclides .............................................................. 101

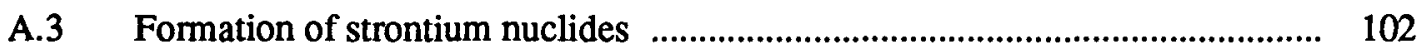

A.4 Formation of silver nuclides ............................................................... 103

D.1 Situation assumed for chemical desorption model ........................................ 113 



\section{LIST OF TABLES}

Table

1.2-1 Fission product categories

1.3-1 Equilibrium masses and activities of principal I, Cs, $\mathrm{Sr}$, and $\mathrm{Ag}$ nuclides in the MHTGR core

1.4-1 Comparison of expected DOE and FRG fuel particle failure fractions

1.4-2 As-manufactured defects and EOL fuel particle failure fractions for release of fission gases and metals, projected for the MHTGR

1.4-3 Fuel element temperature distribution and approximate fuel temperatures

3.1-1 Radioactivity on circulating dust in Peach Bottom Core 2

3.1-2 Radioactivity associated with carbon filamentary dust on an end-of-life Peach Bottom fuel element

3.1-3 Peach Bottom Core 2 circulating dust concentrations and estimated dust production rates and plateout levels

4.2-1 Determination of adhesive force constant, A, of Eq. (4.2-2)

4.2-2 Order-of-magnitude lift and drag force on $1 \mu \mathrm{m}$ particle using Eqs. (4.2-3) and (4.2-4)

4.6-1 Wen and Kasper (1989) liftoff model constants

5.1-1 Iodine nuclide release rates from fuel, based on Eqs. (5.1-1) and (5.1-2) and estimated, average failure fractions, Table 4.1-2

5.2-1 Assumed MHTGR dust levels extrapolated from Peach Bottom surveillance data

5.3-1 Plated iodine distribution in the primary system (speculative) 67

5.3-2 Distribution of circulating iodine forms 68 
5.4-1 Estimated sorbed and circulating amounts of the significant iodine isotopes in the primary system at EOL of the MHTGR

5.4-2 Iodine removal rate constants from the primary systems 72

5.5-1 Estimated iodine levels in the MHTGR primary system at EOL 73

5.5-2 Comparison of predicted MHTGR circulating I131 concentration on dust with Peach Bottom surveillance data 73

5.6-1 Quantities of iodine chemically desorbed due to depressurization 74

5.6-2 Predicted degrees of dust liftoff for two locations in the MHTGR steam generator 77

6.1-1 Typical impurity compositions for determination of gaseous species 82

6.1-2 Gaseous cesium species predicted for compositions in Table 6.1-1 


\section{ABBREVIATIONS}

BOL Beginning-of-life

EFPD

Equivalent full power days

EOL

End-of-life

FG

Fission gases

FP

Fission product

HM

Heavy metal, i.e., primarily uranium

MHTGR

Modular High Temperature Gas-Cooled Reactor

PS

Primary system

PyC

Pyrocarbon

SG

Steam generator 



\section{ACKNOWLEDGEMENTS}

Several people have given me significant help in the performance of this study which I must gratefully acknowledge. A. L. Wright (Chemical Technology Division) provided reports from his extensive files on the key topic of aerosol liftoff which undoubtedly saved several months labor. Numerous and extensive discussion with B. F. Myers (Metals and Ceramics Division) were invaluable in providing detailed information on fuel behavior. O. Stansfield (Metals and Ceramics Division) provided very helpful guidance regarding the thrust of the DOE program in the area of FP plateout and liftoff. 


\section{INTRODUCTION}

\subsection{OBJECTIVE AND SCOPE}

The objective of this study is to evaluate the technical status of modeling the "liftoff" release of fission products from the primary systems of an MHTGR resulting from a dry depressurization accident. Ultimately, the evaluation may be used to aid in policy making with respect to containment requirements for the MHTGR. The term "liftoff" is commonly used to signify a variety of chemical and physical processes that contribute to the removal of fission products from PS surfaces into the gas phase. Similarly "plateout" refers to the various forms of fission product deposits, e.g., chemisorption, attachment to plated dust, chemical compound formation, etc., and is not restricted to its literal meaning. Since "liftoff" forces act on FP material deposited in various ways through the course of normal reactor operation, an essential initial part of the evaluation deals with the prediction of the amount and nature of the deposit, i.e., with "plateout" modeling.

The significant mechanisms affecting plateout, and their response to depressurization conditions, can differ for the various FP elements due to major differences in chemical affinities and physical properties. Therefore, plateout and liftoff prediction methods are first discussed generally, then specifically, referring to particular properties of iodine, cesium, strontium and silver. In this current version of the study, iodine plateout and liftoff modeling is dealt with more thoroughly than the other elements. Conclusions regarding iodine liftoff are based on a sample calculation using simple models. The unique characteristics of cesium, strontium, and silver plateout and liftoff are discussed qualitatively.

\subsection{FISSION PRODUCT (FP) CATEGORIES}

The subdivision of FPs into two groups, the fission gases (including iodine) and the socalled condensables, has been a long-standing practice in HTGR safety analysis. In contrast LWR analysts, beginning with WASH-1400, have employed a finer categorization which more accurately reflects the significant chemical and transport property variations between iodine and the rest of the fission gases and between the various elements within the condensable category. For example, the FP categories used in recently developed LWR severe accident models (e.g., USNRC, 1989) are listed in Table 1.2-1, which is a slight variation from that originally used in WASH-1400.

Since evaluation of several plateout and liftoff phenomena are highly dependent upon these chemical and physical property variations, between FP groups, recognition of the finer categories listed in Table 1.2-1 is more appropriate for plateout and liftoff analysis. The four FP elements highlighted in the table are emphasized in this review; that is, iodine, cesium, strontium, and silver.

The characteristic features of each FP category which bear upon plateout and liftoff in HTGR systems are summarized briefly below. Further illustration of the effect of these property variations is provided in Sect. 1.5 and in sections 5 and 6. 
Table 1.2-1. Fission product categories

\begin{tabular}{|c|c|c|c|}
\hline Group & Name & Elements & $\begin{array}{c}\text { Traditional } \\
\text { HTGR } \\
\text { grouping }\end{array}$ \\
\hline 1 & Noble gases & $\mathrm{Kr}, \mathrm{Xe}$ & Fission gases \\
\hline 2 & Halogens & $\mathrm{Br}, \mathrm{I}^{a}$ & Fission gases \\
\hline 3 & Alkali metals & $\mathrm{Rb}, \mathrm{Cs}^{a}$ & Condensables \\
\hline 4 & Te-group & $\mathrm{Se}, \mathrm{Sb}, \mathrm{Te}$ & Condensables \\
\hline 5 & Alkaline earths & $\mathrm{Sr},{ }^{a} \mathrm{Ba}$ & Condensables \\
\hline 6 & Noble metals & $\mathrm{Mo}, \mathrm{Tc}, \mathrm{Ru}, \mathrm{Rh}, \mathrm{Pd}, \mathrm{Ag}^{a}$ & Condensables \\
\hline 7 & Rare earths & $\mathrm{La}, \mathrm{Ce}, \ldots \ldots, \mathrm{Nb}, \mathrm{Zr}$ & Condensables \\
\hline 8 & Actinides & $\mathrm{Th}, \mathrm{U}, \mathrm{Np}, \mathrm{Pu}$ & Condensables \\
\hline
\end{tabular}

${ }^{a}$ Emphasized in this review.

Noble gases. These form no chemical association. All noble gases that leak from the fuel particle exist in the gas phase, either in the circulating coolant or within graphite pores.

Halogens. Data indicate that these behave approximately like the noble gases with respect to rate of release from fuel particles. However, because of a modest chemical affinity for metals and less for carbon and oxides, halogens outside the fuel tend to chemisorb on solid surfaces, including graphite, metallic piping, and on circulating or plated dust.

Alkali_Metals. These have a higher chemical affinity for graphite than the halogens, tending under some conditions to form weak carbides of various compositions. Under HTGR conditions, cesium contained in graphite is associated principally with the incompletely graphitized binder phase as chemisorbed material. The sorption is sufficiently strong such that graphite appears to be an effective barrier to release from the core under normal operating conditions (Helmbold, 1983). In the circulating helium, the affinity of cesium for oxygen and moisture is such that three vapor species $\mathrm{Cs}, \mathrm{CsO}$ and $\mathrm{CsOH}$ may be prevalent in cooler regions $(\mathrm{T}<500 \mathrm{~K})$ (Feber et al., 1976). At higher temperatures the equilibrium shifts to monatomic Cs as the main gaseous species. The most significant feature of cesium chemistry relative to plateout and liftoff is its high affinity for numerous oxides, particularly chromium and molybdenum oxides, by forming compounds such as $\mathrm{Cs}_{\mathbf{x}} \mathrm{MO}_{\mathbf{y}}$. These form on diffusion of cesium into the oxide protective layer on steel and tend to fix the plated material in place. In addition, such compounds may form with flaked oxide particles circulating as dust, chemically fixing cesium to circulating and plated dust.

The Tellurium Group. This group has not received much study due to prioritization of interests. However tellurium can become a significant hazard under severe accident conditions which, however, appear to be precluded in MHTGRs. The transport characteristics of the elements in this group are not clear. Tellurium may in fact be closer to iodine in behavior than either selenium or antimony. 
The Alkaline Earths. These are highly reactive elements which tend to form modestly strong carbides and extremely stable oxides. Typical concentrations may be insufficient for carbide formation. However, the chemical affinity for carbon is manifested by a strong degree of chemisorption relative to cesium (e.g., Zumwalt, 1983). The chemical affinity for oxygen is so strong that the refractory oxide, SrO, is the expected chemical form outside the core even under the strong reducing conditions which normally exist. Since vapor pressures of alkaline earth oxides are exceedingly low at normal HTGR temperatures, circulating or deposited strontium would most likely exist either as dust particles or as a condensed phase on dust particles.

The Noble Metals. The six elements traditionally listed in this category have significantly different chemical affinities under HTGR conditions, and hence should not be treated as a group. Interest here focuses on silver, due to its high release rate from $\mathrm{PyC}$ and graphite enclosures and the radiologically important Ag-110m nuclide. Silver is a relatively inert material which is expected to exist as the elemental metallic species throughout the primary system. Its diffusion through graphite is unique both for its speed and its dependence on total pressure, indicative of a gas-phase transport mechanism. Its low vapor pressure at HTGR temperatures indicates an existence predominantly as a condensed phase. A property of silver that needs to be considered is its small but possibly significant solubility in nickel, the principal constituent of Incoloy 800 , the MHTGR superheater tubing material.

The Rare Earths. The rare earth group also includes the non-rare earth FPs niobium and zirconium, due to a similarity in chemical affinities. This group generally possesses a high affinity for formation of oxides and carbides. They would likely exist in this refractory form in all except the most severe accident events, and hence are not considerations for MHTGRs.

\subsection{FP FORMATION AND ABUNDANCE}

Formation diagrams for the principal nuclides of iodine, cesium, strontium and silver resulting from thermal fission of U235 are shown in Appendix A. Examination of such diagrams is a necessary early step in a transport analysis in order to determine the possible existence of significant precursor effects. The silver formation diagram is reproduced in Fig. 1.3-1 for illustration and may involve such a precursor transport effect. Note, the Ag110m nuclide is born mainly as Pd109 as signified by the vertical arrow indicating a yield of 0.03 mols per 100 mols of fission. ${ }^{*}$ The formation path leads through $\mathrm{Ag} 109$, which is stable as indicated by the boxed border, followed by neutron absorption for formation of Ag110m. The effective "half-life" of the precursor Ag109 awaiting transmutation is estimated as $\ln 2 / \sigma_{109} \phi_{\text {th }}$, by analogy with radioactive decay. A thermal absorption cross-section of 93.5 barns and thermal flux of $1.88 \times 10^{14} \mathrm{n} / \mathrm{cm}^{2} \mathrm{~s}$ (PSID, 1988) yields an effective "half-life" of 456 days for Ag109. Therefore, if Ag109 transport from the fuel particle is significant for the temperature range of the fuel, a Ag110m production rate based on complete retention of $\mathrm{Ag} 109$ in the fuel would be an overestimate.

\footnotetext{
"The yield from Pu239 is significantly higher.
} 


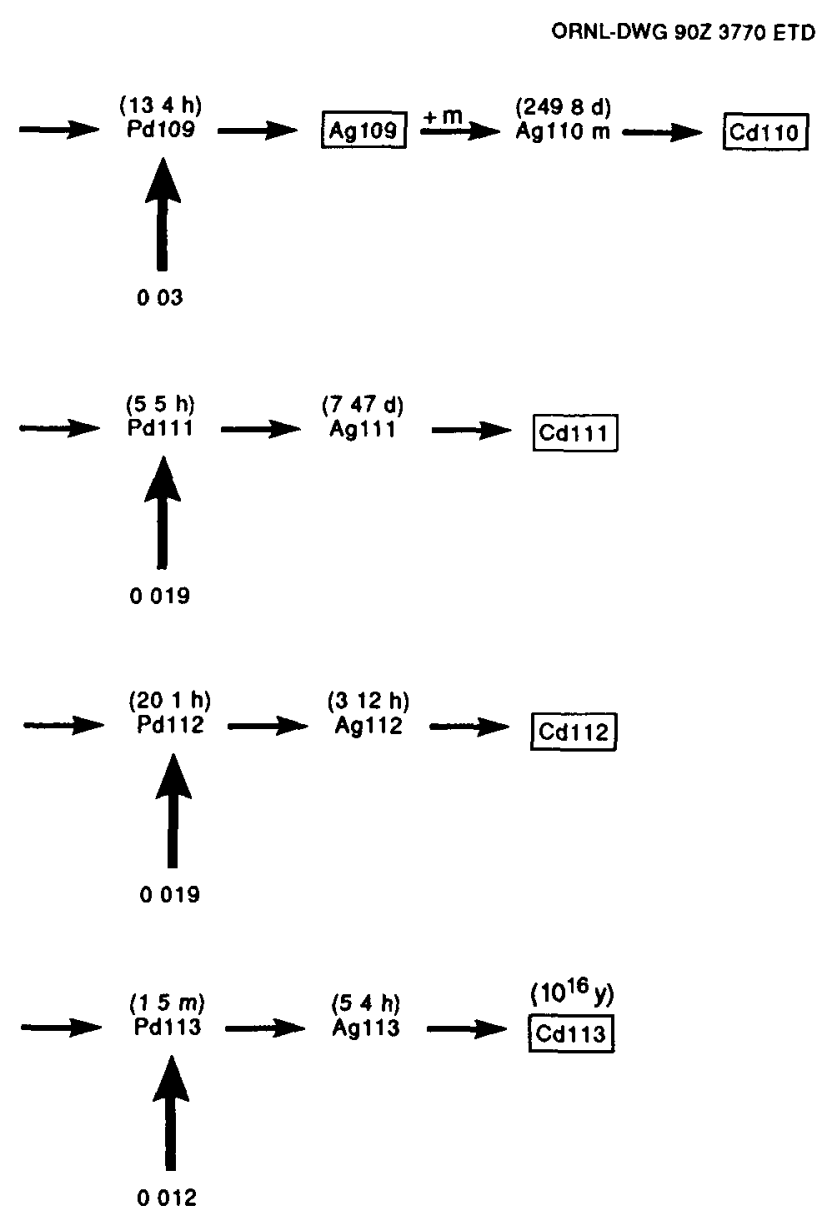

Fig. 1.3-1. Formation of silver nuclides.

Similar situations exist for the formation of the activation products Cs134 from stable Cs133 and for formation of Cs136 from nearly-stable Cs135 (see Fig. A.2). The thermal absorption cross-section for Cs133 is 29 barns which results in an effective "half-life" of more than 3 years. As seen from Fig. A.2, the direct fission yield of Cs136 is small, with the larger part generated by neutron absorption in nearly-stable Cs135. Since Cs 135 has a relatively small absorption cross-section of 8.7 barns, its "half-life" with respect to neutron absorption is about 13 years. Therefore some of the potential source for Cs 136 will be transported from the neutron flux zone as Cs135.

Examination of the formation diagrams for cesium and iodine in Appendix A reveals no other precursor transport events that warrant attention. All iodine nuclides exist in earlier life as less mobile tellurium and as antimony for relatively short times. Hence iodine nuclides should not be significantly effected by precursor transport. A similar situation exists for the cesium nuclides (except for the two cases cited) in that precursors iodine and xenon evidently possess only equal or less mobility in fuel coatings than does cesium and in most cases have fairly short half-lives. 
The situation may be somewhat different for strontium, most of which is born as krypton and decays through rubidium (see Fig. A.3). Evidence indicates that strontium is firmly held by $\mathrm{U}-\mathrm{C}-\mathrm{O}$ kemels for compositions where the $\mathrm{O} / \mathrm{U}$ atom ratio exceeds about 1.7 (Tiegs et al., 1981). The behavior of strontium in such kernels appears to be similar to that in pure oxide kemels, where strontium is held firmly even with damaged coatings. Therefore strontium release rates from damaged fuel particles with kernels of $\mathrm{O} / \mathrm{U}$ ratio exceeding 1.7 may depend on the more mobile precursors, krypton and rubidium. However, the half-lives of the krypton and rubidium precursors of $\mathrm{Sr} 89$ and $\mathrm{Sr} 90$ are relatively short. Therefore the effect could not be very large.

The transport behavior of FPs may also depend on the quantity or concentrations of material in the primary system. For extremely small concentrations typical of FPs, surface adsorption plays a significant role in determining mobility and deposit location. Since all isotopes of a particular FP element possess identical chemical properties, the effective sorbtivity of a particular isotope depends in part on the total concentration for the element. This frequently means that transport behavior of important nuclides must be understood in terms of total element masses, which are usually dominated by the stable or near-stable nuclides. For this purpose, the total masses of the important nuclides of I, Cs, Sr, and $\mathrm{Ag}$ present at equilibrium in the MHTGR core is summarized in Table 1.3-1, [PSID (1986)]. A small fraction of these masses would be present outside the core as a result of failed fuel particle and uranium contamination. We note that the transport behavior of iodine would be largely characterized by the behavior of the mass numbers 127 and 129 which predominate with $96 \%$ of the element mass. We may also note that the cesium abundance in the equilibrium core is relatively high amounting to about $34 \mathrm{~kg}$, and that the important $\mathrm{Ag} 110 \mathrm{~m}$ nuclide represents only about $0.2 \%$ of the total mass of silver.

\subsection{FP RELEASE FROM FUEL}

\subsubsection{Expected Fuel Failure Fractions}

A comprehensive discussion of this extensive subject is beyond the scope of this review. However, some evaluation is necessary in view of the direct relation between the degree of plateout over the life of the reactor and the integrity of the fuel particle coatings. It is the DOE's goal, as stated by Williams et al., (1989) to restrict the degree of plateout by use of fuel particles manufactured to high standards. The goal is to limit as-manufactured defects that lead to nearterm release of fission gases and metals to a fraction of $6 \times 10^{-5}$, a total comprised of 5 parts coating defects and 1 part HM contamination." In addition, other manufacturing defects occur

\footnotetext{
*Note added in review: Two basically different definitions of HM contamination exist, partly for historical and partly for practical reasons. The difference is significant from the stand-point of estimating FP release from failed fuel, including contamination. Definition 1 as the term "contamination" implies, refers to the HM material unintentionally deposited on various fuel element surfaces during manufacture, e.g., on particle coatings. Definition 2 includes all such material plus the HM in exposed, as-manufactured fuel kernels.

The second definition results from the need to base production standards on measurable QC techniques currently in place which do not distinguish between true contamination (i.e., definition-1 contamination) and the HM in exposed kernels. Review comments by Myers (1990) indicate that, in general, HM in as-manufactured exposed kernels exceeds the true contamination level by about a factor of 10. (Footnote continues on page 7.)
} 
Table 1.3-1. Equilibrium masses and activities of principal I, Cs, Sr, and Ag nuclides in the MHTGR core (PSID, 1986)

\begin{tabular}{|c|c|c|c|c|}
\hline Element & $\begin{array}{l}\text { Mass } \\
\text { No. }\end{array}$ & $\begin{array}{l}\text { Half } \\
\text { life }\end{array}$ & $\begin{array}{c}\text { Mass } \\
(\mathrm{kg})\end{array}$ & $\begin{array}{l}\text { Activity } \\
\text { (Ci) }\end{array}$ \\
\hline \multirow[t]{7}{*}{ I } & 127 & $\infty$ & 0.829 & 0 \\
\hline & 129 & $1.6 \times 10^{7} \mathrm{y}$ & 2.43 & $\sim 0$ \\
\hline & 131 & $8.04 \mathrm{~d}$ & 0.0943 & $1.17 \times 10^{7}$ \\
\hline & 132 & $2.29 \mathrm{~h}$ & $1.58 \times 10^{-3}$ & $1.64 \times 10^{7}$ \\
\hline & 133 & $20.8 \mathrm{~h}$ & 0.0185 & $2.10 \times 10^{7}$ \\
\hline & 134 & $52.6 \mathrm{~m}$ & $8.77 \times 10^{-4}$ & $2.34 \times 10^{7}$ \\
\hline & 135 & $6.59 \mathrm{~h}$ & $6.07 \times 10^{-3}$ & $2.14 \times 10^{7}$ \\
\hline \multirow[t]{6}{*}{ Cs } & 133 & $\infty$ & 10.8 & 0 \\
\hline & 134 & $2.06 \mathrm{y}$ & 0.818 & $1.06 \times 10^{6}$ \\
\hline & 135 & $\sim 00$ & 12.0 & $\sim 0$ \\
\hline & 136 & $13.0 \mathrm{~d}$ & $2.67 \times 10^{-3}$ & $1.97 \times 10^{5}$ \\
\hline & 137 & $30.1 \mathrm{y}$ & 10.7 & $9.26 \times 10^{5}$ \\
\hline & 138 & $32.2 \mathrm{~m}$ & $4.80 \times 10^{-4}$ & $2.03 \times 10^{7}$ \\
\hline \multirow[t]{7}{*}{$\mathrm{Sr}$} & 88 & $\infty$ & 5.65 & 0 \\
\hline & 89 & $50.5 \mathrm{~d}$ & 0.661 & $1.92 \times 10^{7}$ \\
\hline & 90 & $29.0 \mathrm{y}$ & 7.05 & $9.67 \times 10^{5}$ \\
\hline & 91 & $4.98 \mathrm{~h}$ & $5.45 \times 10^{3}$ & $1.98 \times 10^{7}$ \\
\hline & 92 & $2.71 \mathrm{~h}$ & $1.56 \times 10^{3}$ & $1.99 \times 10^{7}$ \\
\hline & 93 & $7.5 \mathrm{~m}$ & $7.56 \times 10^{-5}$ & $2.04 \times 10^{7}$ \\
\hline & 94 & $1.29 \mathrm{~m}$ & $1.18 \times 10^{-5}$ & $1.83 \times 10^{7}$ \\
\hline \multirow[t]{5}{*}{$\mathrm{Ag}$} & 109 & $\infty$ & 1.58 & 0 \\
\hline & $110 \mathrm{~m}$ & $252 \mathrm{~d}$ & $2.93 \times 10^{-3}$ & $1.38 \times 10^{4}$ \\
\hline & 111 & $7.47 \mathrm{~d}$ & 0.011 & $1.73 \times 10^{6}$ \\
\hline & 112 & $3.13 \mathrm{~h}$ & $7.84 \times 10^{-5}$ & $7.01 \times 10^{5}$ \\
\hline & 113 & $5.3 \mathrm{~h}$ & $7.61 \times 10^{-5}$ & $3.98 \times 10^{5}$ \\
\hline
\end{tabular}

which, together with some degree of unavoidable in-service damage to the SiC layer, are expected to lead to a failure fraction of $1.2 \times 10^{-4}$ at the end of the 3.5 year fuel element life in the core. This is comparable to the fuel integrity assumptions quoted by Moorman et al. (1986) for use in the German HTR-100 and HTR-500 reactor PRAs. Moorman quotes an asmanufactured fuel defect range from a reference value of $3 \times 10^{-5}$ to an upper limit of $6 \times 10^{-5}$, and an EOL range from $1.0 \times 10^{-4}$ (reference value) to an upper limit of $2 \times 10^{-4}$ (see Table 1.4-1 for a summary). 
Table 1.4-1. Comparison of expected DOE and FRG fuel particle failure fractions

\begin{tabular}{lccc}
\hline & DOE & \multicolumn{2}{c}{ FRG (Moorman, 1986) } \\
\cline { 3 - 4 } & (Williams, 1989) & Reference & Maximum \\
\hline $\begin{array}{l}\text { As-manufactured defects which } \\
\text { release FPs }\end{array}$ & $6 \times 10^{-5}$ & $3.0 \times 10^{-5}$ & $6.0 \times 10^{-5}$ \\
& & & \\
$\begin{array}{l}\text { Total EOL failures which } \\
\text { release FPs }\end{array}$ & $1.2 \times 10^{-4}$ & $1.0 \times 10^{-4}$ & $2.0 \times 10^{-4}$ \\
& & & \\
\hline
\end{tabular}

The types of fuel particle failures which release fission products are generally placed into three categories: (1) cracked coatings which expose the kernel, (2) uranium contamination, i.e., including all uranium outside the kernel ${ }^{*}$ and (3) particles with defective SiC layers. Of these, only the first two release fission gases, which are contained by an intact PyC layer, while fission metals are released by all three types of failures. Estimated as-manufactured defect and EOL failure fractions for each failure type are listed in Table 1.4-2 (Williams, 1989). All of the service-induced kernel exposures are attributed to pressure-induced failures resulting from manufacturing defects (e.g., missing buffer layer). Similarly, most of the service-induced SiC layer failures may result from manufacturing defects of the inner PyC. Alternatively, pressures applied in fabricating the fuel compact may cause some cracking of the $\mathrm{SiC}$ layer which ultimately leads to kernel exposure in-service.

If contamination is grouped with exposed kernels, and if exposed kernels develop at a rate proportional to service life, then values in Table 1.4-2 indicate that the time-average coated particle failure fraction for fission gas release (including iodine) is $3.5 \times 10^{-5}$. The similarly estimated time-average coated particle failure fraction for metal release is $9 \times 10^{-5}$.

Stansfield, et al. (1983) describe the various types of coated fuel particle failures and the mechanisms contributing to in-service failures. Most service failures result from a range of

FP release rate estimates cited below [Sect. 1.4.2, Eq. (1.4-4) and Fig. 1.4-1] refer to the definition-1 type of contamination, the data base being simulated, true contamination. On the other hand, authoritative studies may use definition-2 (e.g., Myers, et al., 1977).

Since fuel specifications must also be set in terms of measured parameters, the as-manufactured HM contamination objective of $1 \times 10^{-5}$ fraction (see Table 1.4-2) currently refers to definition-2 HM contamination, i.e., it includes exposed kemels and "contamination." The significance for FP release from fuel is that definition-1 contamination is a more exposed location and thus results in higher FP release rates than exposed fuel kemels. The net effect is that release rate estimates for short-lived FGs (including all significant iodines except I127 and I129) are significantly too high if definition-1 type HM contamination is assumed, but if in fact the contamination is defined to include the exposed kernels, the difference is about a factor of 10 , approximately the ratio of type-2 to type-1 contamination.

* See footnote beginning on page 5 and continued above. 
Table 1.4-2. As-manufactured defect and EOL fuel particle failure fractions for release of fission gases and metals, projected for the MHTGR (Williams, 1989)

\begin{tabular}{|c|c|c|}
\hline & As-manufactured & $\begin{array}{c}\text { End of normal } \\
\text { service life }\end{array}$ \\
\hline \multicolumn{3}{|l|}{ Fission gas } \\
\hline release & $1 \times 10^{-5}$ & $6 \times 10^{-5}$ \\
\hline Exposed kernels ${ }^{a}$ & $(0)$ & $\left(5 \times 10^{-5}\right)$ \\
\hline Contamination $^{a}$ & $\left(1 \times 10^{-5}\right)$ & $\left(1 \times 10^{-5}\right)$ \\
\hline \multicolumn{3}{|l|}{ Fission metal } \\
\hline release & $6 \times 10^{-5}$ & $12 \times 10^{-5}$ \\
\hline Exposed kernels & $(0)$ & $\left(5 \times 10^{-5}\right)$ \\
\hline Contamination & $\left(1 \times 10^{-5}\right)$ & $\left(1 \times 10^{-5}\right)$ \\
\hline Defective SiC & $\left(5 \times 10^{-5}\right)$ & $\left(6 \times 10^{-5}\right)$ \\
\hline
\end{tabular}

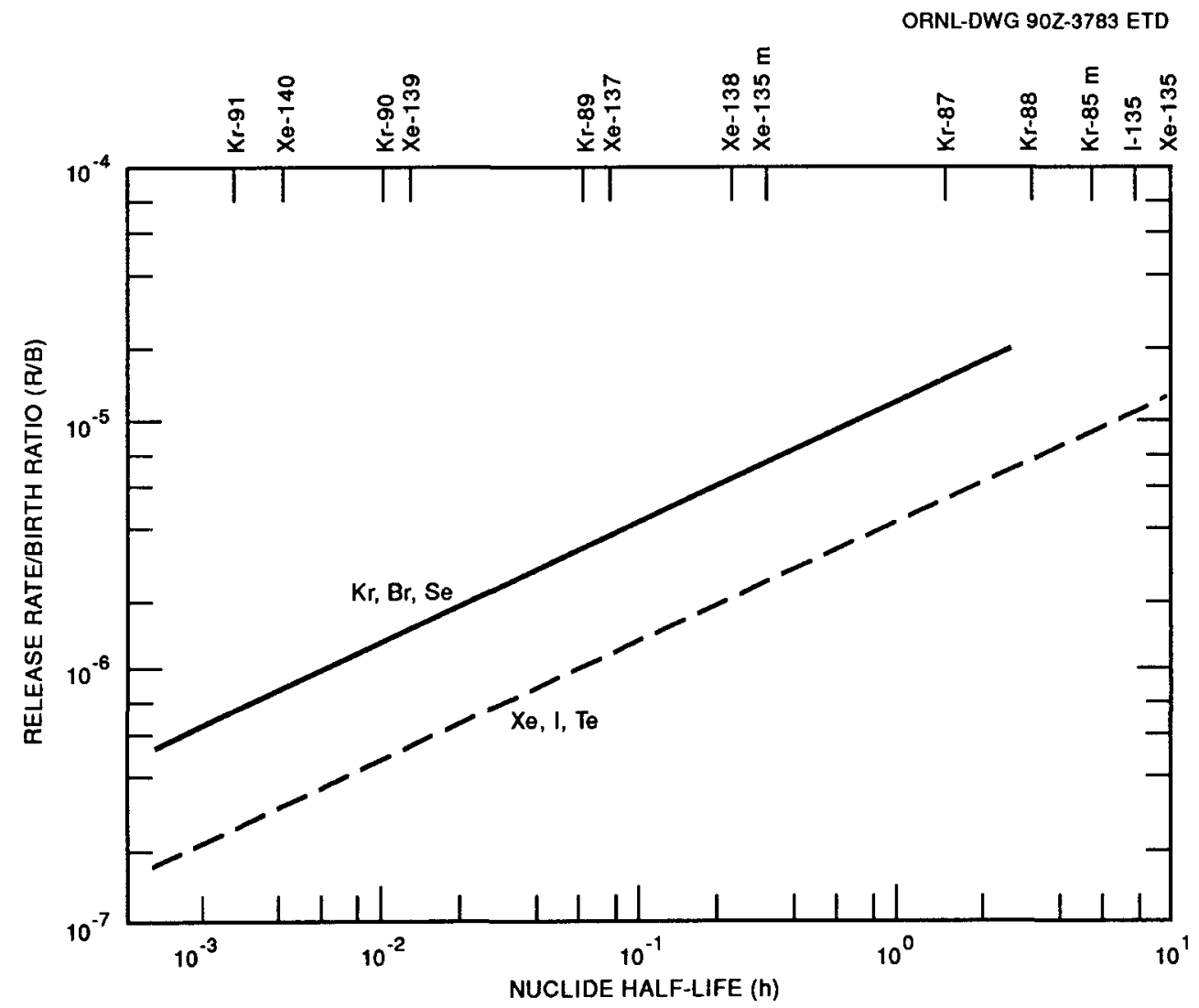

Fig. 1.4-1. Fission gas release from contamination (Stansfield, et al., 1983). Conditions: $\mathrm{T}=1373 \mathrm{~K}\left(1100^{\circ} \mathrm{C}\right)$; contamination fraction $=10^{-4}$ of total $\mathrm{HM}$. 
manufacturing defects which initially retain FPs until some further failure occurs. The onset of the further event which allows FP release from the fuel particle depends on the nature of the defect and, generally, the service environment. The EOL failure fractions quoted in Tables 1.4-1 and 1.4-2 result from estimates of the frequency of the non-releasing defects and the behavior of each in the service environment. The process leading to uranium contamination results from exposure of fuel kernels in the manufacturing process to various coating or vessel surfaces. Therefore, uranium contamination may exist in several exposed locations, particularly coating surfaces and the fuel element matrix material. Release rates from contamination depend on the location of the contamination, and are significantly higher than releases from exposed kernels. ${ }^{*}$ In contrast, exposed kernels may still strongly hold fission products, especially dense kernels operating at moderate temperatures and fission density.

The rate of fission gas and fission metal release from failed and unfailed fuel depends in part on the expected service temperatures during normal operation. Table 1.4-3 lists the distribution of average fuel element temperature expected in normal operation and a rough estimate of the corresponding fuel particle temperatures. We note from the table that only about $10 \%$ of the fuel experiences temperatures above $1200 \mathrm{~K}$. The significance is that Bullock (1983) reports no detectable cesium or silver release from intact fuel particles irradiated at

*See footnote on pages 5 and 7.

Table 1.4-3. Fuel element temperature distribution $a$ and approximate fuel temperatures

\begin{tabular}{|c|c|c|c|}
\hline \multirow{2}{*}{$\begin{array}{l}\text { Fuel block } \\
\text { average } \\
\text { temperature } \\
\text { range } \\
\text { (K) }\end{array}$} & \multirow{2}{*}{$\begin{array}{l}\text { Fuel particle } \\
\text { temperature range } \\
\text { (approximate) } \\
(\mathrm{K})\end{array}$} & \multicolumn{2}{|c|}{$\begin{array}{l}\text { Elements in } \\
\text { stated range }\end{array}$} \\
\hline & & No. & (\%) \\
\hline $600-650$ & $700-750$ & 18 & 2.3 \\
\hline $650-700$ & $750-800$ & 60 & 8.0 \\
\hline $700-750$ & $800-850$ & 81 & 10.8 \\
\hline $750-800$ & $850-900$ & 93 & 12.4 \\
\hline $800-850$ & $900-950$ & 171 & 22.8 \\
\hline $850-900$ & $950-1000$ & 72 & 9.6 \\
\hline $900-950$ & $1000-1050$ & 81 & 10.8 \\
\hline $950-1000$ & $1050-1100$ & 45 & 6.0 \\
\hline $1000-1050$ & $1100-1150$ & 30 & 4.0 \\
\hline $1050-1100$ & $1150-1200$ & 27 & 3.6 \\
\hline $1100-1150$ & $1200-1250$ & 39 & 5.2 \\
\hline $1150-1200$ & $1250-1300$ & 12 & 1.6 \\
\hline $1200-1250$ & $1300-1350$ & 15 & 2.0 \\
\hline \multirow[t]{2}{*}{$1250-1300$} & $1350-1400$ & 6 & 0.8 \\
\hline & TOTAL & 750 & 100.0 \\
\hline
\end{tabular}

$a_{\text {Estimates from S. J. Ball, ORNL. }}$ 
$1173 \mathrm{~K}$ to $20 \%$ FIMA for a variety of kernel types. Therefore, just as for the fission gases, during normal operation most of the fission product metals would be released to the primary system from failed particles and uranium contamination, with possibly a small additional amount due to diffusive release from the $10 \%$ of the fuel above $1200 \mathrm{~K}$.

\subsubsection{Fission Gas Release Rates}

It is generally agreed that the noble gases and iodine are completely contained by intact $\mathrm{PyC}$ and $\mathrm{SiC}$ coatings for the expected range of normal fuel temperatures and for the anticipated duration of the fuel element in the core. Thus the rate of noble gas and iodine release from fuel depends directly on the fuel failure fraction, that is effective for releasing gases, i.e., (1) uranium contamination, and (2) exposed kemels.

Several reviews of fission gas plus iodine release from failed fuel particles are available, including publications by Nabielek and Myers (1982), Pointud and Chenebault (1977) and Myers et al. (1977). Some prefatory remarks regarding release mechanisms may be helpful.

Release rates of "short-lived" gases are frequently expressed by an empirical expression of the form [Myers et al. (1977), Pointud and Chenebault (1977)]

$$
(\mathrm{R} / \mathrm{B})_{\mathrm{i}}=\mathrm{A}\left(\mathrm{T}_{1 / 2}\right)^{\mathrm{n}}
$$

where $(\mathrm{R} / \mathrm{B})_{\mathrm{i}}$ is the release to birthrate ratio for isotope-i with half-life, $\mathrm{T}_{1 / 2}$. Parameters $A$ and $\mathrm{n}$ differ for the low mass and high mass FPs and also vary with temperature and burnup. Data and theory show that for steady-state conditions the exponent, $n$, ranges from $\sim 0.2$ to 0.5 (Myers et al., 1977). High values of " $n$ " signify slow release process (i.e., the greatest dependence on half-life). The lowest values of $n$, which render $R / B$ almost independent of $T_{1 / 2}$, signify rapid transport process with little radioactive decay. The slowest transport process occurs when solid state diffusion through the grain of fuel kernel is limiting. For such case the well-known Booth equation describes steady-state release as approximately,

$$
\frac{\mathrm{R}}{\mathrm{B}}=\frac{3}{\sqrt{\ln 2}} \sqrt{\frac{\mathrm{D} \mathrm{T}_{1 / 2}}{\mathrm{a}^{2}}}
$$

where " $a$ " is the radius of an equivalent sphere representing the grain, D the diffusion coefficient and $T_{1 / 2}$ the half-life. Contribution from more rapid transport processes, such as, recoil into open porosity followed by gas phase diffusion, reduce the half-life dependency to $\left(T_{1 / 2}\right)^{0.2}$ for reactor conditions (Myers, 1977).

Long-lived nuclides experience no radioactive attenuation during transport. Therefore if loss by neutron absorption is neglected, ultimately the steady-state release of long-lived nuclides from failed fuel particles becomes,

$$
\mathrm{R} / \mathrm{B}=1 \text {. }
$$

The half-life range included in the "short-lived" category extends through about $130 \mathrm{hr}(5.3 \mathrm{~d})$. Such data sets generally include Xe133 with the $5.3 \mathrm{~d}$ half-life as its longest lived member. 
Iodine-131, with a $8.04 \mathrm{~d}$ half-life, is slightly outside this range, but the extrapolation is not large and I131 may be considered "short-lived" in this context probably with small error.

Long-lived nuclides in this context are those with half-lives significantly exceeding the transport delay from failed fuel. Data indicate (see below this section) the transport delay to be on the order of $70 \mathrm{~d}$ for iodine. Therefore, long-lived nuclides may be defined for this purpose as having half-lives significantly greater than $70 \mathrm{~d}$. The various mechanisms effective for releasing fission gases from the fuel element (including the fuel particles and the matrix material forming the fuel stick) are the following, listed in order of importance.

(1) Transport from contamination. Typically, this would entail recoil from contamination in the matrix and diffusion into open porosity. ${ }^{*}$ In view of its accessibility, there appears to be general agreement that HM contamination accounts for the predominant share of fission gases released from fuels under MHTGR conditions. Figure 1.4-1 illustrates a model for contamination release at $1373 \mathrm{~K}\left(1100^{\circ} \mathrm{C}\right)$ as a function of half-life for light and heavy FPs where a $10^{-4}$ contamination fraction has been assumed (Stansfield, 1983). Note, this model predicts $\sim 60 \%$ release for $1131\left(T_{1 / 2}=8.04\right.$ days) at $1373 \mathrm{~K}$ from contamination. The equation describing the dashed line in Fig. 1.4-1 (referring to iodine) is the following.

$$
(\mathrm{R} / \mathrm{B})_{\mathrm{c}}=0.0433 \sqrt{\mathrm{T}_{1 / 2}}
$$

where

$$
\begin{aligned}
(\mathrm{R} / \mathrm{B})_{\mathrm{c}} & =\text { release fraction from contamination }, \\
\mathrm{T}_{1 / 2} & =\text { half life }, \mathrm{h} .
\end{aligned}
$$

Analyses have shown (Myers, 1986) that the temperature dependence of mechanism controlling release of fission gas atoms from contamination sources follows a typical Arrhenius form with an activation energy, $\Delta \mathrm{H}$, of approximately $45 \mathrm{~kJ} / \mathrm{mol}$. Therefore, scaling $\mathrm{Eq}$. (1.4-4a) from $1100^{\circ} \mathrm{C}$ to more the typical MHTGR fuel temperature of $1073 \mathrm{~K}\left(800^{\circ} \mathrm{C}\right)$ is achieved by applying the factor,

$$
\exp \left(-\frac{\Delta H}{R \cdot 1073}\right) / \exp \left(-\frac{\Delta H}{R \cdot 1373}\right)=0.33,
$$

to yield

$$
(\mathrm{R} / \mathrm{B})_{\mathrm{c}}=1.43 \times 10^{-2} \sqrt{\mathrm{T}_{1 / 2}}
$$

Note that Eq. (1.4-4b) predicts an $(\mathrm{R} / \mathrm{B})$ of 0.20 for $\mathrm{I} 131\left(\mathrm{~T}_{1 / 2}=193 \mathrm{~h}\right)$ from contamination at $1073 \mathrm{~K}\left(800^{\circ} \mathrm{C}\right)$.

(2) Diffusive release from fuel grains. The majority of R/B data for short-lived nuclides are presented in the form of Eq. (1.4-1) with exponent value near 0.5 , signifying that diffusion

\footnotetext{
${ }^{*}$ See footnote, Sect. 1.4.1, pages 5 and 7.
} 
in the grain is the controlling step as per Eq. (1.4-2). For example, data presented by Vanslager, et. al. (1970) for xenon and iodine release from Peach Bottom Core 1 fuel are correlated by

$$
(\mathrm{R} / \mathrm{B})_{\mathrm{k}}=5.00 \times 10^{-4} \sqrt{\mathrm{T}_{1 / 2}}
$$

with $\mathrm{T}_{1 / 2}$ expressed in hours. Since Peach Bottom Core 1 fuel experienced $100 \%$ fuel failure rate (as a result of using an early fuel particle design), the measured (R/B)s for short-lived fission gases, reflected in Eq. (1.4-5a), would be the result primarily of diffusive release from exposed kernels, dominating over contamination release. Peach Bottom HTGR fuel operated at higher temperatures than projected for the MHTGR conditions, therefore, Eq. (1.4-5a) should overpredict diffusive releases from exposed kernels relative to failed fuel in the MHTGR. Applying the same temperature corrections factor of 0.33 used to modify the expression for contamination release at $1100^{\circ} \mathrm{C}$ to more typical MHTGR fuel temperatures yields the $R / B$ for diffusive release from kernels,

$$
(\mathrm{R} / \mathrm{B})_{\mathrm{k}}=1.65 \times 10^{-4} \sqrt{\mathrm{T}_{1 / 2}}
$$

Combining expressions for contamination and exposed kernel release yields,

$$
(R / B)=f_{c} \cdot 0.0143 \sqrt{T_{1 / 2}}+f_{k} \cdot 1.65 \times 10^{-4} \sqrt{T_{1 / 2}}
$$

where $f_{c}$ and $f_{k}$ are contamination and exposed kernel fractions, respectively, and $T_{1 / 2}$ is expressed in hours. DOE design objectives for the time-average values of $f_{c}$ and $f_{k}$ are $1 \times 10^{-5}$ and $2.5 \times 10^{-5}$ respectively, as noted in Table 1.4-2.

Equation (1.4-6) indicates that for typical MHTGR fuel conditions, the bulk of the shortlived fission gas release (including all iodines except mass numbers 127 and 129) results from contamination. For example using the design values, $f_{c}=1 \times 10^{-5}$ and $f_{k}=2.5 \times 10^{-5}$, Eq. (1.4-6) indicates that the fractional release from exposed kernels amounts to $2.8 \%$ of the total release, the balance being from contamination. Equation (1.4-6) predicts a surprisingly large fractional decay of $\mathrm{I131}$ in transit from exposed kernels. Using $\mathrm{T}_{1 / 2}=193 \mathrm{~h}$ (8.04d) yields a fractional decay of $99.77 \%$, consistent with a delay time of $\sim 70$ days.

The release rate of stable or near stable nuclides, I127 and I131, are required for characterization of the chemical behavior of iodine in the primary systems. Such nuclides experience no radioactive attenuation during transport, and hence have $R / B$ values of unity. Relationships cited by Myers et al. (1977) indicate that steady state values of unity for "longlived" FPs may be established within a few months.

(3) Eission recoil from the kernel surface. Recoil from the kernel into the buffer layer is sometimes mentioned as a significant contributor to fission gas release, and may be under certain limited circumstances. According to Nabielek, et. al. (1982), the recoil range for heavy fission products is $\sim 7.7 \mu \mathrm{m}$ which would contribute an $R / B$ value of 0.033 from the $350 \mu \mathrm{m}$ diameter kernel. However, the recoiled fission product, departing at high velocity, embeds in the surrounding buffer layer where it remains as embedded material evidently for significantly longer than $100 \mathrm{~h}$, allowing almost complete decay of nuclides with half-lives less than $\sim 100 \mathrm{~h}$. 
Evidence for this is the observation that R/B data for short-lived nuclides taken under reactor conditions generally follow a half-life dependence of the form given by Eq. (1.4-1). In contrast, the recoil-delay mechanism results in a distinctly different half-life dependence which is not seen in any available data set acquired at near realistic temperatures and pressures. However, the recoil-delay transport mechanism may be significant early in the service life when the kernel yet retains its high, as-manufactured density and at low irradiation temperatures $\left(\mathrm{T}<\sim 800^{\circ} \mathrm{C}\right.$, Myers, 1977) which reduce diffusive releases from the kernel. In this condition the basic assumption leading to Eq. (1.4-2) is not valid, namely that the kernel consists of individual grains surrounded by open porosity and diffusive releases predominate. Myers (1990) indicates that the recoil-delay mechanism may be significant up to burnups of $\sim 0.5 \%$ FIMA.

\subsubsection{Metallic FP Release Rates}

Metallic FPs generally have higher diffusivities in PyC and $\mathrm{SiC}$ than the fission gases, but also higher chemical affinities (except for silver) which effect transport through graphite. Diffusivities of metallic FPs through the PyC coatings, which completely stop the fission gases, are sufficiently high so that an intact $\mathrm{SiC}$ coating is required to prevent diffusive release of the metals from fuel particles.

Several recent studies present a fairly consistent picture for release of metals from fuel, except for silver. Bullock (1983) reports that annealing tests at $1173 \mathrm{~K}\left(900^{\circ} \mathrm{C}\right.$ ) for five different types of fuel (including the MHTGR reference fuel) irradiated to 20\% FIMA in HRB$15 \mathrm{~B}$ completely retained $\mathrm{Cs}, \mathrm{Ag}, \mathrm{Eu}$ and $\mathrm{Ce}$ (and presumably also $\mathrm{Sr}$ ). We note from Table 1.4-3 that $\sim 90 \%$ of the fuel under normal operating conditions is expected to lie below this temperature.

Data presented by Groos et al. (1977) agree with Bullock for Sr and Cs release from Triso particles in the 1073 to $1173 \mathrm{~K}$ temperature range, but there is disagreement for silver. Whereas $\mathrm{Sr}$ and Cs releases were observed to be below the detection range of $10^{-9}$, much higher silver releases were observed, at about $3 \times 10^{-2}$ fraction, approximately the same as observed for defective particles. For fuel above about $1300 \mathrm{~K}$, expected to include about $3 \%$ of the MHTGR core (Table 2.3-2), silver releases reached about 0.09 fraction. [The difference with respect to Bullock's (1983) data may be due to the fact the data were acquired under irradiation conditions while Bullock's were obtained using post-irradiation anneals.] Groos also observed some elevated cesium release rates in the 1300 to $1373 \mathrm{~K}$ temperature range. In this range releases of $2 \times 10^{-4}$ were observed, about twice the detection level. This appears to indicate that there may be some amount of diffusive release of cesium from MHTGR fuel above $1300 \mathrm{~K}$, i.e., from about $3 \%$ of the fuel, over and above the release from failed fuel and HM contamination.

Nabielek et al. (1977) report that silver is not held by U-C-O kemels as it is by pure oxide kernels, and its release through $\mathrm{SiC}$ is somewhat unpredictable, perhaps dependent on $\mathrm{SiC}$ coating quality. In a later paper, Nabielek and Myers (1982) conclude that intact Triso particles retain $\mathrm{Cs}$ and $\mathrm{Sr}$ to temperatures well above that expected in normal operation, but that silver is readily released above $\sim 1423 \mathrm{~K}\left(1150^{\circ} \mathrm{C}\right)$. According to this conclusion, some diffusive silver release may be expected in the higher temperature portion of the MHTGR core from intact particles. 
The calculational approach taken in the GA code TRAFIC, as described by Alberstein et al. (1975), is to treat metallic FP release from Triso particles under normal operation in the same way as fission gas release, i.e., depending exclusively on the failed fuel particle fraction and HM contamination. This approach may slightly underestimate Cs release from Triso particles and perhaps more than slightly underestimate silver release.

\subsection{FP DEPOSITION LOCATIONS AND MECHANISMS}

\subsubsection{General Features}

The principal "plateout" mechanisms effective under normal operating conditions are illustrated in Fig. 1.5-1. The term "plateout" is commonly used loosely to signify a number of diverse temporary and permanent FP fixation mechanisms. As the figure shows, the initial environment surrounding fission products on leakage from fuel is graphite, which offers a number of types of storage mechanisms within its large mass $\left(\sim 2 \times 10^{5} \mathrm{~kg}\right)$ containing about $2 \times$ $10^{8} \mathrm{~m}^{2}$ of internal surface. Chemisorptive capacities for iodine, cesium and strontium are reported in terms of their respective sorption isotherms.

Other retention mechanisms within graphite are possible but have not been observed and therefore must be considered only hypothetical. These are indicated by the dashed ovals in Fig. 1.5-1. Numerous materials, notably cesium and rubidium may insinuate themselves

*The FP inventory in fuel particles with exposed kemels, not normally included with "plateout," may also be noted as subject to transport during dry depressurization.

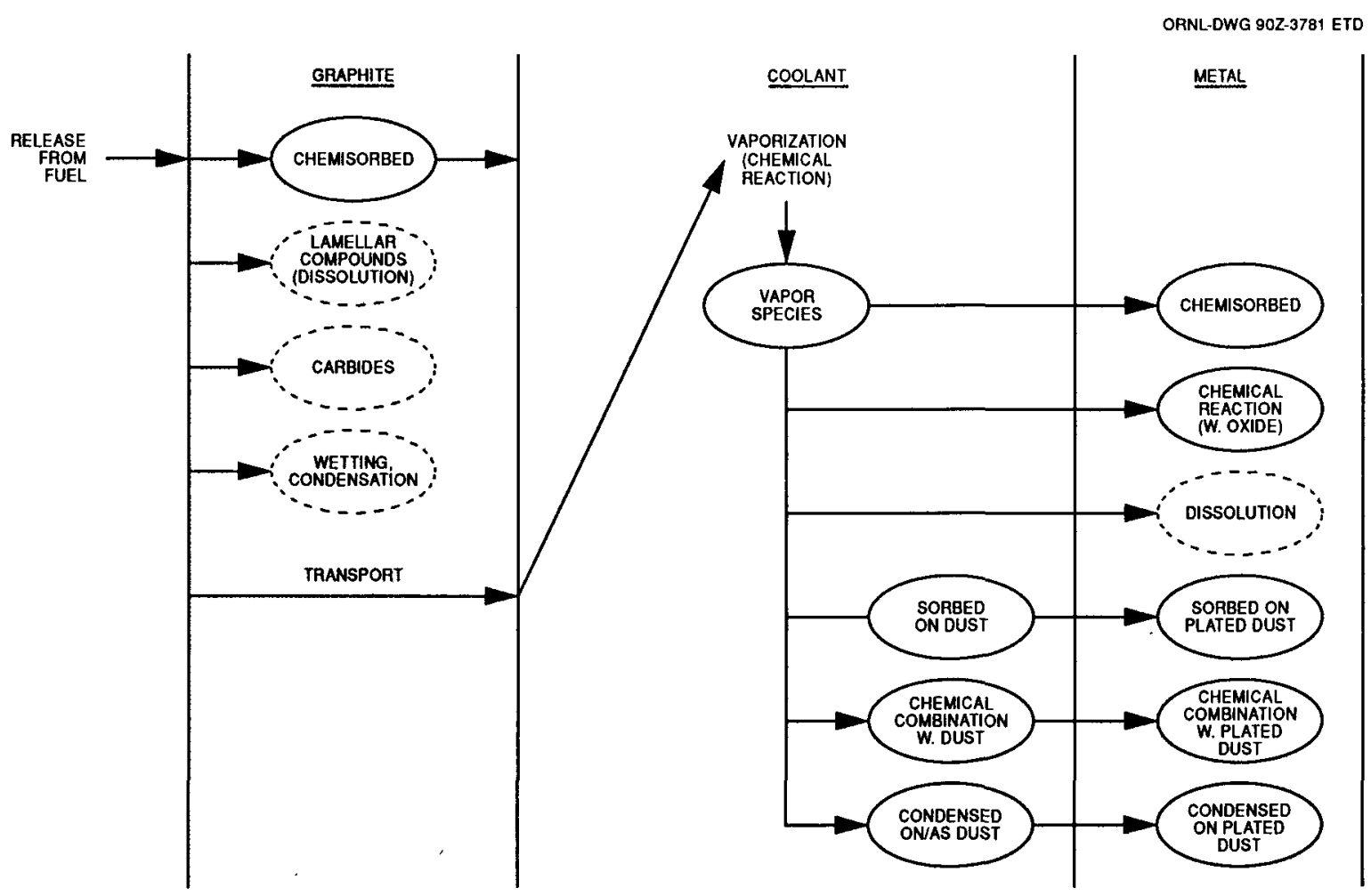

Fig. 1.5-1. Fission product plateout mechanisms. 
between the crystallite planes within graphite to form lamellar compounds of variable composition, and which could also be considered as a form of solubility. However, observations have not identified such an association for an MHTGR condition. Instead, cesium in HTGR-irradiated graphite appears to be associated with the binder phase, where it is considered to be chemisorbed. In addition, some materials such as strontium, show a strong thermodynamic driving force for stable carbide formation. However, required strontium concentrations for carbide formation are evidently not attained in reactor use, and hence carbide-formation is not expected.

At graphite surfaces, the sorbed FPs equilibrate with gaseous forms that circulate with the helium coolant. In tum, the circulating gaseous compounds can form various types of chemical associations with other contacting solid materials, both the circulating dust and the steel surfaces of the SG tubing and pressure boundary. As indicated, these associations may range from simple physical condensation, to chemisorption, or chemical compound formation. For materials which tend to form stable compounds (like cesium-metal-oxides or SrO), liftoff behavior depends critically on the competition for these compounds between the fixed surfaces and the circulating or plated dust material.

\subsubsection{General Deposition and Liftoff Characteristics of Iodine}

The chemical behavior of iodine under normal PS conditions is relatively simple and well known, at least based on observations made at generally higher concentrations. There is always the chance that unexpected chemical associations occur at the minute concentration levels $\left[\sim 10^{-10} \mathrm{~Pa}\left(10^{-15} \mathrm{~atm}\right)\right.$ partial pressure $]$ of the MHTGR PS. With this caution aside, the "plateout" behavior of iodine in the PS may be described with fair confidence.

Based on equilibrium estimates, the chemically similar gaseous species, I and $\mathrm{HI}$ predominate in high temperature locations with equilibrium shifting to $I_{2}$ in cooler regions. No stable chemical compound formation is expected at these temperatures and concentrations with any of the major materials in the PS. Also, no dissolution or diffusion into any material is expected.

The major chemical form in the PS is clearly expected to be as a chemisorbed layer on all surfaces to varying degrees. The sorptivity [defined as mols sorbed/(area.partial pressure)] of metallic surfaces of alloys is significantly higher than other surfaces, as may be surmised from the observation that iodine will form chemical compounds with many metals, including iron and chromium, at higher concentrations and lower temperatures. The sorptivity on oxidized surfaces of alloys is perhaps a factor of 100 lower than bare metal (Osbome, et al., 1982) and about a factor of $10^{6}$ lower on graphite [Lorenz, et al. (1982)], again, relative to bare metal. Since the circulating dust in the PS appears to be principally non-metallic, (see Sect. 3), the chemisorptive association of iodine with dust may not be significant except at high dust levels. It is also important to observe that the enormous available surface of graphite $\left(\sim 1 \mathrm{~m}^{2} / \mathrm{g}\right)$ tends at least partly to offset its low sorptivity. This is discussed quantitatively in Sect. 5.

As for chemisorption generally, equilibrium shifts away from sorption toward the gaseous forms with increasing temperature. Hence the principal repository for iodine in the PS is 
expected to be the cooler region of the SG, where both the surface material and temperature favor chemisorption.

The blowdown release of iodine therefore involves first determining the relative distribution of the total iodine quantity between the principal circulating forms and sorption surfaces. The response of these repository locations needs then to be analyzed under specified depressurization conditions. Osborne et al. (1982) and Lorenz et al. (1982) have shown that iodine chemisorption on steel and graphite is reversible as expected, however not always completely or instantaneously, especially below $\sim 700 \mathrm{~K}$. However, presumption of instantaneous absorptive equilibrium during depressurization appears to be a fair approximation. The behavior of iodine associated with plated dust is far more problematical, depending on a series of poorly known chemical and physical items, namely, (1) the dust quantity, (2) its chemical nature with respect to iodine sorptivity, (3) its effective surface area for sorption per unit mass, (4) its distribution between circulating and plated locations, and (5) the behavior of plated dust on depressurization.

An attempt to evaluate the relative significance of these processes forms a large part of this report. Section 5 is devoted to placing these chemical and physical factors in context by attempting to quantitatively go through a "plateout" and "liftoff" estimate for iodine using dust source data cited in Sect. 3, dust liftoff model information reviewed in Sect. 4, and the sorptive character of the various surfaces. Qualitative features of cesium, silver and strontium liftoff behavior are presented in Sect. 6 . 


\section{CHEMICAL ENVIRONMENT}

\subsection{GENERAL FEATURES}

The chemical environment within the primary system forms the basis of understanding and predicting the various phenomena involved with plateout and liftoff. Dust formation, the condition of metallic surfaces, and the chemical forms of fission product elements are some of the factors effecting disposition of the small quantity of fission products which escape the fuel during normal operation. In turn, the physical and chemical form as well as the quantity of the deposited material is the necessary starting point for estimating the degree of release from the primary system as a consequence of depressurization. While general factors effecting the chemical condition of the primary system are known as trends or in a qualitative way, many important specific details are not known. As a result, a definitive physico-chemical basis for predicting plateout and liftoff quantitatively does not exist. A clear symptom of this situation is the persistent uncertainty in the predicted degree of liftoff despite years of study.

The chemical character of the primary system is dominated by the presence of the graphite core which imposes a reducing environment throughout, except under some steam or air ingress accident conditions. The effect of graphite is dominant because it contains the highest temperatures, possesses the greatest surface area (counting internal porosity), and unlike the metallic surfaces which are coated with an oxide diffusion barrier, graphite presents a chemically clean surface for interaction with circulating impurities.

\subsection{IMPURITY SOURCES AND EFFECTS}

The gaseous impurity sources and some of the resulting effects are illustrated in Fig. 2.2-1. Oxidants such as moisture may enter through small leaks in the steam generator tubing, and air may enter during refueling and maintenance operations. Reaction of these oxidants with graphite produce principally $\mathrm{CO}$ and $\mathrm{H}_{2}$. A balance is struck by chemical equilibration between the level of the oxidizing species, $\mathrm{H}_{2} \mathrm{O}$ and $\mathrm{CO}_{2}$, and the oxidation products $\mathrm{CO}$ and $\mathrm{H}_{2}$, depending on the chemical reactivity of the core, the rate of oxidant inleakage, and the rate of purification flow. Though the oxygen concentration becomes vanishingly small, the oxidizing power of the environment is defined in terms of an oxygen potential, $\mu_{0_{2}}$ defined by

$$
\mu_{0_{2}}=R T \ln \left(P_{0_{2}} / P_{0_{2}}^{0}\right)
$$

where $\mathrm{P}_{\mathrm{O}_{2}}$ is the partial pressure of oxygen and $\mathrm{P}_{\mathrm{O}_{2}}^{\mathrm{o}}$ is the reference pressure conventially taken as $10^{5} \mathrm{~Pa}(\sim 1$ atmosphere).

In addition to steam and air ingress, graphite outgassing of air (oxygen and nitrogen), $\mathrm{H}_{2}$ diffusion through steam generator tubing and inleakage of lubricant (water or oil) provide material to the primary circuit which contribute to the overall chemical environment. Herein lies one of the principal difficulties in formulating plateout and liftoff predictive methods; namely, that different reactor types have inherently different impurity ingress rates which create different primary system environments. The result may be significantly different plateout and 
ORNL-DWG 90Z-3772 ETD

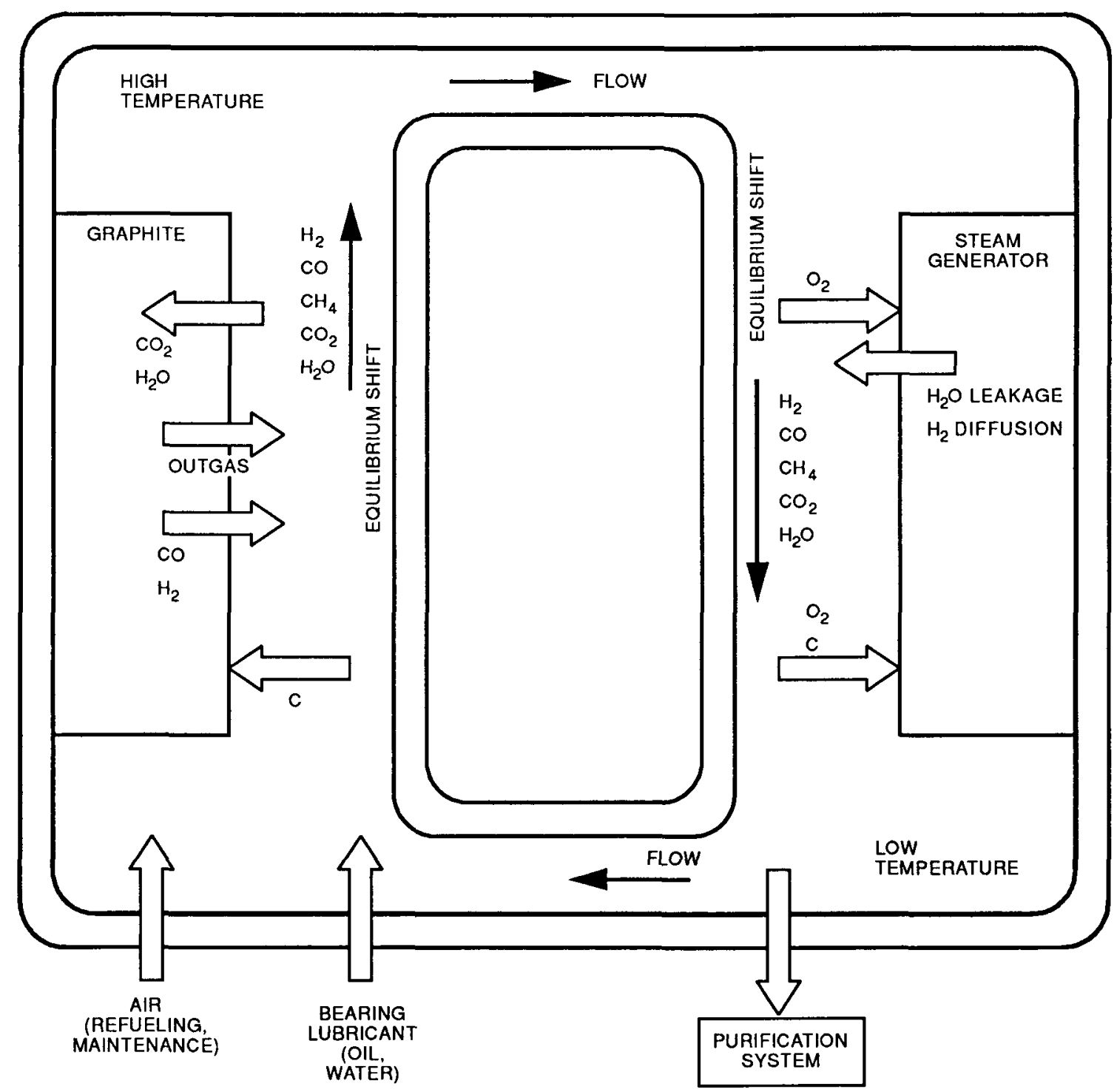

Fig. 2.2-1. Influences on the chemical environment in the primary system.

liftoff characteristics between reactor types. The same may hold true for different reactors within a particular type (which, for example, could easily have significantly different steam ingress rates) or for in-pile or out-of-pile experiments. Without a sound physico-chemical basis for understanding the various phenomena affecting plateout and liftoff, it is difficult to extrapolate observations from a particular reactor, in-pile or out-of-pile test to some future situation.

As shown in Fig. 2.2-1, the principal gaseous species resulting from the interaction of the impurities with graphite are the reducing species $\mathrm{CO}, \mathrm{H}_{2}$ and a smaller amount of $\mathrm{CH}_{4}$, in 
balance with the oxidizing species $\mathrm{H}_{2} \mathrm{O}$ and $\mathrm{CO}_{2}$. Equilibrium amounts of each may be predicted by methods which minimize the total chemical potential (or free energy) of the system, including gaseous, sorbed, pure condensed and dissolved material, under constraints of constant mass, and either constant volume and/or constant pressure. Such methods, however, do not apply to a non-isothermal, flow situation unless it can be shown that chemical equilibration is rapid compared with the flow circuit time of $\sim 10 \mathrm{~s}$. If such is the case, the flow loop may be subdivided into lumped parameter cells and free energy minimization applied to each cell. However, since equilibration required gas/solid reactions and mass interchange between phases, chemical equilibration is probably incomplete at each location, available equilibrium methods are probably not accurate. At the other extreme, if chemical equilibration is quite slow relative to the $10 \mathrm{~s}$ circuit time, or if mass transport resistances effectively retard reactions, alterations of the gas phase composition around the primary circuit would be far smaller than predicted from differences in temperature. An additional consideration, which is important for high surface to volume ratio systems, is the proper accounting of adsorbed and dissolved species in free energy minimization. Frequently, however, free energy data for sorbed and dissolved species is lacking.

Passage of the coolant and impurities from low to high temperatures in the core (i.e., from $532 \mathrm{~K}$ to $960 \mathrm{~K}$ ) tends to shift the equilibrium mixture shown in Fig. 2.2-1 towards an increase in reducing species concentrations, due to a shift to the right in the principal oxidation reactions;

$$
\begin{aligned}
& \left(\mathrm{H}_{2} \mathrm{O}\right)+\langle\mathrm{C}\rangle=(\mathrm{CO})+\left(\mathrm{H}_{2}\right), \text { and } \\
& \left(\mathrm{CO}_{2}\right)+\langle\mathrm{C}\rangle=2(\mathrm{CO})
\end{aligned}
$$

The equilibrium constant for each of the above reactions increases by about a factor of $10^{4}$ between inlet and outlet temperatures of the core. However, mass transport controls limit the actual compositional swing to a much lower range. Conversely, flow from high to low temperature through the heat exchanger tends to shift the above reactions to the left, tending to increase levels of the oxidizing species, $\mathrm{H}_{2} \mathrm{O}$ and $\mathrm{CO}_{2}$, and to deposit carbon in some form. Such is the essential mechanism of the Carbon Transport Cycle described by Everett et al. (1967), Gainey (1977) and others. A portion of carbon formed at the lower circuit temperatures becomes circulating or deposited dust; i.e., the carbon transport cycle is one of several dust-producing mechanisms in the primary system. In addition, some of the carbon deposited in the steam generator may form carbides with the more reactive alloying constituents, chromium and molybdenum, which consequently effects the chemisorptive characteristics of the surface. The special conditions required for carbide formation are described by Gainey (1977). The complex nature of the carbide-forming mechanism is described by Plumlee (1984).

In addition to steam and air, impurity ingress from the circulator lubrication system has in the past occasionally been significant. Water ingress from the water-lubricated thrust bearing at FSV on occasion added large amounts of oxidizing material to the primary system, undoubtedly

\footnotetext{
*The brackets ( ) and $<>$ signify gas and solid.
} 
contributing to dust formation via the carbon transport mechanism. The oil lubrication system for the Peach Bottom HTGR also malfunctioned at times, injecting oil into the primary system. As opposed to water, oil ingress reduced the oxygen potential of the primary system by the net addition of $\mathrm{H}_{2}$ and methane, and also produced dust as a result of pyrolysis. The net effect of oil pyrolysis may be symbolically written:

$$
\text { oil } \rightarrow \mathrm{C}+\mathrm{H}_{2}+\mathrm{CH}_{4} \text {. }
$$

The oil injected in the cold leg would begin pyrolysis at $\sim 600 \mathrm{~K}$ as the coolant entered the core, forming the dust deposits observed in the Peach Bottom Surveillance program (Dyer, et al., 1977).

Two other impurity sources shown in Fig. 2.2-1 are diffusive transport of $\mathrm{H}_{2}$ through steam generator tubing and graphite outgassing. Hydrogen diffusion may occur in either direction, depending on the relative partial pressures of $\mathrm{H}_{2}$ on the steam and He sides. Graphite outgassing contributes principally $\mathrm{N}_{2}, \mathrm{O}_{2}$ and $\mathrm{H}_{2} \mathrm{O}$ adsorbed on the graphite as a result of air exposure prior to reactor insertion. (Adsorbed $\mathrm{N}_{2}$ on graphite is the principal source of $\mathrm{C}-14$ in the core.) Some $\mathrm{N}_{2}$ may also enter with the steam inleakage due to dissolved air in the feedwater. 


\section{DUST SOURCES AND PLATEOUT}

\subsection{REACTOR DUST DATA}

If present in sufficient quantity and if physico-chemical conditions permit significant association of FPs with dust material, the inventory of circulating and plated dust in the PS may play an important role in determining the degree of activity release due to depressurization. However, dust levels have only minor impact on the total FP inventory in the PS.* Principally dust may effect (1) the FP circulating fraction, consequently the amount available for direct depressurization release, (2) the plateout distribution throughout the PS, and (3) the chemical and physical form of both plated and circulating FPs.

Despite this potentially key role, there is only sparse information available on dust types, quantities and other characterization data representative of real HTGR dust. Therefore, a fairly heavy reliance is placed here on the relatively comprehensive dust examinations conducted in the Peach Bottom, Core 2 Surveillance Program. Peach Bottom HTGR dust data tend to be discounted due to the sporadic lubricating oil ingresses during the early stages of Core 2 operation. However, dust formation mechanisms generally expected in HTGRs operated as well in Peach Bottom, and the oil ingress events are not sufficiently significant to warrant discarding the information, especially since there is very little else. Peach Bottom Core 2 dust data are contained mainly in the primary system surveillance report (Dyer et al., 1977).

Dust examinations were also conducted on the Peach Bottom Core 1 system as reported by Busch, et. al. (1972). However, these data are extremely difficult to interpret quantitatively in view of the extensive fuel element damage experienced in Core 1.

The only other HTGR for which dust data exist is the AVR. However, at this date (10/31/89) only a very brief synopsis is available. However, it is fairly clear from the available AVR information that the principal dust-producing mechanism in pebble bed reactors is graphite abrasion, which contributes to high levels of graphite particulates. In contrast, graphite abrasion is far less significant in prismatic HTGRs. Therefore, dust types and quantities are likely to be significantly different in these two types of HTGRs.

\subsubsection{Peach Bottom Core 2 Surveillance}

Several types of measurements dealing with dust in the primary system were performed and reported by Dyer, et. al. (1977) including:

(1) Coolant sampling for circulating dust by means of isokinetic samplers placed upstream and downstream from the steam generator,

(2) examination of dust collected by cyclone separators located in a continuously operating bypass line,

(3) examination of dust collected from deposit locations on two fuel elements.

\footnotetext{
*The small effect is due to the influence of circulating dust on the level of circulating FPs and, therefore, on the removal rate to the purification system. The effect is small because FPs are predominantly plated in one form or another for anticipated dust levels, as is shown in Sect. 5 , and consequently largely unaffected by the purification flow.
} 
Other measurements monitored fission gas levels in the primary coolant and plated radioactivity levels along accessible portions of the cold duct. Companion examinations dealt with characterizing a series of fuel elements (the last in the series is Wichner et al., 1979). The Peach Bottom Surveillance reports are principally data transmission reports, containing very little in the way of interpretation or modeling. ${ }^{*}$

Some of the relevant dust data are abstracted below including the types of circulating dust observed, indicative of dust formation mechanisms, observed dust concentrations and their associated radioactivity levels. An attempt is made to interpret the data in terms of dust production rates and resulting plateout levels.

Observed types of Peach Bottom dust. The following types of dust were observed by means of metallographic and SEM examination of samples taken from the circulating coolant, the cyclone separator, and fuel element exterior.

(1) Graphite particles were clearly evident in the cyclone separator samples in sizes ranging from $\sim 0.5 \mu \mathrm{m}$ to $\sim 100 \mu \mathrm{m}$. (The collection efficiency of the cyclone separator was low for sizes $<0.5 \mu \mathrm{m}$.) The formation mechanism evidently was abrasion due to relative movement of fuel elements. Pebble bed reactors therefore would certainly contain far higher graphite dust levels than prismatic fuel types.

(2) Rust flakes were seen in both the circulating coolant and cyclone separator samples. Sizes ranged from $\sim 0.2 \mu \mathrm{m}$ to tens of microns. These particles are identified by their distinctive shape and iron or chromium content, but compositions varied. Iron carbide $\left(\mathrm{Fe}_{3} \mathrm{C}\right)$ was identified in early circulating coolant samples. Later samples contained iron oxide instead, occasionally magnetic $\mathrm{Fe}_{3} \mathrm{O}_{4}$. The potential for chemical complexity of "rust flakes" formed from Incoloy 800 and $2.25 \mathrm{Cr}$-1Mo steels in the primary systems is indicated in a recent study by Schneider et al. (1989).

(3) Carbon filaments, superficially resembling sooty deposits were taken from the exterior of fuel elements. Approximately $200 \mathrm{mg}$ were taken from each of two elements, which, for 800 fuel elements, represents $\sim 0.16 \mathrm{~kg}$ of such a dust deposit in the core. The filaments ranged from $\sim 0.1$ to $0.5 \mu \mathrm{m}$ diameter and were several microns in length. According to Busch et al. (1972), such pyrocarbon structures grow from the gas phase via the reaction,

$$
2 \mathrm{CO}=\mathrm{CO}_{2}+\mathrm{C} \text {, }
$$

which is the deposition end of the carbon transport cycle. If so, similar deposits would exist in cooler portions of the steam generator. Gainey (1977) indicates that this deposition reaction is catalytically enhanced. Spectrographic analysis of the filaments revealed it to consist primarily of carbon (92 wt\%) with the balance almost exclusively iron (7.94 wt\%).

(4) Construction debris dominated the earlier cyclone separator samples and persisted to a smaller extent throughout the sampling period. Most prominant were large pieces of steel insulating foil.

\footnotetext{
*However, the surveillance data were used to develop a tritium pathways analysis (Wichner and Dyer, 1977), a carbon-14 budget (Wichner and Dyer, 1980) for Peach Bottom Core 2 operation, and an analysis of strontium diffusion in graphite (Haire, 1979).
} 
(5) Other types of dust. This category is included to illustrate that much of the dust material was not clearly identified. For example X-ray diffraction showed the existence of some complex silicates of unknown origin. Early "rust" particles contained $\mathrm{Fe}_{3} \mathrm{C}$ and an iron-silicon compound which left no diffraction pattern. Later samples were primarily oxides but contained some elemental iron and no $\mathrm{Fe}_{3} \mathrm{C}$. Much remains unknown regarding the nature of the dust and its formation mechanisms.

\section{Radioactivity Associated with Circulating Dust}

Table 3.1-1 lists observed activity levels on circulating dust samples acquired during Peach Bottom Core 2 operation. The isokinetic sample designation listed in Column 1, relates the data to its tabulated source in Dyer et al. (1977). Note sample acquisition times are given in terms of EFPDs, and samplers were located both upstream and downstream from the SG. These values are approximate because the total amount of dust on the various portions of the sampler was difficult to determine accurately.

It is well to note here the differences between the Peach Bottom HTGR and the MHTGR which may contribute to differences in dust activity levels.

(1) Peach Bottom fuel had a quite high failure fraction of $2.8 \times 10^{-3}$, as manufactured, and from $1.7 \times 10^{-3}$ to $1.9 \times 10^{-2}$ observed in an end-of-life element (Wichner and Botts, 1978). Therefore, the radioactivity levels on dust noted in Table 3.1-1 may be higher than for the MHTGR.

(2) Fully enriched fuel was used as opposed to $20 \%$ enrichment for the MHTGR. Therefore, $\mathrm{Ag} 110 \mathrm{~m}$ production would be significantly higher in the MHTGR, reflecting the higher mass 109 yields from Pu fissions.

(3) The Peach Bottom fuel element contained an intemal gas purge flowing through charcoal traps located within each element. An equivalent trapping mechanism exists in MHTGRs in the graphite surrounding the fuel sticks, but trapping efficiencies may be significantly different.

Given these differences, the Peach Bottom Core 2 data on activities associated with circulating dust cannot be directly projected to MHTGR conditions.

The most distinctive feature of the data in Table 3.1-1 is the rapid rise in cesium activity on dust near the end of core life at 897 EFPDs. This signifies a diffusive breakthrough of cesium either through the fuel element graphite or the charcoal trap in the fuel element.

Few data exist for activities associated with the carbon filamentary dust observed on fuel element exteriors. These are given in Table 3.1-2 for dust taken from an end-of-life fuel element. Note, these activity levels are about an order of magnitude higher than that associated with the circulating dust samples.

\section{Quantity of Circulating Dust Peach Bottom Core 2}

Figure 3.1-1 shows the measured dust concentrations during Peach Bottom Core 2 operation (Dyer et al., 1977). The circles refer to data collected by the isokinetic samplers; the 
Table 3.1-1. Radioactivity on circulating dust in Peach Bottom Core 2 (Dyer et al., 1977)

\begin{tabular}{|c|c|c|c|c|c|c|c|c|}
\hline \multirow{2}{*}{$\begin{array}{c}\text { Sampler } \\
\text { designation }\end{array}$} & \multirow{2}{*}{$\begin{array}{c}\text { Final } \\
\text { sample } \\
\text { time } \\
\text { (EFPDs) }^{b}\end{array}$} & \multirow{2}{*}{$\begin{array}{c}\text { Sampler } \\
\text { location } \\
\text { relative } \\
\text { to } S G\end{array}$} & \multicolumn{6}{|c|}{ Radioactivity on dust ${ }^{a}$} \\
\hline & & & I131 & \multicolumn{4}{|c|}{$\mu \mathrm{Ci} / \mathrm{mg}$ dust } & Sr90 \\
\hline CG & $\sim 250$ & Upstream & c & $3.1 \times 10^{-2}$ & $7.9 \times 10^{-2}$ & $2.2 \times 10^{-3}$ & & \\
\hline CI & 343 & Downstream & & $2.4 \times 10^{-2}$ & $7.4 \times 10^{-2}$ & $5.0 \times 10^{-3}$ & $4.0 \times 10^{-2}$ & $2.0 \times 10^{-2}$ \\
\hline $\mathrm{CA}$ & 610 & Upstream & $2.4 \times 10^{-2}$ & $2.2 \times 10^{-2}$ & $4.8 \times 10^{-2}$ & $1.3 \times 10^{-3}$ & & \\
\hline $\mathrm{CB}$ & 610 & Downstream & & $2.1 \times 10^{-2}$ & $7.0 \times 10^{-2}$ & $1.8 \times 10^{-3}$ & $5.5 \times 10^{-3}$ & \\
\hline $\mathrm{CC}$ & 818 & Upstream & $7.3 \times 10^{-3}$ & 0.22 & 0.25 & $1.9 \times 10^{-3}$ & & \\
\hline $\mathrm{CD}$ & 818 & Downstream & $c$ & $c$ & $c$ & $c$ & $c$ & $c$ \\
\hline
\end{tabular}

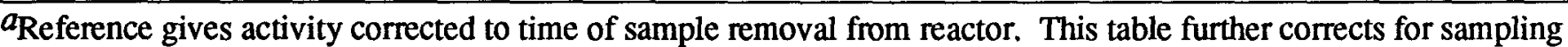
duration.

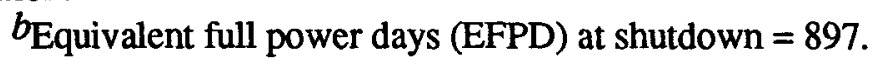

$c_{\text {Insufficient dust for collection. }}$ 
Table 3.1-2. Radioactivity associated with carbon filamentary dust on an end-of-life Peach

Bottom fuel element (Dyer et al., 1977)

\begin{tabular}{cl}
\hline Fission product & Activity level $^{a}$ \\
\hline $\mathrm{Ag} 110 \mathrm{~m}$ & $3.4 \times 10^{-2}$ \\
$\mathrm{Cs} 134$ & 4.2 \\
$\mathrm{Cs} 137$ & 2.4 \\
\hline$a_{\mu \mathrm{Ci} / \mathrm{mg} .}$ &
\end{tabular}

ORNL-OWG 90Z-3777 ETD

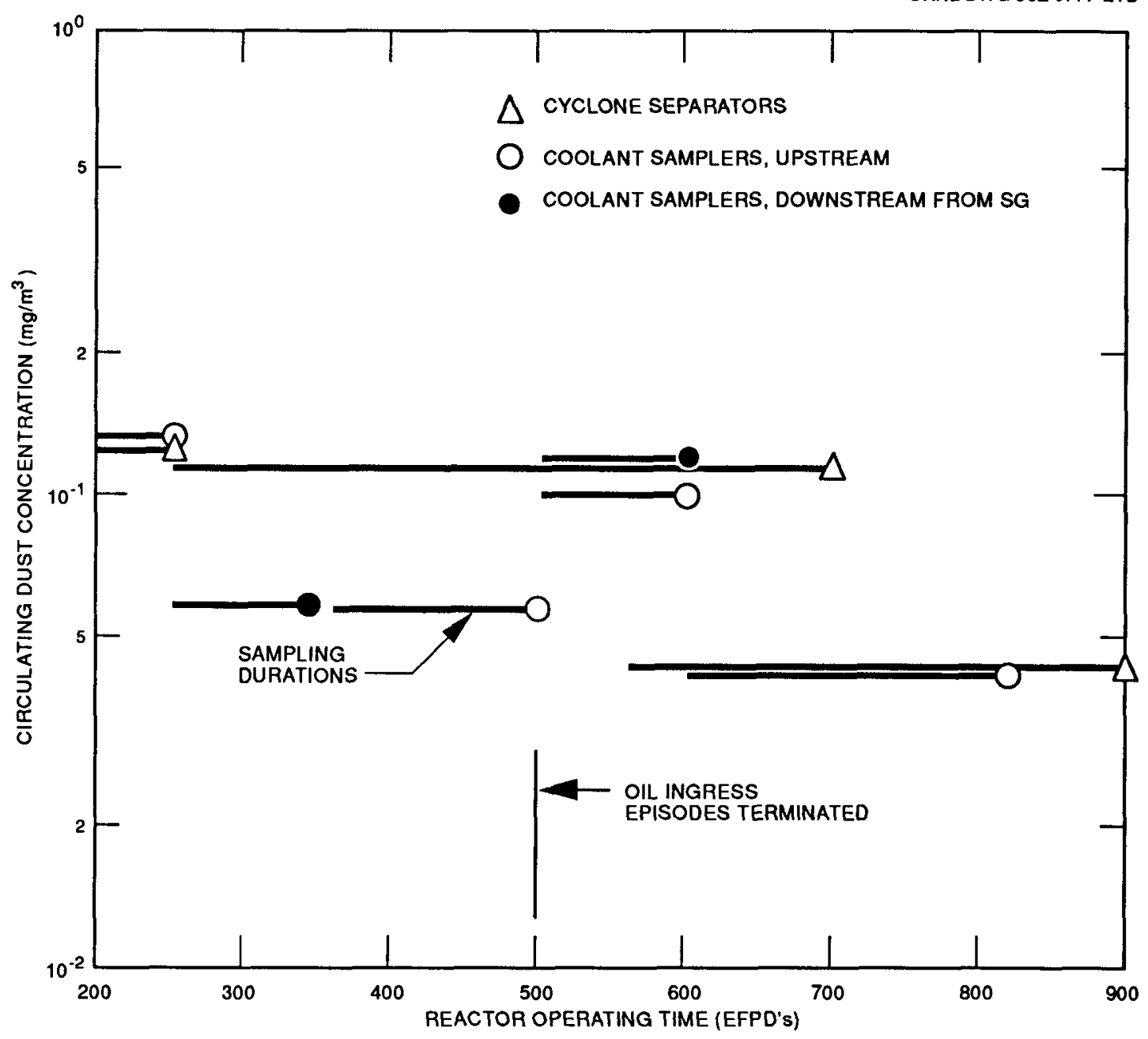

Fig. 3.1-1. Circulating dust concentrations, Peach Bottom HTGR Core 2 operation. (Dyer et al., 1977). 
darkened and open circles refer to the downstream and the upstream locations, respectively, relative to the steam generator. ${ }^{*}$ The triangles refer to data collected from the cyclone separator. For each case, the duration of the sampling period is indicated by the horizontal line, the data point itself referring to time of sample removal from the reactor. The time at which the oil ingress from the compressor lubricating system was supposedly ended is indicated on the graph at 500 EFPDs. No marked difference in dust concentration is seen following this time.

It is noteworthy that the isokinetic and cyclone separator samples yielded quite similar dust concentrations at similar sampling times. The highest observed level of circulating dust was $\sim 0.13 \mathrm{mg} / \mathrm{m}^{3}$. The lowest dust concentration, observed near end-of-life, was $\sim 0.044$ $\mathrm{mg} / \mathrm{m}^{3}$.

\section{Observed Amount of Plated Dust, Peach Bottom Core 2}

About $200 \mathrm{mg}$ of dust deposit consisting of filamentary carbon were removed from each of two Peach Bottom fuel elements. If this was typical for the 800 fuel elements in the core, there was $-0.16 \mathrm{~kg}$ of this sort of dust deposit in the reactor. X-ray diffraction showed characteristics of a vapor-deposited material for this filamentary dust. The filaments were observed to terminate with a metal button which evidently served as an active site for growth.

Unfortunately, examination of the steam generator tubing (GA Staff, 1978) did not include an evaluation of the level of dust deposits on the helium side. A black, matted surface was observed on the exterior of the Incoloy 800 superheater tubes in the vicinity of the steam inlet, where the hot helium from the core first contacts the tubing. The visual appearance indicates that some undeterminable fraction of this black deposit may be removable by fluid

*The isokinetic sampler data are tabulated in Table 3.1-3.

Table 3.1-3. Peach Bottom Core 2 circulating dust concentrations and estimated dust production rates and plateout levels

\begin{tabular}{|c|c|c|c|c|c|}
\hline \multicolumn{3}{|c|}{ Coolant samplers } & \multirow[b]{2}{*}{$\begin{array}{c}\text { Measured } \\
\text { concentration } \\
\left(\mathrm{mg} / \mathrm{m}^{3}\right)\end{array}$} & \multicolumn{2}{|c|}{ Calculated } \\
\hline Designation & Run duration & $\begin{array}{l}\text { Location } \\
\text { relative } \\
\text { to } \mathrm{HEX}\end{array}$ & & $\begin{array}{c}\text { Production } \\
\text { rate }^{a} \\
(\mathrm{~kg} / \mathrm{y})\end{array}$ & $\begin{array}{c}\text { Mass } \\
\text { plated }^{b} \\
(\mathrm{~kg})\end{array}$ \\
\hline GC & $-7 / 71$ & Upstream & 0.23 & 0.65 & 15.0 \\
\hline CI & $7 / 71-12 / 71$ & Downstream & $5.8 \times 10^{-2}$ & 0.17 & 3.5 \\
\hline CAl & $9 / 72-11 / 72$ & Upstream & $5.7 \times 10^{-2}$ & 0.17 & 3.5 \\
\hline $\mathrm{CA} 2$ & $1 / 73-5 / 73$ & Upstream & 0.10 & 0.28 & 6.2 \\
\hline CB & $1 / 73-5 / 73$ & Downstream & 0.13 & 0.37 & 8.5 \\
\hline $\mathrm{CC}$ & $3 / 74-5 / 74$ & Upstream & $4.2 \times 10^{-2}$ & 0.12 & 2.7 \\
\hline $\mathrm{CD}$ & $3 / 74-5 / 74$ & Downstream & $<3 \times 10^{-3}$ & $<0.01$ & $<0.1$ \\
\hline
\end{tabular}

$a_{\text {Calculated from Eq. (3.1-3). }}$

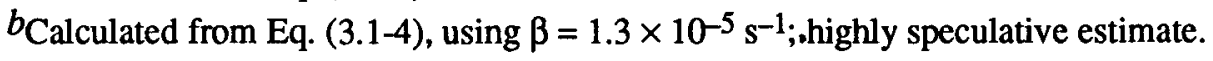


dynamic forces. The interior superheater tubes in the vicinity of the steam outlet were also black, but the deposit here appeared to be lustrous like a black ceramic coating and probably not removable by flow forces. All of the black coatings were attributed to periodic oil leaks into the primary system; however, the evidence for this was only circumstantial. Some of the black deposit was quite thick and was observed in the process of detaching as flakes.

In addition, the carbon steel economizer tubing and the carbon-silicon steel evaporator tubes exhibited a dull black, matted surface. However, there is no further characterization of the deposit. No carbon filamentary deposit was cited on tubing surfaces, but some were observed on the exterior of the coolant sampler located in the helium flow directly downstream from the core outlet, where gas temperatures were $\sim 1010 \mathrm{~K}\left(738^{\circ} \mathrm{C}\right)$.

In sum, while the examination of the steam generator tubing showed some dust and flaking particulate sources, the total amount potentially removable by depressurization flow forces was not estimated.

\section{Dust Production Rates and Total Deposition Estimates for Peach Bottom Core 2}

While the plated dust levels were not measured at Peach Bottom, they may be estimated from the circulating dust concentration data by application of some of the newer liftoff modeling concepts described in Sect. 4. This is rendered possible because the newer concepts view plated and circulating dust as being in dynamic equilibrium. If the equilibrium constant were known, in this case the equivalent liftoff factor, $\beta$, then a mass balance may relate the unknown plated level to the known circulating concentration. The mass balances for circulating and plated dust may with this view be expressed as follows:

$$
\begin{aligned}
& \mathrm{V} \frac{\mathrm{dC}}{\mathrm{dt}}=\mathrm{m}_{\mathrm{p}}-\overline{\alpha \mathrm{h}} \mathrm{AC}(\mathrm{t})-\mathrm{QC}(\mathrm{t})+\beta \mathrm{AS}(\mathrm{t}) \\
& \mathrm{A} \frac{\mathrm{dS}}{\mathrm{dt}}=\overline{\alpha h} \mathrm{AC}(\mathrm{t})-\beta A S(\mathrm{t})
\end{aligned}
$$

The above assumes a single dust region of volume, $\mathrm{V}$, containing a circulating concentration, $\mathrm{C}$. The deposition area, A, holds a dust deposit concentration, S. Also, a single, averaged particle size is implied through use of a net deposition velocity, $\overline{\alpha h}$, averaged over all sizes. Parameters used in Eqs. (3.1-1) and (3.1-2) are more fully discussed in Sect. 3.2 (Plateout Models) and Sect. 4 (Dust Liftoff Models). The term, $m_{p}$, represents the dust production rate, and $Q$ is the purification flow rate which continually removes circulating dust in a bypass stream. Equation (3.1-1) states that the rate of change of the amount of circulating dust, VC, equals the production rate, $m_{p}$, plus the liftoff rate, $\beta A S(t)$, less the amount lost to deposition, $\overline{\alpha h} A C(t)$, and purification, $Q_{p} C(t)$. Equation (3.1-2) states that the rate of change of the amount of deposit, $A S(t)$, equals the deposition rate less the liftoff rate.

The key in the above balances are the terms containing the liftoff constant, $\beta$, which provide a continuous liftoff rate proportional to the deposit level, $S$. Actually, $\beta$ may be 
expected to depend strongly on the flow conditions (e.g., the shear ratio), however the application here is to the steady state condition of dust plateout. For steady conditions, Eqs. (3.1-1) and (3.1-2) may solved algebraically for the deposit, $S$, and dust production rate, $\mathrm{m}_{\mathrm{p}}$,

$$
\begin{aligned}
& \mathrm{m}_{\mathrm{p}}=\mathrm{QC}(\infty), \\
& \mathrm{S}(\infty)=\frac{\overline{\alpha \mathrm{h}}}{\beta} \mathrm{C}(\infty) .
\end{aligned}
$$

Therefore at steady conditions the dust production rate is obtained directly from the product of the purification flow and circulating dust concentration. (The purification flow at Peach Bottom was approximately $0.091 \mathrm{~m}^{3} / \mathrm{s}$, inclusive of both steam generator and fuel element purge flow rates.) Estimated dust production rates are listed in Table 3.1-3 corresponding to the time intervals for the series of sampling time periods. Note, that an initial high dust level of $0.23 \mathrm{mg} / \mathrm{m}^{3}$ was observed, due to activities associated with the installation of the core or resulting from core 1 operation, which experienced a high rate of fuel failure. The dust production rate equivalent to steady operation at this high dust level is estimated as 0.65 $\mathrm{kg} / \mathrm{y}$. Following this initial high dust period, the estimated dust production rate appears to have leveled off to approximately $0.20 \mathrm{~kg} / \mathrm{y}$. These are significantly lower than dust production rates estimated for the AVR (see below).

Estimation of plateout levels using Eq. (3.1-4) is far more conjectural as values for the net deposition velocity, $\overline{\alpha h}$, and the liftoff factor, $\beta$, are required. For this illustration, a value of $0.0083 \mathrm{~m} / \mathrm{s}$ for the net deposition velocity will be used, representative of thermophoretic transport of a $0.3 \mathrm{~mm}$ particle in the steam generator. (Section 3.2 describes the various dust plateout mechanisms.) Actually, $\overline{\alpha h}$ varies strongly with particle size and deposition mechanism hence properly should be averaged using size distribution data. The value of the parameter, $\beta$, has not been determined for MHTGR conditions, but a range of values reported in studies described in Sect. 4.6. From this range, a value of $1.33 \times 10^{-5} \mathrm{~s}^{-1}$ is selected for this illustration." On this basis, the highly speculative dust plateout levels shown in Table 3.1-3 were estimated. However, if more confident values of the liftoff parameter were available, plateout levels may by this procedure be related to circulating concentrations which may be continuously monitored in a test loop or reactor. As the table shows, estimated amounts of plated dust in the Peach Bottom PS, ranged about $4 \mathrm{~kg}$, after the initial dusty startup period. Again, these estimates are significantly lower than reported for the AVR (see below).

\section{Conclusions Regarding Peach Bottom Core-2 Dust}

The downward trend in circulating dust concentrations with operating time, shown in Fig. 3.1-1 and Table 3.1-3, indicates that a significant part of the dust population resulted from some earlier events, such as the installation of Core 2 or carryover from Core 1 operation. This is consistent with the downward trend of the obviously construction-related material picked up

\footnotetext{
*The basis for selection of this value is given in Sect. 4.4.6.
} 
by the cyclone separator, e.g., insulation foil, and also the generally large particle sizes seen in the coolant gas samplers.

It should also be noted that dust production by "rust" flaking or graphite abrasion would also lead to particle sizes that are relatively large compared with condensation nuclei. Most of the dust seen that was not construction related appeared to result either from abrasion or flaking, and thus tended to be relatively large; i.e., larger than $\sim 1 \mu \mathrm{m}$.

Very few extremely small particles were observed on the order of $0.1 \mu \mathrm{m}$ typical of condensation nuclei. These would result either from the carbon deposition phase of the carbon transport cycle or as a result of the oil ingress. Evidently, whatever amount of condensation nuclei formed, the principal location was on solid surfaces, such as seen on the exterior of the fuel element, and very little was gasborne.

Since the sorption surface area of a particle per unit mass increases as the size decreases, the significance of these observations is that the Peach Bottom Core 2 dust would have rather low fission product transport capability, at least for iodine where surface chemisorption is the attachment mechanism.

Also of possible interest are the few FP activity measurements of Peach Bottom Core 2 dust listed in Table 3.1-1. The I131 activity was observed at about $1.6 \times 10^{-6} \mu \mathrm{Ci} / \mathrm{mg}$, which may be translated into an effective sorptivity if the surface area and I131 pressures were known.

\subsubsection{Peach Bottom Core 1 Dust Data}

For completeness, Peach Bottom Core 1 data are mentioned, although its current significance is small. Core 1 dust levels and associated circulating activities were dominated by the extensive fuel particle failures in this early design, and also by major cracking of the graphite fuel elements. (Busch et al., 1972)

\subsubsection{Observed Dust in the AVR}

Currently (11/6/89) some preliminary information is available on the dust environment in the AVR. What is known has been acquired unofficially and is summarized below:

Principal formation mechanism

Particle size range

Size of maximum frequency

Weight \% metal (balance C)

Dust production per operating year

Quantity of plateout

Specific activity

Circulating concentration

Specific activities on dust $(\mu \mathrm{Ci} / \mathrm{mg})$

Cs-134 maximum

Cs-134 average

Cs-137 maximum

Cs-137 average
Abrasion between fuel elements

$0.5-40 \mu \mathrm{m}$

$<1 \mu \mathrm{m}$

5-15\%

$\sim 2.5 \mathrm{~kg} / \mathrm{y}$

$\sim 60 \mathrm{~kg}$

$\sim 11 \mu \mathrm{Ci} / \mathrm{mg}$

$0.040 \mathrm{mg} / \mathrm{m}^{3}$ (maximum)

19

$\sim 0.3$

23

$\sim 0.3$ 
It is interesting to note that the average specific activities of cesium on dust at the AVR are approximately equal to similar, late-in-life observations at Peach Bottom (see Table 3.1-1).

It is reported that the dust production mechanism at the AVR is predominantly due to fuel element abrasion. Approximately $1 \mathrm{~g}$ of graphite is lost per element while in the core, which leads directly to the stated dust production rate of $\sim 2.5 \mathrm{~kg} / \mathrm{y}$. It seems likely that pebble bed reactors differ significantly from prismatic HTGRs with respect to dust production. The graphite abrasion mechanism, dominant for the AVR, is far less significant in prismatic fueled reactors. Therefore also, other parameters such as circulating activity levels, amount and nature of the plated material are likely to be quite different.

\subsection{DUST PLATEOUT MODELS}

\subsubsection{Reviews and Status}

Several recent reviews of aerosol plateout predictions attest to this being an extensively analyzed subject. Plateout prediction is not likely to be a limiting factor in the overall plateout and liftoff issue. Nevertheless, the available plateout correlations are not without limitations in their application to the HTGR primary system.

A review by Roberts et al. (1984) presents a comprehensive evaluation of deposition correlations for LWR primary systems under severe accident condition. Since dry LWR primary systems are assumed, these conditions relate indirectly to the HTGR. Wright (1988) and Yamano and Brockmann (1989) present reviews applicable to dust transport in lengthy sampling lines. Glissmeyer (1983) briefly describes the attributes of 23 aerosol transport codes. None of the 23 codes cited deals with liftoff. All deal solely with transport and plateout and a wide range of special features. A comprehensive dissertation on thermophoretic deposition has recently been published by Conklin (1989). In addition, many of the aerosol transport programs cited in Glissmeyer (1983) come with manuals containing plateout reviews.

Nevertheless, several uncertainties exist regarding dust plateout prediction in HTGR primary systems, some of which may be significant.

\subsubsection{Uncertainties in Plateout Prediction}

(1) Although Roberts (1984) cites one correlation for plateout to the exterior of cylinders in cross-flow [a theoretical calculation due to Brun et al. (1955)], no really suitable correlation exists for the complex flows in the steam generator. This may be a significant limitation since the steam generator is the principal dust repository in the primary system.

(2) There appears to be an inconsistency in the way that particulate bounce-off* is handled in plateout correlations. Rarely is it explicitly mentioned. Theoretical correlations, such as the cited cross-flow correlation and for thermophoretic deposition, generally do not include bounceoff. Indeed, the bounce-off factor cannot be developed theoretically. Therefore, proper use of

\footnotetext{
*Bounce-off is defined as an event where a particle is successfully delivered to a surface, but does not adhere. In contrast, lift-off refers to previously adherent particles.
} 
theoretical plateout correlations should include a multiplicative bounce-off factor for correct results. In contrast, empirical plateout correlations based on data must implicitly include a bounce-off factor, there being no way to experimentally distinguish between a non-plated particle and one that has bounced off. Bounce-off depends on particle size and physical properties of particle and substrate, and the inconsistency in dealing with the phenomenon can lead to significant errors in plateout prediction. An indication of the range of bounce-off factors is given later in this section.

(3) In practice, local geometric details greatly effect aerosol plateout. For example, dust deposits seen on the Peach Bottom fuel element (Dyer et al., 1977) were concentrated downstream from irregularities in the cylindrical surface. Similarly for the steam generator, dust deposits would be affected by flow perturbations caused by support plates, and would also likely vary around the tube with reference to the direction of flow. No plateout correlations cited in the above reviews relate to such local details. Predominantly, they deal with fully established flow in a pipe.

(4) Newer liftoff theories (see Sect. 5) present the notion that liftoff occurs continuously even under steady, normal operation. The circulating and plated concentrations thus represent an equilibration between the rates of deposition versus liftoff. If proven correct, the usual procedure for calculating deposition rates separately from an overall mass balance leads to error, because the deposited material is not permanently lost from circulation.

Some idea of the error caused by irregular use of the bounce-off factor may be gained from data reported by Marple and Willeke (1976). Using single stage impactor data, Marple and Willeke allege that the sticking fraction (i.e., unity minus the bounce-off fraction) depends only on the particle/substrate materials and the Stokes number based on the tube diameter. Sticking fractions of unity are predicted for liquid particles and for solid particles impacting oilcovered substrates for all values of St. However, solid particles on smooth, hard substrates show a sharp drop in sticking fraction for values of St greater than $\sim 0.21$. The relationship is illustrated by Fig. 3.2-1, which is reformulated from smoothed graphical data, and hence is only approximate. The particle sizes noted along the abscissa are determined using approximate steam generator flow conditions, assuming light $\left(\rho_{p}=1 \mathrm{~g} / \mathrm{cm}^{3}\right)$ and heavy $\left(\rho_{p}=5.2 \mathrm{~g} / \mathrm{cm}^{3}\right)$ particles. Note that hard, light particles above $\sim 2 \mu \mathrm{m}$ diameter are predicted to exhibit significant bounce off, with sticking fractions reduced to $\sim 30 \%$ for sizes approaching $3 \mu \mathrm{m}$. The heavier particles are shown to begin significant bounce off at $\sim 0.9 \mu \mathrm{m}$ and exhibit sticking fractions of $\sim 30 \%$ as sizes reach about $1.3 \mu \mathrm{m}$.

${ }^{*}$ Stokes No. $(\mathrm{St})=\left(\frac{\text { Stopping length due to viscosity }}{\text { Re ference length }}\right)$

For spherical particles, using $d_{\text {tube }}$ as the reference length,

$$
S t=\frac{\rho_{p} d_{p}^{2} \mathrm{U}}{9 \mu d_{t}} \text {. }
$$

See Appendix B for nomenclature. 
ORNL-DWG 90Z-3780 ETD

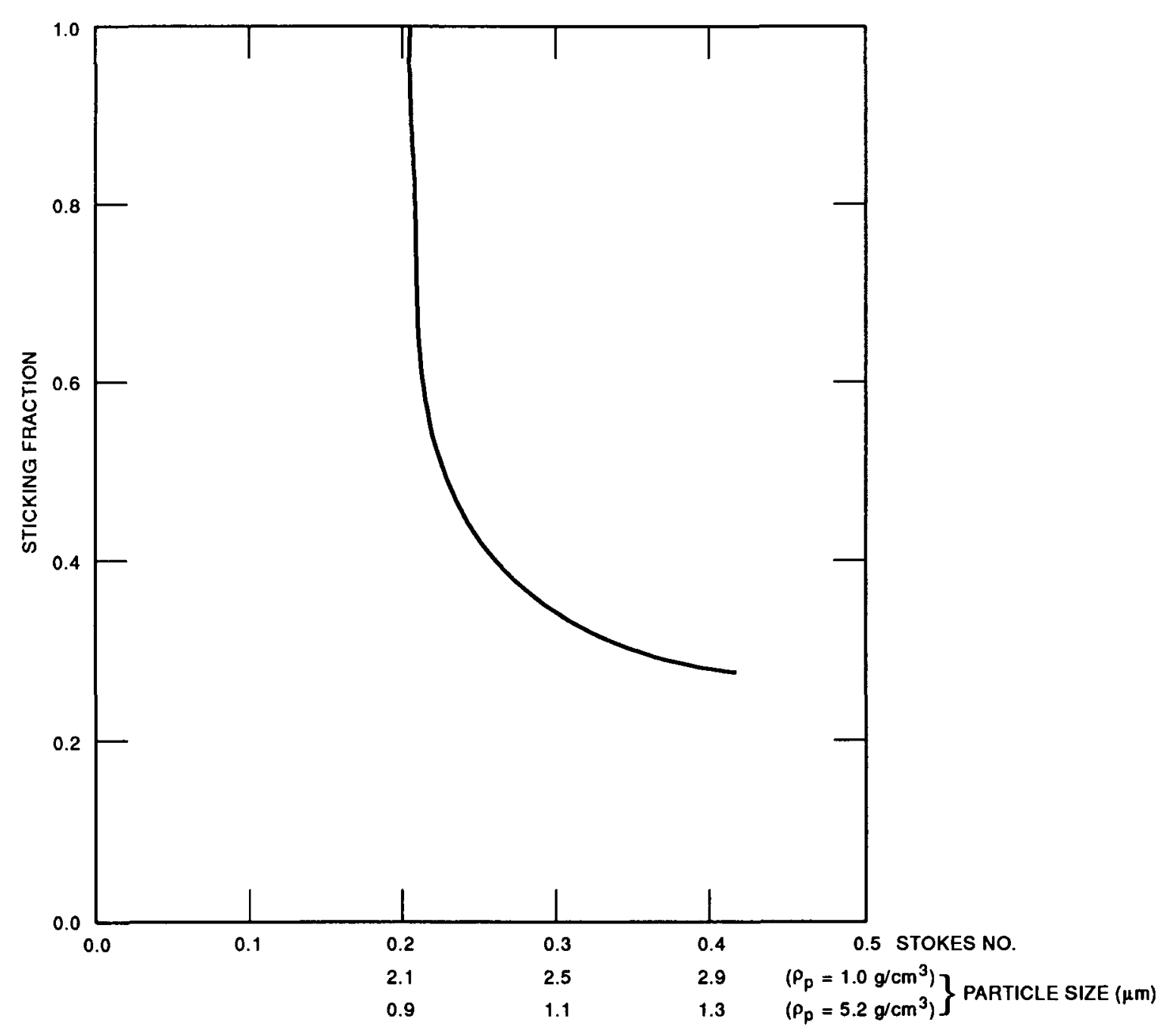

Fig. 3.2-1. Particle sticking fractions vs Stokes No. and particle size, for hard particles and surfaces. (Based on data from Marple and Willeke, 1976).

Particle bounce off is thus predicted to begin at some critical size $(\sim 1$ to $\sim 2 \mu \mathrm{m}$, depending on particle density), and needs to be accounted for in theoretically derived correlations which generally exclude this phenomenon. Specifically, this includes the available correlation for deposition by impaction on tubes in cross-flow.

\subsubsection{Dust Plateout Mechanisms}

A comprehensive review of dust plateout mechanisms applicable to the HTGR primary system is given by Roberts et al. (1984). The four most significant mechanisms for the flow conditions in the steam generator and core area are cited below. Deposition correlations are also taken from the review by Wright (1988). All cited correlations assume spherical particles. 
Brownian Diffusion. In this mechanism, particles are treated like large gas molecules in thermal equilibrium with other gas molecules. Since thermal velocities vary inversely with $\sqrt{m_{p}}$, it is clear that particle diffusion coefficients are much smaller than for molecules. According to Fuchs (1964), the particle diffusion coefficient, $D_{p}$, is given by,

$$
D_{p}=\frac{k T C}{\pi \mu d_{p}},
$$

where

$$
\begin{aligned}
\mathrm{k} & =\text { Boltzmann's constant, } 1.38 \times 10^{-23} \mathrm{~J} / \mathrm{K} \\
\mathrm{T} & =\text { Temperature, } \mathrm{K} \\
\mathrm{C} & =\text { Cunningham's slip factor } \\
\mu & =\text { Helium viscosity, } \mathrm{Pa} \cdot \mathrm{s} \\
\mathrm{d}_{\mathrm{p}} & =\text { Particle diameter, } \mathrm{m} .
\end{aligned}
$$

Using typical values for $\mu$ and $T$ and estimating the slip factor in helium (see Appendix B), yields $D_{p}=1.8 \times 10^{-4} \mathrm{~cm}^{2} / \mathrm{s}$ for a $0.01 \mu \mathrm{m}$ particle, compared with $\sim 0.1 \mathrm{~cm}^{2} / \mathrm{s}$ typical for many common gas molecules. While Brownian diffusion coefficients for particles are generally small, it nevertheless becomes the dominant deposition mechanism for extremely small particles.

In a laminar flow field, diffusive transport of particles perpendicular to the velocity and toward the wall is generally negligibly small in view of the small particle diffusivities and comparatively large distances involved; e.g., the tube radius. However in a turbulent flow field, high turbulent diffusivities rapidly deliver particles to the buffer or laminar sublayer, across which diffusion may be an effective mechanism because of its narrow thickness. In such case, a particle deposition velocity* may be written,

$$
\mathrm{V}_{\mathrm{d}}=\frac{\mathrm{D}_{\mathrm{p}}}{\Delta \mathrm{y}_{\mathrm{sl}}}
$$

where

$\mathrm{D}_{\mathrm{p}}=$ particle diffusivity, Eq. 3.2-1,

$\Delta \mathrm{y}_{\mathrm{sl}}=$ sublayer thickness, $\mathrm{m}$,

$\mathrm{V}_{\mathrm{d}}=$ deposition velocity for Brownian diffusion across a sublayer, $\mathrm{m} / \mathrm{s}$.

Using typical values for an HTGR primary system (see Appendix B), it may be shown that $V_{d}$ begins to dominate over thermophoretic deposition in the steam generator, where there is a favorable temperature gradient, at particle sizes below $0.003 \mu \mathrm{m}$ (see next section). For

\footnotetext{
* Particle deposition rates, $\mathrm{R}$, are commonly expressed in terms of a deposition velocity, $\mathrm{V}$, the relation being $R\left(\mathrm{~kg} / \mathrm{m}^{2} \mathrm{~s}\right)=\mathrm{V}(\mathrm{m} / \mathrm{s}) \mathrm{C}\left(\mathrm{kg} / \mathrm{m}^{3}\right)$, where $\mathrm{C}$ is the dust concentration. In many aspects, this is analogous to the correlation of a heat flux in terms of a heat transfer coefficient.
} 
deposition on coolant hole surfaces in the core, where the temperature gradient for thermophoresis is not favorable, diffusion across the laminar sublayer is the dominant deposition mechanism up to $\sim 0.1 \mu \mathrm{m}$ sizes.

Turbulent Transport plus Inertial Impaction. In this mechanism, particles are impelled across the buffer and laminar sublayers to the wall by means of velocities imparted by turbulent eddies. Since typical sublayer thicknesses under primary circuit flow conditions are on the order of $40 \mu \mathrm{m}$, inclusive of the laminar sublayer and buffer layer, particles with stopping lengths greater than $\sim 40 \mu \mathrm{m}$ may deposit by this mechanism. It may be shown that light $\left(\rho_{p}=1 \mathrm{~g} / \mathrm{cm}^{3}\right)$ and heavy $\left(\rho_{p}=5.2 \mathrm{~g} / \mathrm{cm}^{3}\right)$ particles in helium have stopping lengths greater that $40 \mu \mathrm{m}$ for sizes above $\sim 1$ and $0.5 \mu \mathrm{m}$, respectively. Therefore, this deposition mechanism is expected to be significant for particles larger than the 0.5 to $1.0 \mu \mathrm{m}$ range. As summarized by Wright (1988), the deposition rate is given in terms of the depositions velocity, $V_{I}$ as

$$
\begin{array}{ll}
\mathrm{V}_{\mathrm{I}}=6 \times 10^{-4} \tau_{+}^{2} \mathrm{U}^{*}, & \tau_{+}<12.9 \\
\mathrm{~V}_{\mathrm{I}}=0.1 \mathrm{U}^{*}, & \tau_{+}>12.9
\end{array}
$$

where

$$
\begin{aligned}
\mathrm{U}^{*} & =\text { the friction velocity, } \mathrm{m} / \mathrm{s}, \\
\tau_{+} & =\text {particle stopping length parameter, } \\
\mathrm{V}_{\mathrm{I}} & =\text { deposition velocity, due to turbulent impaction, } \mathrm{m} / \mathrm{s} .
\end{aligned}
$$

The parameter $\tau_{+}$is a type of Stokes number evaluated for spherical particles by,

$$
\tau_{+}=\frac{\rho_{\mathrm{p}} \rho_{\mathrm{g}} \mathrm{d}_{\mathrm{p}}^{2}\left(\mathrm{U}^{*}\right)^{2} \mathrm{C}}{18 \mu^{2}}
$$

where

$$
\begin{aligned}
& C=\text { the Cunningham slip factor, } \\
& \mu=\text { the gas viscosity. }
\end{aligned}
$$

Since this is a semi-empirical correlation [due to Lui and Agarwal (1974)], it is presumed to implicitly include the bounce-off factor.

Thermophoresis. Thermophoresis is the term applied to thermal diffusion where the heavier "molecule" is a particle. As general for thermal diffusion, the effect is small and usually swamped when other transport mechanisms are present. Its importance here lies in that it happens to dominate deposition mechanisms in the critical size range between $\sim 0.01$ and $\sim 0.3 \mu \mathrm{m}$ under typical steam generator conditions where the temperature gradient is favorable. Thermophoretic forces result from the higher momentum transfer rate from helium atoms to the high temperature side of particles. The result is a net force toward the cooler direction which is proportional to the particle diameter and the temperature gradient. Thus thermophoresis is an effective deposition mechanism in the steam generator, but it opposes deposition on core surfaces in the core where the surface is hotter than the gas. 
Opposing the thermophoretic force is viscous drag, which is also proportional to particle size. Therefore to a first approximation, the thermophoretic deposition velocity is independent of particle size. However, a combination of second order effects serves to increase the thermophoretic deposition velocity with diminishing particle size down to a particle size of $\sim 0.1 \mu \mathrm{m}$, below which it remains relatively constant. In the size range between $\sim 0.005$ and $0.2 \mu \mathrm{m}$, where both inertial and diffusive mechanisms are small, thermophoresis becomes the dominant deposition mechanism for typical steam generator conditions. Following the summary by Wright (1988),

$$
\mathrm{V}_{\mathrm{th}}=2 \mathrm{C}_{\mathrm{s}} \mathrm{v} \psi \mathrm{C} \nabla \mathrm{T} / \mathrm{T}
$$

where

$$
\begin{aligned}
\mathrm{V}_{\mathrm{th}} & =\text { Deposition velocity due to thermophoresis, } \mathrm{m} / \mathrm{s}, \\
\Psi & =\frac{1}{\left(1+2 \mathrm{C}_{\mathrm{m}} \mathrm{K}_{\mathrm{n}}\right)} \frac{\left(\mathrm{k}+\mathrm{C}_{\mathrm{t}} \mathrm{K}_{\mathrm{n}}\right)}{\left(1+2 \mathrm{k}+2 \mathrm{C}_{\mathrm{t}} \mathrm{K}_{\mathrm{n}}\right)} \\
\mathrm{C}_{\mathrm{s}}, \mathrm{C}_{\mathrm{m}}, \mathrm{C}_{\mathrm{t}} & =\text { constants with values of } 1.17,1.14,2.18, \text { respectively, } \\
\mathrm{V} & =\text { helium kinematic viscosity, } \mathrm{m}^{2} / \mathrm{s}, \\
\mathrm{C} & =\text { Cunningham slip factor, } \\
\mathrm{Kn} & =\text { Knudsen number, } 2 \lambda / \mathrm{d}_{\mathrm{p}} \\
\lambda & =\text { Mean free path gas atoms, } \mathrm{m}, \\
\nabla \mathrm{T} & =\text { Temperature gradient at the wall, } \mathrm{K} / \mathrm{m}, \\
\mathrm{T} & =\text { Gas temperature, } \mathrm{K}, \\
\mathrm{k} & =\text { Thermal conductivity ratio, gas to particle. }
\end{aligned}
$$

Using typical primary system parameters (see Appendix B) values of $V_{\text {th }}$ and $V_{d}$ from Eqs. (3.2-1) and (3.2-2) are compared in Fig. 3.2-2 as a function of $d_{p}$. These estimates presume turbulent flow in a smooth tube for determination of the sublayer thickness. As seen, the diffusive deposition velocity begins to dominate for sizes below $\sim 0.005 \mu \mathrm{m}$ size.

Inertial Impaction Due to Transverse Flow across a Cylinder. Roberts et al. (1984) cite an analysis due to Brun (1955) who determined particle trajectories in the flow field around a cylinder. An inviscid flow assumption was used to determine the flow field, and Stokes law was assumed for the relative velocity between particle and fluid. The fraction of particles within the flow subtended by the cylinder cross-section that strike the surface is shown in Fig. 3.2-3, reproduced from Roberts. The Stokes number and parameter, $P$ are defined as follows,

$$
\begin{aligned}
& S t=\frac{\rho_{p} d_{p}^{2} U}{9 \mu d_{c y l}}, \\
& P=\frac{9 \rho_{g}^{2} U d_{c y l}}{\mu \rho_{p}} .
\end{aligned}
$$

This correlation is less than satisfactory for predicting deposition in the steam generator since streamlines around tightly bunched tubes are quite different from those for a single 


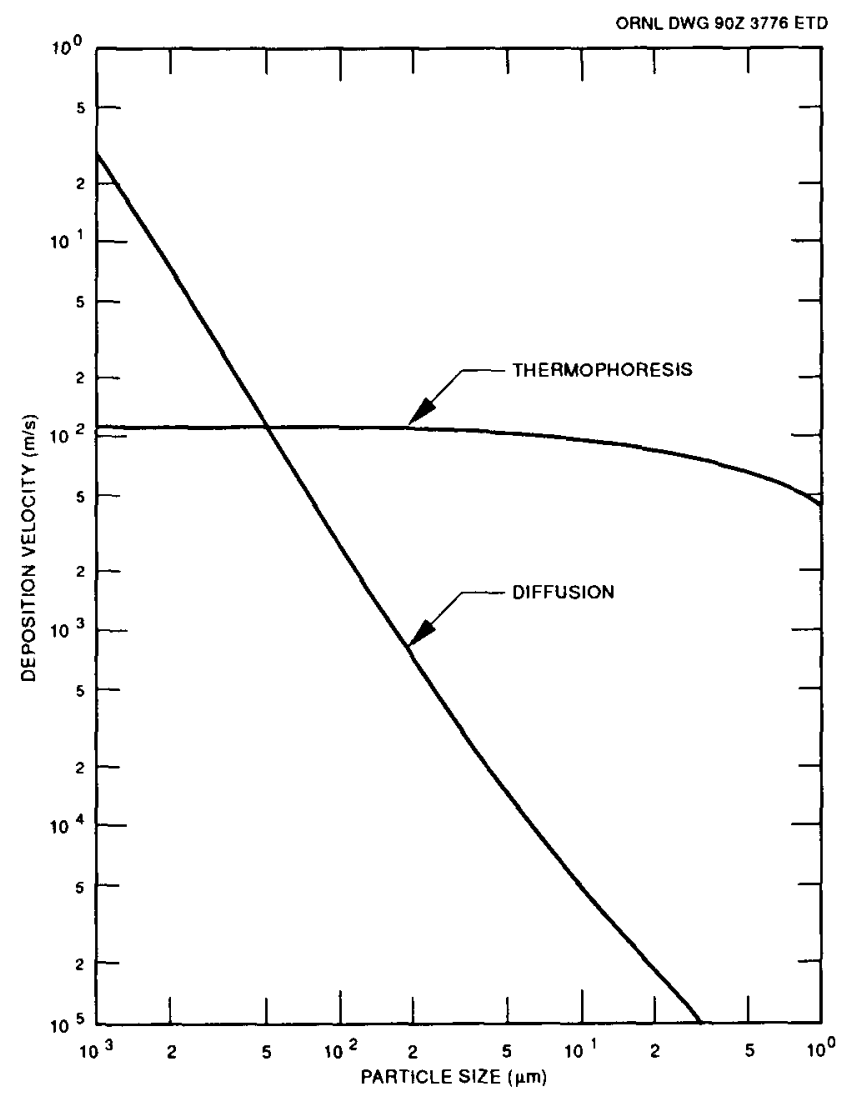

Fig. 3.2-2. Diffusion and thermophoretic deposition velocities for typical steam generator conditions.

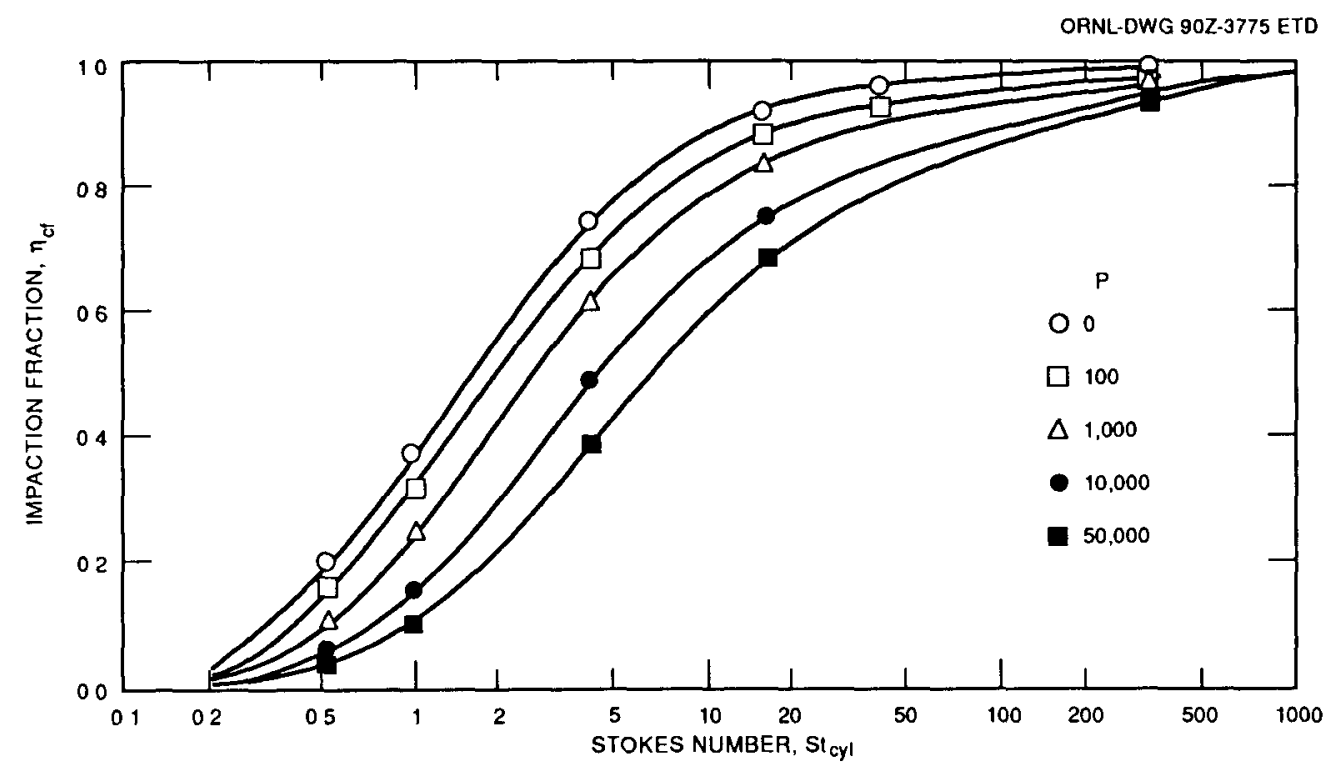

Fig. 3.2-3. Impact fraction of particles in cross-flow to a cylinder, from Roberts et al. (1984) based on Brun et al. (1955). 
cylinder. Also the graphical form of presentation shows unclear values of the strike fraction in the low Stokes number regime. Values of the parameter, $P$, for typical steam generator conditions are

$$
\begin{aligned}
& P=14,000 \text { for } \rho_{p}=1 \mathrm{~g} / \mathrm{cm}^{3}, \\
& P=2,800 \text { for } \rho_{p}=5.2 \mathrm{~g} / \mathrm{cm}^{3}
\end{aligned}
$$

As an expedient for scoping estimates, impaction fractions $\eta_{\mathrm{cf}}$, may be estimated by,

$$
\eta_{\mathrm{cf}}=1-\exp (-0.1 \mathrm{St}) \text {. }
$$

Equation (2.3-6) is a fair estimate of the strike fraction in the Stokes number range 0.1 to 10 as represented in the figure for the pertinent parameter values of P. A Stokes number of 10 corresponds to $\sim 10 \mu \mathrm{m}$ size for typical steam generator conditions.

The net cross-flow deposition fraction per tube is obtained from the product of $\eta_{\mathrm{cf}}$ and the sticking fraction (i.e., unity minus the bounce-off rate obtained from Fig. 3.2-1).

\subsection{PREDICTED DEPOSITION RATES}

An order-of-magnitude estimate of dust deposition rates in the primary systems is developed to illustrate the net effect of the four deposition mechanisms cited in the previous section and to illustrate some of the potential uncertainties of the predictions. The assumed flow conditions, physical properties, geometry and calculational are given in Appendix B.

The basic procedure, following Wright (1988), assumes that deposition velocities for the separate deposition mechanisms are additive when they occur simultaneously. If $\mathrm{V}_{\mathrm{i}}$ is the deposition velocity for mechanism-i, the transport efficiency for mechanism-i, $E_{i}$, is defined as,

$$
\mathrm{E}_{\mathrm{i}}=\frac{\text { exit dust concentration }}{\text { inlet dust concentration }} \text {. }
$$

It may be shown that for steady duct flow, where the deposition velocity may be assumed constant, the transport efficiency is related to $V_{i}$ by

$$
E_{i}=\left(\frac{-V_{i} A_{S}}{Q}\right)
$$

where

$$
\begin{aligned}
A_{s} & =\text { deposition surface area, } \mathrm{m}^{2}, \\
Q & =\text { volume flow rate }, \mathrm{m}^{3} / \mathrm{s} .
\end{aligned}
$$

Therefore, the total deposition efficiency, when several mechanisms are simultaneously effective, may be expressed as the product,

$$
\mathrm{E}_{\mathrm{tot}}=\mathrm{E}_{1} \mathrm{E}_{2} \ldots .
$$


when the individual deposition velocities are assumed to be additive. However, deposition by inertial impaction is not expressed in terms of a deposition velocity. It is therefore necessary to further assume a multiplicative relationship for inertial impaction; i.e.,

$$
E_{n e t}=E_{1} E_{2} \ldots E_{t i} \text {, }
$$

where $\mathrm{E}_{\mathrm{t} i}$ is the inertial transport efficiency due to $\mathrm{N}_{\mathrm{t}}$ flow impactions.

Estimates for transport through (or deposition in) the MHTGR steam generator are shown in Fig. 3.3-1 using the above expressions for the individual and total transport efficiencies. Note that all deposition expressions (except impaction) as well as the assumptions implied in Eqs. (3.3-1) and (3.3-3) relate to flow in a duct and therefore do not strictly apply to cross flow. The presumption is that duct flow correlations may be applied to the steam generator by using an average velocity and Reynolds number to characterize the flow. The results, therefore, are highly approximate. However, the deposition code, PAD, while capable of fine detail, nevertheless employs a completely equivalent assumption.

Particles of unit density are assumed in Fig. 3.3-1 to represent the "soot" particles observed in the Peach Bottom coolant samplers, consisting primarily of porous carbon. Figure 3.3-1 shows that the steam generator is predicted to be a perfect sink for extremely small $\left(d_{p}<\right.$ $0.003 \mu \mathrm{m})$ and light $\left(\rho_{\mathrm{p}}=1 \mathrm{~g} / \mathrm{cm}^{3}\right.$ ) particles due to the particle diffusion mechanism across the buffer and laminar sublayers. Similarly, the steam generator is predicted to appear black to

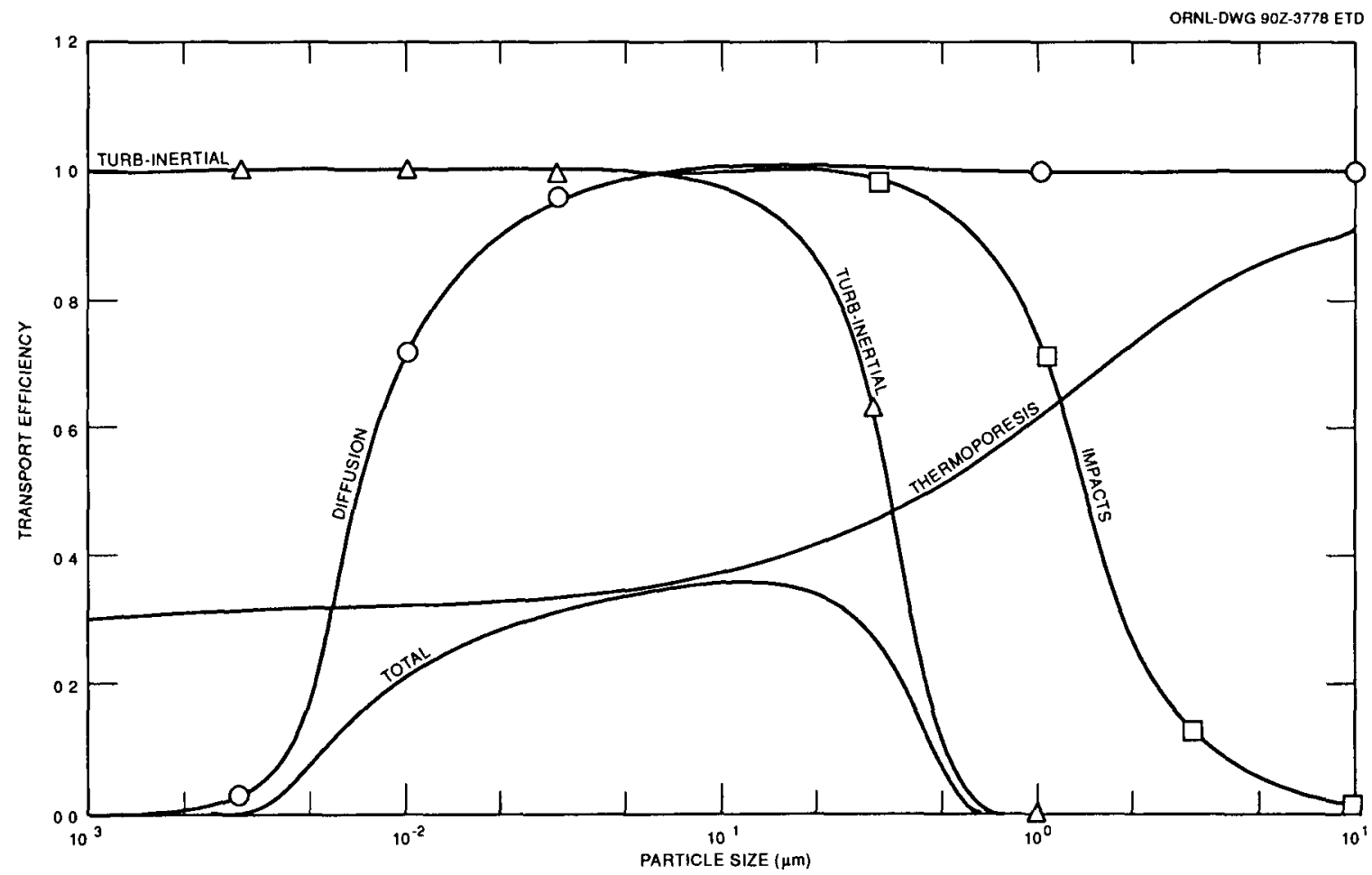

Fig. 3.3-1. Dust deposition in the steam generator-comparison of mechanisms for "soot" particles. 
particles larger than $0.8 \mu \mathrm{m}$, due principally to the turbulent-inertial deposition mechanism. Thermophoresis is seen to be the principal deposition mechanism for the intermediate size range, $0.006<d_{p}<0.2 \mu \mathrm{m}$, which is above the effective diffusive size but below the size for effective deposition by turbulent-inertia. Deposition by inertial impacts is seen to become significant above $\sim 1 \mu \mathrm{m}$ size.

The net effect of the four deposition mechanisms is shown by the curve labeled "total," obtained as a product of the individual transport efficiencies. It is seen that a slight window of dust transport for "soot" particles through the steam generator is predicted to appear for the intermediate size range, approximately between 0.01 and $0.6 \mu \mathrm{m}$. In this range, $\sim 25 \%$ of the "soot" particles entering the steam generator are predicted to pass through.

A simi'ar estimate assuming typical "rust" particles is shown in Fig. 3.3-2, using an assumed density of $5.2 \mathrm{~g} / \mathrm{cm}^{3}$. As expected, the inertial deposition mechanism becomes effective at a lower particle size due to the higher density. The lower thermal conductance of the "rust" particles relative to "soot" does not seem to greatly alter deposition by thermophoresis. The deposition velocities due to diffusion across the buffer and laminar sublayers are unaffected by particle properties other than size. Thus the net effect of the four mechanisms applied to "rust" particles is to predict a slightly smaller window transport through the steam generator, of approximately between 0.003 and $0.3 \mu \mathrm{m}$ sizes.

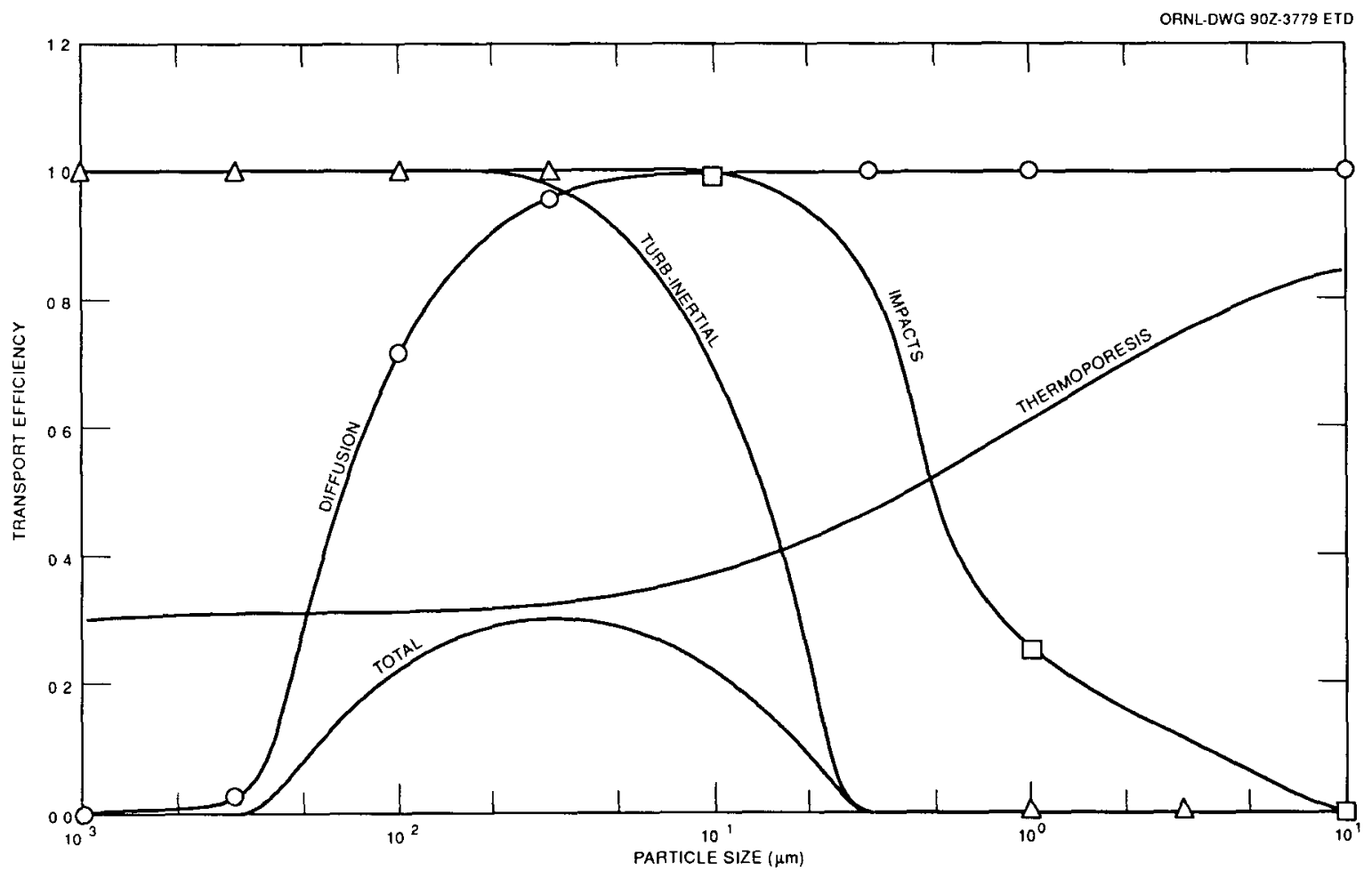

Fig. 3.3-2. Dust deposition in the steam generator-comparison of mechanisms for "rust" particles. 
The inherent uncertainties of the deposition correlations were noted in Sect. 3.2. These results, however, seem to emphasize certain items. Firstly, the high effectiveness seen for the inertial deposition mechanisms seems to be contradicted by the Peach Bottom Core 2 surveillance data. Whereas complete deposition is predicted for sizes above 0.8 and $0.3 \mu \mathrm{m}$ for "soot" and "rust" respectively, both coolant sampler and cyclone separator samples contained significant amounts of particles in the 1 to $10 \mu \mathrm{m}$ range. Therefore, the particle bounce-off estimate for the inertial impact mechanism perhaps needs to be improved in the high Stokes number range, i.e., St $>0.4$. In addition, predicted high effectiveness of the turbulent-inertial mechanism for sizes above $\sim 0.6$ and $0.2 \mu \mathrm{m}$ for "soot" and "rust," respectively, needs to be viewed with some suspicion. It too is inconsistent with the observed sizes circulating with the coolant in Peach Bottom Core 2.

It should be noted here that three of the deposition mechanisms-diffusion, thermophoresis, and turbulent-inertial-require assumption of high dust transport rates within the turbulent core and only vary in effect within the buffer and laminar sublayer. The principal difficulty here is that the sublayer width is determined from correlations developed for flow in a pipe. The sublayer thicknesses would certainly be different for cross-flow situation on the exterior of a tube, and would also be expected to vary peripherally around the tube. Thus, while particle deposition may be a relatively well-studied field, major prediction errors are certainly possible, particularly for the complex flow in the steam generator. 


\section{AEROSOL LIFTOFF MODELS}

\subsection{BACKGROUND}

Particle liftoff has been one of the traditional difficult areas of fluid mechanics for at least the past 50 years. Original problems dealt principally with saltation or dunes formation, and hence involved sandgrains or similarly sized particles moved about by tidal or wind flows. Later on, air pollution control and industrial hygiene problems came into focus, eliciting the often-cited studies by B. Fish and M. Corum and coworkers. Lately, reactor safety analyses have added to the field of application. LMFBR safety studies led to the development of aerosol transport codes (like HAARM) and ultimately the application of its derivatives to LWR severe accidents. Some severe LWR accident scenarios involve aerosol plateout in the containment vessel under quiescent conditions and subsequent liftoff in cases of containment failure (e.g., see Lipinski et al., 1985). Therefore, the past 20 years have seen a fairly substantial literature concerning particle-substrate adhesion forces, lift-off models and fluid-mechanic analyses of lift-off mechanisms.

However, HTGR liftoff presents a unique set of circumstances which precludes a direct carryover from published studies. The HTGR situation is unique in that liftoff flows act on particles plated out under the high surface shear conditions existing during normal operation. In contrast, most studies involve either quiescently deposited particles or deposits formed under unspecified conditions. The significance of depositing particles at high flows is that small sizes are deposited preferentially. This is illustrated in Fig. 4.1-1, where lift-off velocities, developed from the Force Ratio model (described in Sect. 4.3), are plotted against particle size for an assumed high and low adhesive force. The approximate normal velocity is indicated by the horizontal line at $160 \mathrm{~m} / \mathrm{s}$. Note that if conditions typical of the presumed maximum adhesive force prevail, normal operation permits deposit of particles less than about $10 \mu \mathrm{m}$. On the other hand, if particle-substrate forces prove to be closer to the lower limit, the normal flow-shearing force would allow plateout of only extremely small particles of less than about $0.02 \mu \mathrm{m}$. This illustrates that particle deposition in an HTGR Primary system may be highly selective for small, strongly adherent particles.

Figure 4.1-2 illustrates some of the physical factors involved in the determination of the liftoff velocity. The horizontal dashed line indicates the nominal surface location, and the pits and protursions represent the roughness range for extruded tubes; i.e., approximately from $0.5 \mu \mathrm{m}$ to $5 \mu \mathrm{m}$. The plated particles are shown to represent possible plateout situations. Forces acting on the plated particle are generally discussed in terms of an adhesion force shown perpendicular to the surface at contact, a drag force defined parallel to the nominal surfaces, and a lift force perpendicular to the nominal surface. It is obvious from viewing this roughly-toscale sketch that the significance and manner in which each of these force components are estimated can depend uniquely on the particle shape and size and its relation to the various shapes and sizes of surface roughness. One can sense that larger particles are more easily removed than small ones. A removal mechanism suggested by some has the drag force to initially dislodge the particles, i.e., break the adhesive bond, followed by an adequate lift force to complete the resuspension. The rationale is that drag forces are generally much larger than 


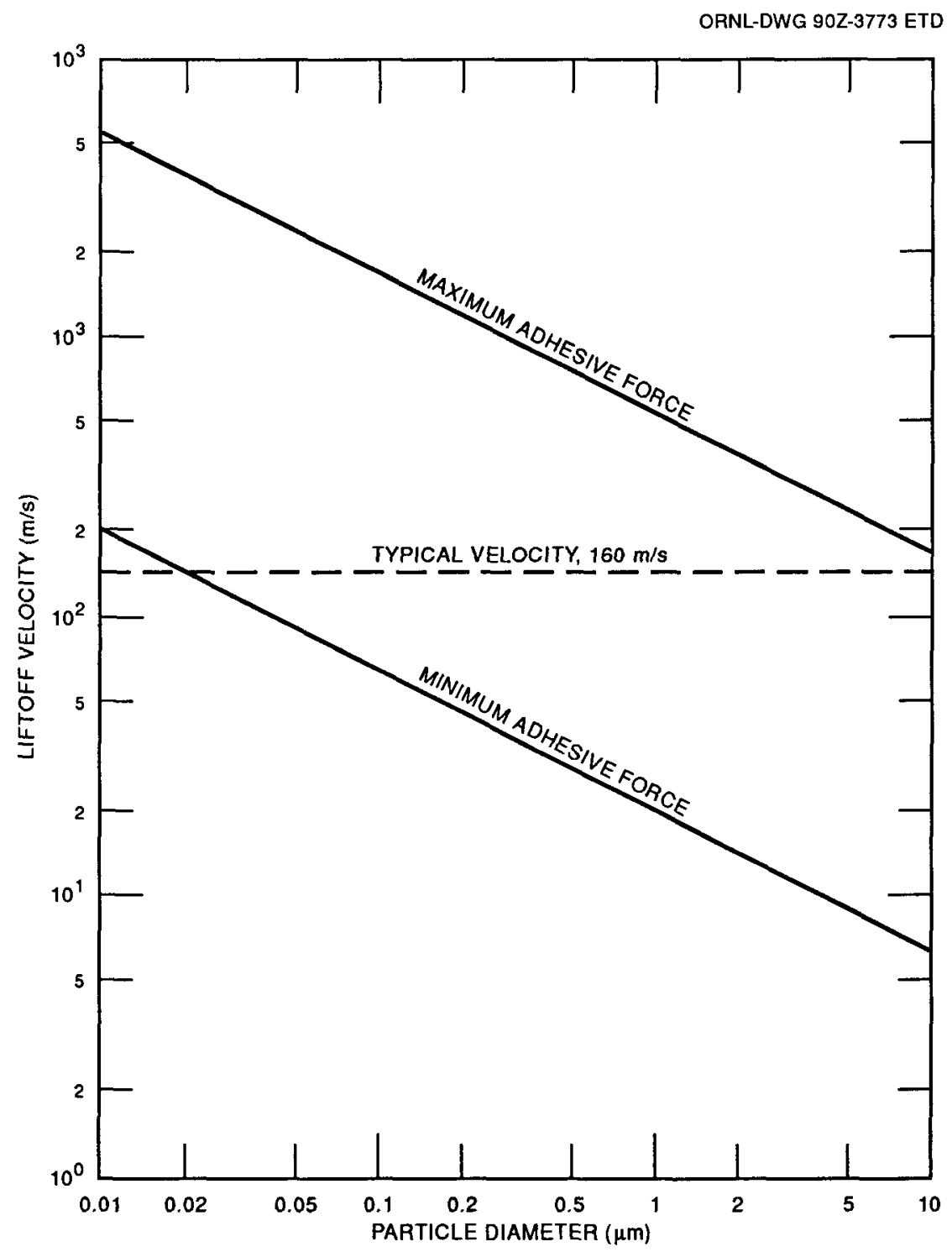

Fig. 4.1-1. Liftoff velocity vs particle diameter for high and low adhesive force estimates. (Based on force ratio model, section 4.3).

lift forces and therefore will provide the initial movement. But, the drag (or lift) force relationship may be quite different for the five situations shown on the figure. Particles smaller than the roughness scale, as illustrated by the $0.1 \mu \mathrm{m}$ particles in $4 \mu \mathrm{m}$ pits, would seem to be particularly difficult to remove.

Figure 4.1-2 also illustrates two concepts of velocity behavior in the wall-affected sublayer, the outer limit of which is shown at approximately $40 \mu \mathrm{m}$, typical for normal flow in the HTGR primary system. The traditional view, shown at left, presumes a proportionality between a time-average axial velocity, $\overline{\mathrm{u}}$, and distance $\mathrm{y}$ from the nominal wall surface (usually 


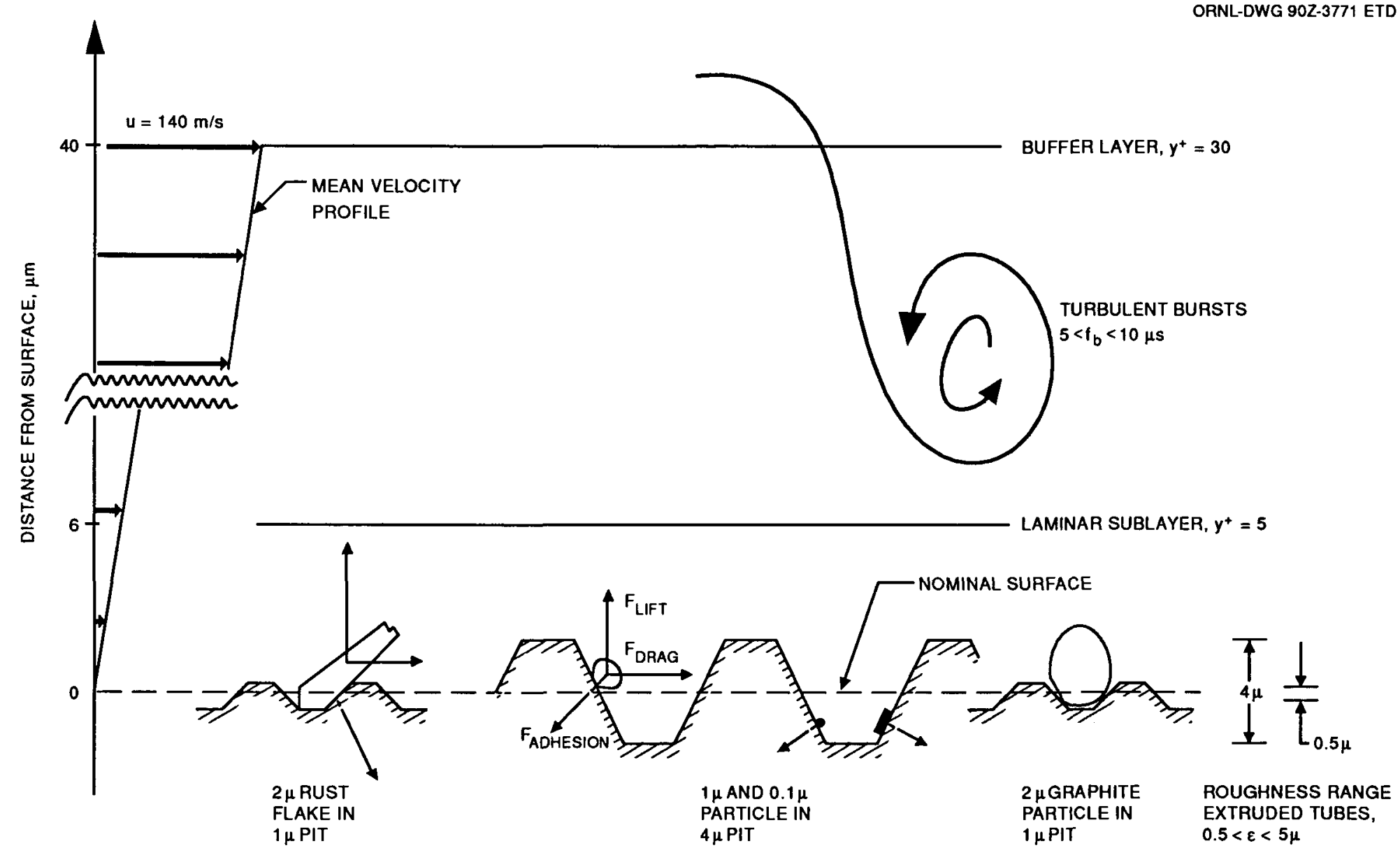

SIZE RANGE $-0.1<\mathrm{dP}<-10 \mu$

Fig. 4.1-2. Representative dust plateout configurations and factors affecting particle liftoff. 
expressed as $\mathrm{u}^{+}=\mathrm{y}^{+}$). This traditional view is assumed by force ratio theories, e.g., Brockman (1985), Craig (1975) and is also implicit in the shear ratio concept. Such models estimate the drag or lift force based on a steady, time-average velocity assumed to act on the particle at its mid-point; i.e., at the distance y equal to $d_{p} / 2$. More recently, beginning with Cleaver and Yates (1975), liftoff criteria are instead ascribed to turbulent bursts (shown at right) penetrating the laminar sublayer with high frequency. In this view, the degree of liftoff obtained is related to the frequency and size of these penetrating turbulent bursts.

Probably the most significant and most intractable aspect of predicting liftoff is estimation of the adhesive force. Mean shear stresses and turbulent burst frequencies may be estimated, but dry adhesive forces are extremely difficult to determine, both theoretically and experimentally. (Under wet conditions, adhesion is a more predictable function of particle size and the surface tension of water.) Although techniques for direct measurement of particlesubstrate adhesive forces are reported (Corn, 1966), they have not been applied to particles less than $5 \mu \mathrm{m}$, nor for any materials typical of HTGRs. As shown in Sect. 4.2, current data can predict the dry adhesive force between particle and substrate only between extremely broad limits of about a factor of 1000. Moreover, it appears to be the type of problem that is difficult to improve on by either theoretical or experimental approaches.

\subsection{FORCES ON A PLATED PARTICLE}

\subsubsection{Adhesive forces}

As noted above, the limiting factor for obtaining a reliable liftoff estimate is, most likely, the uncertain and unpredictable value of the adhesive force. According to a review by Com (1966), adhesive forces between dry surfaces are primarily due to Van der Waals forces and possibly also electrostatic forces. There appears to be significant uncertainties regarding both.

With respect to electrostatic forces, Dennis (1976) cites the maximum surface charge density on a spherical particle sustainable in dry air to be $8 \mathrm{esu} / \mathrm{cm}^{2}$. It can be shown that electrostatic forces between nearly-contacting, charged spheres are independent of the distance of closest approach. Spheres of equal size, changed to the maximum surface density of 8 $\mathrm{esu} / \mathrm{cm}^{2}$, will repel or attract as predicted by

$$
F=63 d_{p}^{2} \text {, }
$$

where $d_{p}$ is in meters and $F$ in newtons. ${ }^{*} \quad$ Equation $(4.2-1)$ predicts a $6.3 \times 10^{-6}$ dyne electrostatic force between two such particles of $1 \mu \mathrm{m}$ diameter, a value which will be compared with predicted chemical forces.

\footnotetext{
* A significantly different situation is reported by Com (1966) for electrostatic adhesion. A charge of 15 esu is reported for a $1 \mu \mathrm{m}$ particle, which seems unlikely, since it is a factor of $6 \times 10^{7}$ higher than the $8 \mathrm{esu} / \mathrm{cm}^{2} \mathrm{charge}$ density. The form of the attractive force is given as $F=q^{2} / h^{2}$, where $h$ is the separation distance, which is also significantly different. Numerical values cited appear incorrect; e.g., a charge of 15 esu at $10^{\circ} \mathrm{A}$ is said to yield $5 \times$ $10^{-3}$ dynes force. Therefore the discussions in Corn (1966) on electrostatic adhesion appear to contain internal inconsistencies.
} 
In any case it is not clear whether electrostatic adhesion forces can be sustained in the HTGR primary circuit environment due to the intense radiation field. Also, contact of electrically charged dust with a conducting substrate, such as the SG tube or the graphite core, will simply cause a discharge.

Particle adhesion may also result from a weak, chemical force, the Van der Waals force. Van der Waals forces are short-range intermolecular forces which depend on either the permanent dipole or the polarizability of interacting molecules. Hence, molecules with permanent dipoles, like chromium or iron oxides (i.e., rust), would exhibit larger self-attraction than molecules with no permanent dipole, such as carbon. In addition, polarizability generally increases with atomic number. Hence on this score also, rust particles would exhibit larger attractive force to oxide-coated metal or graphite than carbon particles.

Van der Waals forces diminish much more rapidly with separation distance than electrostatic forces. Corn (1966) cites an analysis which shows that integration of the Van der Waal's force over the surface of a theoretically smooth sphere adjacent to a plane leads to an attractive force diminishing with the square of the separation, $h$,

$$
\mathrm{F}=\frac{\operatorname{Ad}_{\mathrm{p}}}{\mathrm{h}^{2}}
$$

where $d_{p}$ is the diameter of the sphere and A depends on chemical characteristics. The significance of Eq. (4.2-2) is that the integrated Van der Waals adhesive force is quite sensitive to distance of approach. Estimation of an adhesive force using Eq. 4.2-2 rests almost entirely on proper description of the zones of close contact between the particle and the substrate. A few, very close contacts down to the molecular level $\left(\mathrm{h}=\sim 10^{\circ} \mathrm{A}\right.$ or $\left.1 \mathrm{~nm}\right)$ effective over small areas will dominate the magnitude of the attractive force. Moreover, the size of the contact area itself depends on surface roughness and particle shape on a scale down to the molecular level, and hence also on the degree of local deformation of the particle at the point of contact. [Particle deformations are included in the resuspension theory of Reeks et al. (1989)].

Unfortunately, this presents a daunting set of obstacles for developing a better estimate for the particle adhesive force. Not only is it dependent on particle size, material, shape and roughness, but also evidently on the mechanical properties which determine local deformation. Realistically, perhaps the most that may be expected from particle adhesion theory and data is some understanding of mechanism which could be used as a rough guide for liftoff modeling or experiments.

Corn cites several experimental measures of the constant, A, Eq. (4.2-2), which are reproduced in Table 4.2-1. Note that the values extend from 0.01 up to 60 pico ergs, a range of 6000. The generally higher trend with separation distance, shown for the glass plate tests, may indicate an error in the form of Eq. (4.2-2). Otherwise the range probably reflects the difficulty of the experiment.

A frequently used expression for the particle attractive force is the following contraction of Eq. (4.2-2),

$$
\mathbf{F}=\mathrm{A}^{\prime} \mathrm{d}_{\mathrm{p}}
$$


Table 4.2-1. Determinations of adhesive force constant, $A$, of Eq. (4.2-2); from Corn (1966)

\begin{tabular}{clcl}
\hline Test $a$ & \multicolumn{1}{c}{ Materials } & $\begin{array}{c}\text { Minimum } \\
\text { separation } \\
\left(\mathrm{A}^{\circ}\right)\end{array}$ & $\begin{array}{c}\mathrm{A} \\
\text { (pico ergs) }\end{array}$ \\
\hline 1 & Borate and quartz spheres & 3 & $2-5$ \\
2 & Glass plates $^{b}$ & 200 & $0.01-0.015$ \\
& & 2500 & 1.1 \\
& & 3000 & 11 \\
3 & Mica & 5000 & 60 \\
4 & Quartz sphere and plate & $5-25$ & $0.1-10$ \\
5 & Glass plate & - & 0.05 \\
6 & Theory & $0.1-10$ \\
\hline \multicolumn{4}{c}{$\begin{array}{l}\text { SSee Com (1966) for primary references. } \\
\text { bSeveral higher values of A are here omitted based on }\end{array}$} \\
discussions in Corn (1966).
\end{tabular}

relegating the Van der Waals adhesive force preportional to the particle size. Comparison with Eq. (4.2-2) shows that $A^{\prime}$ is the material constant, $A$, divided by some averaged square of the distances of approach.

Were Eq. (4.2-2a) proven to be a viable approximation, it would be a great boon for liftoff analysis, providing as it does a simple expression for the adhesive force as a function of particle size, which could easily be coupled with expressions for the liftoff force, also expressed in terms of particle size. Generally, force ratio liftoff models, including those cited in Sect. 4.3, employ Eq. (4.2-2a) as a basic assumption. Comparing with Eq. (4.2-2) shows that the constant, $A^{\prime}$, may be thought of as,

$$
A^{\prime}=\frac{A}{\left\langle h^{2}\right\rangle} ;
$$

i.e., as the Van der Waals' material constant divided by $\left\langle\mathrm{h}^{2}\right\rangle$, the mean square separation distance averaged over the nominal contact surface.

An extremely rough estimate for $A^{\prime}$ is obtained using the average value of the Van der Waals material constant, $\mathrm{A}$, from Table 4.2-1 and assuming a value of $100^{\circ} \mathrm{A}$ for $\mathrm{h}$, the distance of closest approach. This yields,

$$
A^{\prime}=7.7 \times 10^{-3} \mathrm{~N} / \mathrm{m}
$$

with at least a factor of 1000 uncertainty. ${ }^{*}$

*In comparison, Brockman (1985) used $A^{\prime}=4 \times 10^{-6}$ or $4 \times 10^{-7} \mathrm{~N} / \mathrm{m}$ in his analysis of liftoff from dry, LWR containment vessels. He concluded for this low adhesion force that $100 \%$ resuspension would occur in a severe $L W R$ accident. 
Reviews of measured particle adhesive forces are presented by Corn (1966) and later by Brockmann (1985) and Fromentin (1989). Humid conditions and large sizes (>5 $\mu \mathrm{m})$ predominate, rendering most of the data inapplicable to HTGR conditions.

A model proposed by Vatistos (1989) uses a new idea of a time-dependent adhesive force. Vatistos uses this notion to develop an estimate for the particle sticking fraction, the idea being that particles which permantly adhere require some time to adjust before adhesion takes its full effect. During this period, the particle may be rejected if subjected to a turbulent burst extending through the laminar sublayer. The concept of turbulent bursts extending through the laminar sublayer, as opposed to the traditional view given by the universal velocity profile expression, $\mathrm{u}^{+}=\mathrm{y}^{+}$, was introduced by Cleaver and Yates (1976) and appears now to be widely accepted. As used by Vatistos, the adsorption time, expressed by an unknown, first order parameter, is compared with the frequency and extent of turbulent bursts, the comparison yielding an estimated sticking probability. The model contains a number of unknown parameters, but represents a recent attempt at estimating particle adhesion under dry conditions.

\subsubsection{Lift and Drag Forces}

In contrast to the realism depicted in Fig. 4.1-2, flow forces on plated particles are generally estimated in terms of the highly idealized geometry shown in Fig. 4.2-1. The flow force is shown as being composed of a drag force parallel to an ideal surface and a lift force perpendicular to the surface, each acting through the center of the particle. The particle is invariably considered to be spherical since lift forces have been derived only for spherical particles in a linear velocity gradient. Drag forces however, may be estimated for particle shapes other than spherical, in terms of the projected area on a plane perpendicular to the flow.

ORNL-DWG 90Z-3374 ETD

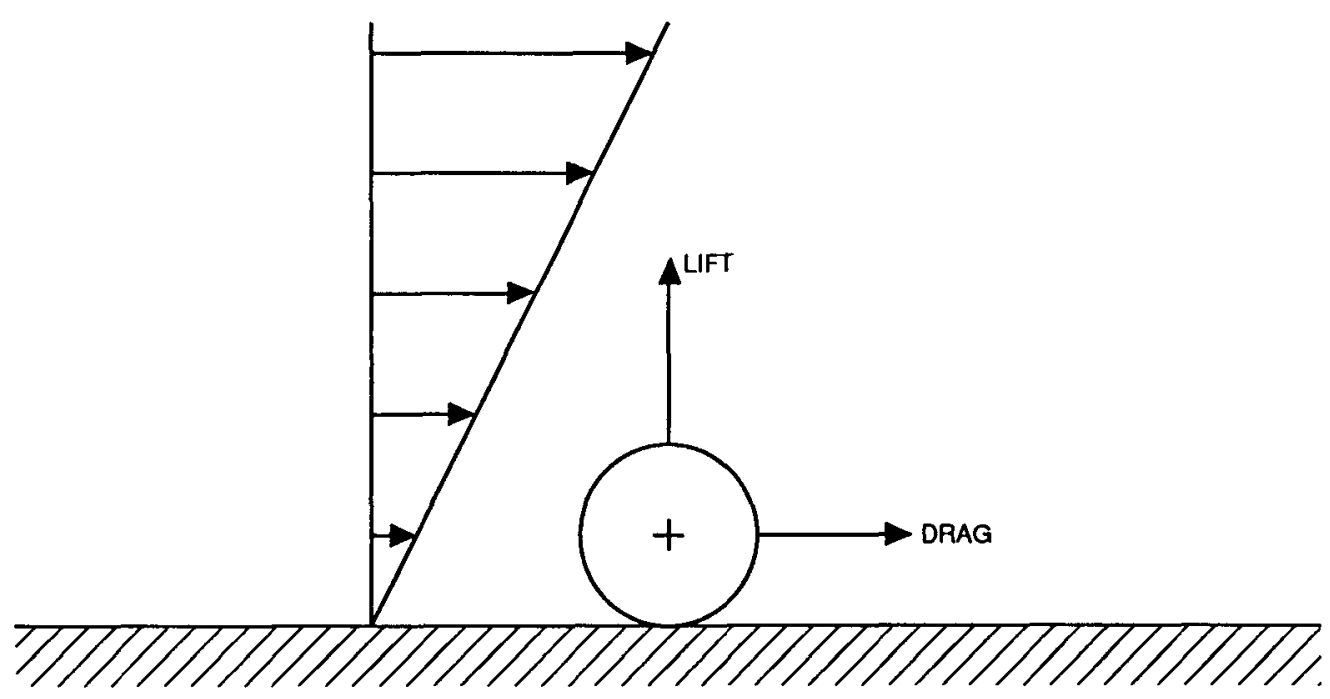

Fig. 4.2-1. Idealized situation used for Force Ratio model. 
Comparing Fig. 4.2-1 with 4.1-2 shows that the actual situation is far more complex for particles on the size scale of the surface irregularities. Typically, the laminar sublayer thickness for the HTGR primary system is $100 \mu \mathrm{m}$. Therefore, both the particle size range of interest $(<1 \mu \mathrm{m})$ and the roughness scale are well within the laminar sublayer where the velocity is proportional to the distance from the wall.

The magnitude of the lift force for the idealized case shown in Fig. 4.2-1 may be estimated from the theoretical expression of Saffman (1965),

$$
F_{L}=1.62 \sqrt{\mu \rho} d_{p}^{2} U_{p} \sqrt{\frac{d U_{p}}{d y}}
$$

where

$\mathrm{U}_{\mathrm{p}}=$ gas velocity at particle midplane,

$\mu, \rho=$ fluid viscosity and density,

$\mathrm{d}_{\mathrm{p}}=$ particle diameter.

Equation (4.2-3) applies strictly to free spheres in an infinite regime of low flow with a linear velocity gradient, but is also used in some particle liftoff models.

The drag force on a particle is conventionally written,

$$
\mathrm{F}_{\mathrm{D}}=\frac{1}{2} \rho \mathrm{U}_{\mathrm{p}}^{2} \mathrm{C}_{\mathrm{D}} \mathrm{A}_{\mathrm{p}}
$$

where

$C_{D}=$ drag coefficient,

$A_{p}=$ particle area facing flow.

For particle Reynolds numbers $\left(\operatorname{Re}_{\mathrm{p}}\right)$ less than about 100 , which is the usual case for micronsized particles in the laminar sublayer, $C_{D}$ is a strong function of $\operatorname{Re}_{p}$.

Typical values for the drag and lift force on a plated, $1 \mu \mathrm{m}$ diameter particle are developed in Table 4.2-2, assuming a free-stream velocity of $160 \mathrm{~m} / \mathrm{s}$ in a $0.01 \mathrm{~m}$ diameter channel, roughly representative of flow between heat exchanger tubes. The flow is actually far more complex, and the estimates are intended only to give an order of magnitude value of disturbing forces due to flow. It is interesting that the lift force is only a factor of 2 less than the drag in this estimate.

It should be noted that even newer liftoff theories use an estimate of particle removal force as given by Eq. (4.2-4), although in disguised forms. For example, Vatistos (1989) writes the removal force as,

$$
F_{R}=\alpha \rho d_{p}^{2} U^{* 2}
$$

where

$$
\begin{aligned}
\mathrm{F}_{\mathrm{R}} & =\text { particle removal force, } \mathrm{N}, \\
\mathrm{U}^{*} & =\text { the friction velocity, } \mathrm{m} / \mathrm{s}, \\
\alpha & =\text { unknown constant. }
\end{aligned}
$$


Table 4.2-2. Order-of-magnitude lift and drag force on $1 \mu \mathrm{m}$ particle using Eqs. (4.2-3) and (4.2-4)

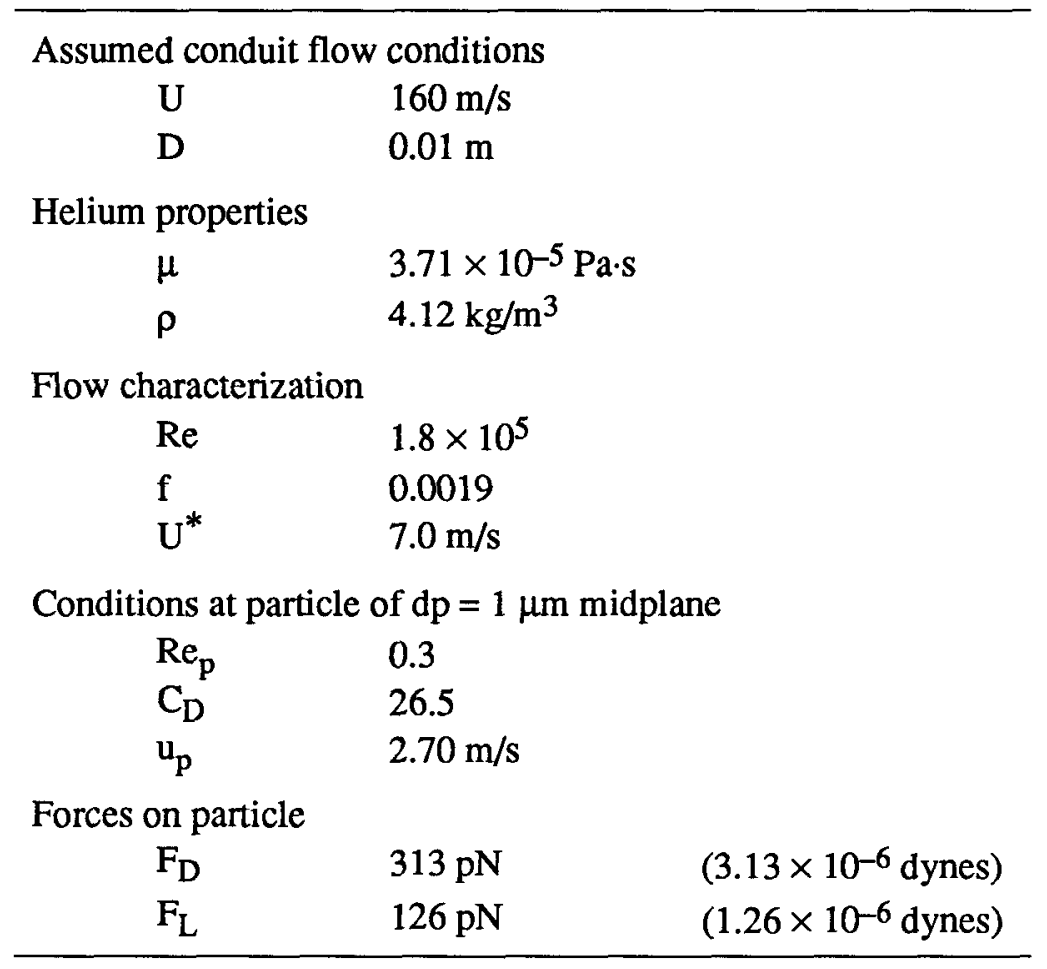

Since $U^{*}$ is defined as $\sqrt{\tau_{w} / p}$, where $\tau_{w}$ is the wall shear stress, Eq. (4.2-5) may be written,

$$
F_{R}=\alpha d_{p}^{2} \tau_{w}
$$

It can be shown that this same result is obtained form Eq. (4.2-3) for $F_{D}$ by substituting values for $U_{p}$ from the laminar sublayer portion of the universal velocity profile, and using $24 / \mathrm{Re}_{p}$ as an estimate for the drag coefficient, $C_{D}$. The derivation is outlined in Appendix $C$, where the result obtained is,

$$
\mathrm{F}_{\mathrm{D}}=4.71 \mathrm{~d}_{\mathrm{p}}^{2} \tau_{\mathrm{w}}
$$

These results, with implications for the Shear Ratio concept discussed in Sect. 4.4, show that the removal force is proportional to the wall shear stress as assumed, but that it varies as the square of the particle size. The effect is that a given wall shear preferentially allows plateout of smaller sized particles which are subject to correspondingly lower removal forces.

\subsection{LIFTOFF BASED ON FORCE RATIO}

Several investigators have developed liftoff models based on the ratio of either the lift or drag force to the adhesive force. For all of these, the extremely idealized particle and wall 
geometry depicted in Fig. 4.2-1 is assumed in contrast to the larger complexity suggested by Fig. 4.1-2. In addition, the common assumption is that the flow force is exerted by the timeaverage velocity at the particle mid-plane as estimated by the universal velocity profile. Since the particle is generally within the laminar sublayer, the correlation

$$
\mathrm{u}^{+}=\mathrm{y}^{+},
$$

is used to determine the velocity effective on the particle at midplane.

As a group, liftoff models based on force ratio omit consideration of several important elements: (1) The universal velocity profile format does not apply to the buffeting flow through the steam generator, which is the region of highest interest. In such case lift and drag forces would be expected to vary considerably around the periphery of the tube in cross-flow; (2) The idealized sphere on a perfect plane is far from realistic for particles of a scale equal to or less than the surface roughness; (3) The adhesive force is generally not known.

However, force ratio models have the virtue of being straightforward and after all, could present a useful format for interpreting test data. Several investigators have presented similar treatments based on comparing either the lift or drag force on a plated particle with the adhesive force; e.g., Craig (1975), Fuchs (1964), Corn (1966), Brockman (1985) and others. Presented below are the specific assumptions generally used and the resulting liftoff criterion. The derivation is given in Appendix C. Several details and results differ somewhat from the cited references, but the basic concept is the same. The specific assumptions of the model are as follows:

(1) A spherical particle on a perfectly smooth flat plate is assumed.

(2) The particle diameter, $d_{p}$, is smaller than the laminar sublayer thickness.

(3) The velocity gradient is given by the Universal Velocity Profile model for fully established flow in smooth pipes.

(4) Liftoff occurs when the drag force on the particle, $F_{D}$, exceeds the adhesive force, $F_{A}$.

(5) The drag force is estimated from,

$$
F_{D}=\frac{1}{2} \rho U_{p}^{2} A_{p} C_{D},
$$

where

$u_{p}=$ is the velocity at the particle midplane,

$\rho=$ gas density,

$A_{p}=$ projected particle area, $1 / 4 \pi d_{p}^{2}$,

$C_{D}=$ drag coefficient for spherical particles.

(6) The adhesive force is estimated from,

$$
\mathrm{F}_{\mathrm{A}}=\mathrm{A}^{\prime} \mathrm{d}_{\mathrm{p}} \text {, }
$$

where

$\mathrm{A}^{\prime}=$ adhesive force constant, Eq. (4.2-2b). 
These assumptions lead to the following liftoff criterion:

$$
\mathrm{U}_{\mathrm{LO}}>0.461 \sqrt{\frac{\mathrm{A}^{\prime}}{\mathrm{d}_{\mathrm{p}} \rho \mathrm{f}}} .
$$

The friction factor, $\mathrm{f}$, is defined as $\tau_{\mathrm{w}} / \mathrm{p} \mathrm{U}^{2}$. A numerical example of this criterion is illustrated in Fig. 4.1-1 using the upper and lower limit values of $A^{\prime}$ defined by Eq. (4.2-2), a helium gas density of $4.12 \mathrm{~kg} / \mathrm{m}^{3}$ and a friction factor (as defined above) of 0.0019 , typical of helium flow in a smooth, $1 \mathrm{~cm}$ diameter tube at $160 \mathrm{~m} / \mathrm{s}$.

According to this criterion, a particle of diameter, $d_{p}$, remains plated so long as the mean conduit velocity is less than $\mathrm{U}_{\mathrm{LO}}$. Therefore, for a plated dust of uniform size the liftoff criterion is given by,

$$
\begin{array}{ll}
\mathrm{U}<\mathrm{U}_{\mathrm{LO}}, & \text { liftoff }=0 \\
\mathrm{U}>\mathrm{U}_{\mathrm{LO}}, & \text { liftoff }=100 \% .
\end{array}
$$

Stated a bit differently, the force ratio criterion means that a particular liftoff velocity, $\mathrm{U}_{\mathrm{LO}}$, removes 100 percent of the particles above some critical size while allowing 100 percent of all smaller sizes to remain plated. Therefore, application of Eq. (4.3-3) to determine a degree of liftoff for a particular velocity requires knowledge of the plateout size distribution.

A corollary of the force ratio criterion which is consistent with the shear ratio concept, is that a given velocity, $\mathrm{U}$, allows only particles less than some critical diameter, given by Eq. (4.3-3), to permanently deposit. This is illustrated in Fig. 4.1-1. Referring to the assumed normal mean velocity of $160 \mathrm{~m} / \mathrm{s}$, the figure shows that only particles larger than $10 \mu \mathrm{m}$ will plate if the maximum adhesive force estimate is valid, while the low estimate allows particles larger than $0.05 \mu \mathrm{m}$ to permanently plate.

An interesting consequence of this result is that an experimental observation of the maximum plated particle size can be used as a measure of the adhesive force. That is, the adhesion constant, $\mathrm{A}^{\prime}$ may be determined from the known mean velocity, friction factor, and measured value of the maximum plated particle size from Eq. (4.3-3).

\subsection{THE SHEAR RATIO CONCEPT}

The principle of the shear ratio concept is that particles plated under a particular set of flow conditions will not lift off unless subsequent flows create higher wall shears. This is consistent with the Force Ratio model described in the previous section. However, the shear ratio concept is not, strictly speaking, a model in the sense that it predicts a degree of liftoff for a given value of the shear ratio. As currently expressed, the concept merely states that,

$$
\begin{array}{ll}
F_{L O}=0 & \text { when } S R \leq 1, \text { and } \\
F_{L O}=f(S R) & \text { when } S R>1,
\end{array}
$$


where

$$
\begin{aligned}
F_{L O}= & \text { fractional liftoff, } \\
S R= & \text { shear ratio; i.e., the wall shear stress due to depressurization flow relative to } \\
& \text { normal conditions, } \\
\mathrm{f}(\mathrm{SR})= & \text { an undetermined function of } \mathrm{SR} .
\end{aligned}
$$

Time-dependence is excluded from consideration; the fractional liftoff is assumed to occur instantaneously upon application of the higher shear stress. The form of the liftoff function $\mathrm{f}(\mathrm{SR})$ is left completely to experimental determination. Experiments to date indicate a different functional dependence for different fission products; i.e., Eq. (4.4-1) should instead be written separately for each fission product, $i$, as

$$
\mathrm{F}_{\mathrm{LO}, \mathrm{i}}=\mathrm{f}_{\mathrm{i}}(\mathrm{SR}) \quad \text { when } \mathrm{SR}>1 .
$$

However, a great deal of data scatter causes this to be an uncertain conclusion. If true, this can only mean that different FPs are associated with different sizes of plated particles.

As a practical matter, it is usually desirable to determine some form of the function $\mathrm{f}(\mathrm{SR})$ to guide experimentation and data interpretation. However, the result would be in terms of the unknown value of the adhesive constant, $A^{\prime}$ and the size distribution of the plated material. For example, recasting Eq. (4.3-3) yields,

$$
\mathrm{d}_{\text {crit }}=0.213 \frac{\mathrm{A}^{\prime}}{\mathrm{U}^{2} \rho \mathrm{f}},
$$

where $U$ is the free stream velocity. If now a depressurization event generates higher values of $\mathrm{U}$, some particles smaller than $\mathrm{d}_{\text {crit }}$ will be removed. That is, the higher flow rate corresponds to a new, and smaller critical particle size. The degree of liftoff thus depends on the fraction of plated material lying between these two sizes. In this view, the liftoff function, $f(S R)$ may be evaluated using the Force Ratio Criterion and the size distribution of plated particles, providing of course the value of $A^{\prime}$ were known.

In summary, the chief advantage of the shear ratio approach is its simple basic starting point-that particles in the primary system are deposited under high shear conditions and are thereby preselected for strong adherence which is a distinctive feature of MHTGR primary loop liftoff. Its deficiencies, as a predictive concept as currently expressed, are the following:

(1) It is extremely awkward to have no expression at all for the liftoff function, $f(S R)$, [or liftoff functions, $f_{i}(S R)$ ] of Eq. (4.4-1). This places too much burden on experimentation. Determination of unknown functions solely from data may result in large error, especially if the experiments are difficult or biased.

(2) In addition to data interpretation, some theoretical basis for the liftoff function, $f(S R)$, is needed. The usual motivation for theoretical development is identification of key factors which control results. Without theoretical basis, it is difficult to rationally select experiments.

(3) The assumed result of the Shear Ratio Concept-that the liftoff is zero when the SR is equal to or less than unity-may not be completely correct. One result of the newer liftoff 
concepts discussed below is that some liftoff occurs continuously at shear ratios of one and even below.

\subsection{TURBULENT BURST CONCEPTS OF CLEAVER AND YATES (1973)}

A significant turn in particle liftoff analyses was created by the influential work of Cleaver and Yates (1973). The important concept of the unsteady laminar sublayer, originally observed in the 1930's, was reintroduced and proposed as the principal liftoff mechanism. Cleaver and Yates noted that the theoretical, time-steady laminar sublayer between a wall and a turbulent flow while being a useful approximation for many purposes, in fact like many idealizations, does not completely exist. The actual, non-steady nature of the laminar sublayer appears to have been submerged beneath the simplicity and popularity of the universal velocity profile format, which is the chief expression for the idealized laminar sublayer.

Cleaver and Yates observed that liftoff of colloidal-sized particles due to fluid shear is frequently unexpectedly small unless the shear layer lies adjacent to a turbulent core of flow. They assert, therefore, that the steady viscous shear itself is not the mechanism for liftoff. Instead they note that turbulent eddies extend through the laminar sublayer to the wall with a high frequency that is predictable for simple flow configurations. Liftoff, they assert, is due to these turbulent bursts. The liftoff rate, according to this view, would be proportional to the frequency and the fractional area covered by the penetrating eddies.

Beyond this point, Cleaver and Yates attempt to develop a quantitative liftoff relationship by balancing the opposing actions of the turbulent bursts and particle adhesive forces. It may be that all such fundamental attempts are destined to be impracticle (at least) due to the impenetrable details regarding adhesion and flow forces on submicron particles. However, the recognition of the appropriate liftoff mechanism, which appears now to have been supported by subsequent work, is at least a prerequisite for improved developments in this area.

\subsection{PARTICLE "DESORPTION" MODEL}

According to the model of Wen and Kasper (1989), plated particles are reentrained by flow forces at a fractional rate dependent on the ratio of the adhesive force to dislodging force; i.e., when negligible deposition is occurring, they assume,

$$
\frac{\mathrm{d} S}{\mathrm{dt}}=-\beta(\mathrm{F}) \mathrm{S}
$$

where,

$S=$ particles per unit area, $1 / \mathrm{m}^{2}$,

$\mathrm{b}=$ removal rate constant, $1 / \mathrm{s}$,

$F=$ force ratio on particle, $F_{A} / F_{D}$.

$\mathrm{F}_{\mathrm{A}}=$ attractive force to substrate,

$F_{D}=$ drag force due to flow. 
The attractive feature here is that a time-dependency for liftoff is incorporated, which appears to be the physical reality. For example, liftoff data are shown for 0.5 and $1.0 \mu \mathrm{m}$ diameter latex particles in stainless steel tubes where an initial removal rate of $\sim 25$ particle/s is shown to reduce with time, down to $\sim 0.25$ particle/s.

The mathematical development and further assumptions of Wen and Kasper may or may not prove to be useful. However, liftoff data from numerous tests using sensitive particle counters were interpreted fairly well in terms of their model concepts. Beyond the initial assumption of Eq. (4.6-1), Wen and Kasper assume the following relation between the liftoff constant and the force ratio on the particle,

$$
\beta(F)=A e^{-F},
$$

i.e., the liftoff constant is assumed in a form taken from chemical kinetics, the parameter $F$ replacing the Arrhenius term, E/RT. There is probably no physical basis for this assumption, which was first suggested by a highly speculative theory outlined by Reeks et al. (1988). However, the result is an expression which matches liftoff data fairly well. Therefore, if satisfactory expressions for the attractive force, $F_{A}$, and the drag force, $F_{D}$, are available then the expression for $\beta$ can form the basis of a consistent, liftoff model that can be applied to the course of a depressurization event. (A speculative attempt to do so is described below and applied to two predicted MHTGR depressurization schedules in Sect. 5.6.)

A second feature of the model is the mathematical device of using the parameter, F, as a dependent variable, and as the variable defining the particle size distribution. In both cases, direct use of the particle size, $d_{p}$, as the principle characterization parameter may have resulted in a more readily interpretable result. The final assumption, that plated particles are distributed uniformly with $\mathrm{F}$ from some minimum to maximum value, is required in to obtain a result in closed form. Any other assumption such as normal or log-normal distribution with $F$, would have required numerical evaluation. Use of these assumptions leads to the following result:

$$
S(t)=\frac{S_{0}}{\left(F_{\max }-F_{\min }\right) t}\left\{\exp \left[-A \exp \left(-F_{\max } t\right)-\exp (-A \exp )\left(-F_{\min } t\right)\right]\right\}
$$

where,

$$
\begin{aligned}
\mathrm{S} & =\text { liftoff rate, } 1 / \mathrm{m}^{2} \mathrm{~S} \\
\mathrm{~S}_{\mathrm{o}} & =\text { initial plateout density, } 1 / \mathrm{m}^{2} \\
\mathrm{~F}_{\max }, \mathrm{F}_{\min } & =\text { the extreme of } \mathrm{F} .
\end{aligned}
$$

This result matches test data in that at early times the liftoff rate is seen to be approximately proportional to $1 / \mathrm{t}$. The departure from the $1 / \mathrm{t}$ decay in the liftoff rate at later times, also exhibited by Eq. (4.6-3), has similarly been observed.

Wen and Kasper evaluated the model constants, $A, F_{\min }$ and $F_{\max }$ for a series of liftoff tests, some of which are reproduced in Table 4.6-1. The parameters were evaluated to provide the best fits for the test data. The final two columns in Table 4.6-1 list the fitted values of the liftoff rate factors for the initial and the final phase of each test. It is important to note that Wen and 
Table 4.6-1. Wen and Kasper (1989) liftoff model constants ${ }^{a}$

\begin{tabular}{|c|c|c|c|c|c|c|c|c|c|}
\hline \multicolumn{4}{|c|}{ Flow conditions } & \multirow{3}{*}{$\begin{array}{c}\text { Air } \\
\text { velocity } \\
(\mathrm{m} / \mathrm{s})\end{array}$} & \multirow{2}{*}{\multicolumn{5}{|c|}{ Model }} \\
\hline \multicolumn{2}{|c|}{ Tube } & \multicolumn{2}{|c|}{ Particles } & & & & & & \\
\hline$\underset{(\mathrm{cm})}{\mathrm{ID}}$ & Material & $\begin{array}{l}\text { Size } \\
(\mu \mathrm{m})\end{array}$ & Material & & $\underset{(1 / h)}{A}$ & $F_{\min }$ & $F_{\max }$ & $\begin{array}{c}\beta_{i} \\
(1 / h)\end{array}$ & $\begin{array}{c}\beta_{\mathbf{f}} \\
(1 / \mathrm{h})\end{array}$ \\
\hline 0.46 & ss? & $?$ & $?$ & 10 & 4 & 0 & 5.2 & 4 & 0.022 \\
\hline 2.45 & ss & $?$ & $?$ & 30 & 10 & 0 & 5.0 & 10 & 0.067 \\
\hline 0.125 & ss & 0.51 & Latex & $100^{b}$ & 17.5 & 0 & 5.0 & 17.5 & 0.012 \\
\hline 0.125 & ss & 1.02 & Latex & $100^{b}$ & 25 & 0 & 6.0 & 25 & 0.062 \\
\hline$?$ & Teflon & $?$ & $?$ & $100^{b}$ & 25 & 2.4 & 3.5 & 2.3 & 0.076 \\
\hline
\end{tabular}

${ }^{a} \beta_{\mathrm{i}}$ and $\beta_{\mathrm{f}}$ are the initial and final liftoff rate constants that best fit this data set.

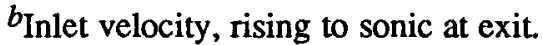

Kasper's tests differ significantly from PS depressurizations in that the initial condition, although poorly defined, appears to have been characterized by significant amounts of fairly loose dust. This is noted in Table 4.6-1 by large values of the initially observed fractional liftoff rate, that is the value of $\beta_{\mathrm{i}}$. As the test progressed, generally from 10 to 100 hours at constant flow rate, flow forces on the plated particles progressively stripped increasingly adherent particles. This is indicated by the observed increase in the characteristic force ratio, $F$, and reduction in $\beta$ as the test progressed. Note, this behavior differs significantly from force ratio and shear ratio model predictions, both of which would have indicated a rapid initial liftoff of all particles characterized by $\mathrm{F}<1$ and no subsequent liftoff of other particles.

It is thus interesting to note that Wen and Kasper's tests show that liftoff can extend to relatively adherent particles, characterized by force ratios, $F_{A} / F_{D}$, of up to 3.5 to 6.0 , significantly higher than presumed by force or shear ratio models. The physical basis for doing so is by means of the "turbulent burst" concept reintroduced by Cleaver and Yates (1973) and discussed in Sect. 4.5. Table 4.6-1 also shows that the final observed liftoff factors at test termination ranged from 0.012 to $0.076\left(\mathrm{~h}^{-1}\right)$, which are values possibly more consistent with what may occur under MHTGR depressurization conditions. The average value of the liftoff parameter at the end of these tests, that is, average $\beta_{\mathrm{f}}$, was $0.048 \mathrm{~h}^{-1}\left(1.3 \times 10^{-5} \mathrm{~s}^{-1}\right)$. This is the value of the liftoff factor used for the order of magnitudes estimate of iodine liftoff presented in Sect. 5.6.

In summary, the main significance of Wen and Kasper's work is that an assumption of a simple, first order liftoff constant Eq. (4.6-1) can account for the observed time-dependency of the liftoff rate in simple experiments. This provides some chance for direct improvement of the Shear Ratio concept, which is currently limited to assumed instantaneous liftoff. An additional significant point is that there is no sharp cutoff point in shear stress, above which liftoff occurs and below which it does not. Instead, the model predicts a gradually diminishing liftoff rate as progressively more-tightly held particles are removed. In addition, an experimental procedure is described for evaluation of the lift-off rate constant, $\beta$, for a range of flow conditions using fairly simple test equipment. 
A speculative method for adapting Wen and Kasper's approach to MHTGR liftoff modeling may start with their assumption of the dependence of $\beta$ on the force ratio, F; i.e., Eq. (4.6-2), rewritten as,

$$
\beta=\beta_{\mathrm{o}} \exp \left(-\mathrm{F}_{\mathrm{A}} / \mathrm{F}_{\mathrm{D}}\right)
$$

Here, the constant $A$ is rewritten as $\beta_{0}$, which is the steady-state value of the liftoff constant, $\beta$, when the particle attractive force, $F_{A}$, and removal force, $F_{D}$, are equal. Therefore, we may identify, $\beta_{0}$, as the value of the liftoff constant for a shear ratio of unity, the steady state value. A mass balance for liftoff from a single surface region may then be written (neglecting deposition during liftoff),

$$
\frac{\mathrm{dS}}{\mathrm{dt}}=-\beta(\mathrm{F}) \mathrm{S}(\mathrm{t})
$$

where $S(t)$ is the degree of plateout $\left(\mathrm{kg} / \mathrm{m}^{2}\right)$ and the liftoff parameter shows its functional dependence on the force ratio, $F$. Rearranging and defining a liftoff fraction, $F_{L O}(t)$ to be,

$$
F_{L O}(t)=1-S(t) / S(0)
$$

leads to,

$$
F_{L O}(t)=1-\exp \left[\int_{0}^{t} \beta(F) d t\right]
$$

Therefore, if the variation of $F$ with time during a depressurization could be approximated and the functional dependence of $\beta$ with $F$ were known, integration of Eq. (4.6-6) would yield the variation of the fractional liftoff with time. Equation (4.6-4) strongly suggests the following dependance of $\beta$ on flow,

$$
\beta=\beta_{\mathrm{o}} \exp (\operatorname{SR}(\mathrm{t})-1),
$$

where $\beta_{o}$ is the liftoff parameter during normal flow when the shear ratio is unity and $S R(t)$ is the shear ratio during the blowdown.

Although highly speculative, Eq. (4.6-6) and the assumption of shear ratio dependency of $\beta$ in Eq. (4.6-7) are used in section 5.6 to estimate fractional liftoff for two MHTGR depressurization cases for which the shear ratio history are available from RATSAM.

\subsection{TURBULENT ENERGY THEORY OF REEKS AND COWORKERS}

Reeks and coworkers have published a series of reports, the latest being Reeks et al. (1988), which attempt to develop a particle resuspension theory as nearly as possible from basic physics concepts. The general approach, appears consistent with the concepts reintroduced by Cleaver and Yates (1973) whereby sporadic turbulent bursts, intruding through the laminar sublayer, are the principal cause of dust resuspension. As a class, therefore, Reeks' approach falls with Cleaver and Yates, and Wen and Kasper and apart from force or shear ratio based models. 
No attempt is made here to describe the model which is fairly complex both as to assumptions and mathematical development. However, several useful features should be noted. Possibly most useful is the clear illustration of the extensive basic information required for development of a liftoff model from basic principles. Description of the adhesive force, which is presumed chemical in nature and not electrostatic, requires an intimate description of the particleto-substrate geometry. Deformation energies are a feature of the development which in turn depend on elastic-plastic property data and presumptions regarding contact geometry. Similarly, details are required regarding the turbulent energy spectrum of the eddies which penetrate to the wall. All of which present a formidable set of required input information.

Two results of the model development are (1) a probability for particle liftoff in the form,

$$
\beta=A \exp (-Q / R T) \text {, }
$$

which suggested the form of the liftoff rate constant, $\beta$, to Wen and Kasper (1989), and (2) a result which indicates that often liftoff conditions follow a $1 /$ time dependency, consistent with some of the data presented by Reeks et al. (1988) as well as a large portion of data presented by Wen and Kasper.

\subsection{CONCLUSIONS REGARDING THE STATUS OF LIFTOFF MODELS}

It seems clear that formulation of a liftoff model from basic chemical and physical principles is not a practical objective, certainly not for any near-term reactor safety objective. Such efforts seem destined to be frustrated by theoretical and experimental difficulties in determining particle adhesive forces. Direct measure of adhesive forces appears limited to sizes above $\sim 5 \mu \mathrm{m}$. The particle size range of interest, $\sim 0.1$ to $1 \mu \mathrm{m}$, may be out of reach. Moreover, theoretical treatments stumble on the diversity of sizes, shapes and materials. A major block is determination of the contact geometry, the most sensitive determiner of the adhesive force. A broad view proposed by Corn has the adhesive force proportional to particle size. This allows some theoretical development but is quite uncertain. In general, the adhesive force of a particle on a substrate is known only to within a factor of 1000 .

On the other hand, some modeling framework is highly desirable at least as a guide to selection of experimentation and treatment of data. To be useful in this manner, the framework should as much as possible be based the most significant factors causing liftoff.

The Shear Ratio concept does not appear to be very useful as such a modeling framework, as currently expressed. As described, the Shear Ratio concept merely indicates that no liftoff occurs below a shear ratio of unity (which may not be fully correct) and that some occurs above. A guide to the expected degree of liftoff is absent, leaving an excessive burden on experimentation to develop the required functional relationships.

Adaptation of Force Ratio concepts (section 5.4) may provide such a framework. Force ratio and shear ratio concepts are at basis identical. However, the force ratio model includes particle and aerodynamic details absent in the Shear Ratio concept and which, although highly idealized, may provide some useful guidance. 
There are currently two divergent views regarding the principal manner in which particles are removed by flow forces. One view (the Force Ratio) presumes a classical, laminar sublayer below which adherent particles may be removed by viscous forces acting through a time-steady velocity gradient. The second view [based on concepts reintroduced by Cleaver and Yates (1973)] holds that adherent particles are occasionally buffeted by bursts of turbulence extending through the laminar sublayer, and that the liftoff rate depends largely on the frequency and area of these bursts. The more recent liftoff modeling efforts [e.g., Wen and Kasper (1989) and Reeks et al. (1988)] are outgrowths of the turbulent burst concept.

Although approaches based on both the force ratio and turbulent burst views of liftoff may be useful as a modeling basis, physical reality appears to lean toward concepts based on turbulent bursts. Knowledge that turbulent bursts disturb the laminar sublayer is well established, but has not been applied, possibly due to the popularity of the universal velocity profile format which presumes the ideality of a steady laminar sublayer. In addition, data appear to support the notion that application of a flow shear stress causes liftoffs extending over 10's of hours rather and nearly immediately as assumed by force ratio concepts.

Wen and Kasper (1989) present a useful approach by defining a liftoff rate parameter as a function of attractive and drag forces. With some further assumptions they show that their assumptions lead to a liftoff rate dependence with time that diminishes as $1 / \mathrm{t}$, consistent with test data, a result which is also shown by the more elaborate model of Reeks et al. (1988). A method of adapting the parameter, $\beta$, to a liftoff analysis is presented in Sect. 4.6.

The review conducted for this section reveals no unique feature of radiation that is vital to liftoff or particle adhesion. While there does seem some chance that electrostatic adhesion is lower in the presence of radiation, this does not seem to be significant for electrically conducting substrates. 


\section{IODINE PLATEOUT AND LIFTOFF ESTIMATE}

An order-of-magnitude estimate of iodine "plateout" in the PS and subsequent "liftoff" due to a dry depressurization event is presented in this section. The principal motivation is to place all the contributory factors cited earlier in context and to identify the key factors affecting the "liftoff" source term. As usual, the terms "plateout and liftoff" here include chemical factors as well as dust transport.

The chemical behavior of iodine under MHTGR primary loop conditions is reasonably straightforward, and hence the principal inventory locations and their characteristics can be identified with some confidence. This is a superior situation relative to that of cesium which has more complex chemistry. In comparison, iodine may be expected to form only weak chemical associations with PS materials, characterized by means of chemisorptive isotherms. In addition, there is no indication that sorbed iodine diffuses into materials, as may cesium into oxides, or dissolves in any primary circuit material, as may silver in nickel-containing steel.

Chemisorption isotherms are available for steel under the strongly reducing conditions of the PS, and to a far lesser extent for graphite and oxidic materials. Since both iron and chromium can form iodides at lower temperatures and higher iodine partial pressures, it is reasonable to expect fairly strong chemisorption under condition where stable compound formation does not occur. Although other data are sparse, Osborne et al. (1982) have shown chemisorption on oxidic surfaces to be roughly two orders of magnitude below that of steel at similar conditions. Similarly for graphite, the work of Lorenz (1982) indicates significantly lower sorption for graphite relative to steel. (See Sects. 5.3 and 5.4 below for further discussion of iodine chemisorption).

In the gas phase, the simple chemical forms, atomic I, HI, and molecular $\mathrm{I}_{2}$ are expected to predominate. Equilibrium levels of methyl iodide are vanishingly small. At the high temperature locations in the PS, chemical equilibrium tends to shift the gaseous forms to I and HI, the subdivision between the two depending on the oxygen potential. Lower temperature regions favor $\mathrm{I}_{2}$ formation. An additional circulating chemical form of iodine is as chemisorbed iodine on circulating dust, the relative importance of which depends upon the concentration of dust and its sorbtivity for iodine.

Summarizing then, the principal repositories of iodine in the PS outside the fuel compacts are:

\section{Plated Forms}

(1) chemisorbed on steel

(2) chemisorbed on graphite

(3) chemisorbed on plated dust

\section{Circulating Forms}

(4) chemisorbed on circulating dust

(5) gaseous forms. 


\subsection{IODINE RELEASE FROM FUEL}

Reasonable approximations for iodine release rates from fuel were outlined in Sect. 1.4.2 and are summarized below:

Short-lived isotopes, including I131

$$
\frac{R}{B}=\left(f_{c} 0.0143 \sqrt{T_{1 / 2}}\right)+\left(f_{k} 1.65 \times 10^{-4} \sqrt{T_{1 / 2}}\right)
$$

Long-lived isotopes. I127 and I129

$$
\frac{R}{B}=f_{c}+f_{k}
$$

where,

$f_{c}=$ heavy metal contamination fraction, $1.0 \times 10^{-5}$,

$f_{k}=$ time-average fraction of fuel with exposed kernels, $2.5 \times 10^{-5}$,

$\mathrm{T}_{1 / 2}=$ half-life, hr.

The stated failure fractions are DOE estimates summarized in Table 1.4-2. The effective value of $f_{k}$ is taken as the average of the stated as-manufactured and EOL values. The parenthesis in the first term of Eq. 5.1-1 is an estimate of the attenuation of short-lived iodines from contamination sources (see Fig 1.4-1). Its maximum value is 0.20 , which it takes for I131. The second parenthesis in Eq. (5.1-1) is an estimate of radioactive attenuation for diffusive transport from fuel grains, based on Peach Bottom Core 1 data which had a known, $100 \%$ failure rate. The maximum value for this second parenthetical term in Eq. (5.1-1) is $2.3 \times 10^{-3}$, the value it takes for I131. That is, according to this relationship, $99.77 \%$ of the I131 born in failed fuel with exposed kernels, decays prior to diffusive release from the kemel.

On these bases, the estimated R/B values for the seven most significant iodine nuclides are listed in Table 5.1-1.

\subsection{IODINE SORPTION ISOTHERMS}

\subsubsection{Iodine Sorption on Steel}

Numerous expressions for chemisorptive isotherms are available, however, none is more convenient than the Langmuir isotherm nor more appropriate for classical chemisorptive behavior, such as exhibited by iodine on steel. In fact, sorptive behavior that differs significantly from the Langmuir isotherm may in fact be driven by other phenomena. The Langmuir isotherm has the additional advantage in that its two constants have clear mechanistic significance. Extrapolations with temperature or for differing materials can therefore be made with more confidence. 
Table 5.1-1. Iodine nuclide release rates

from fuel, based on Eqs. (5.1-1) and (5.1-2)

and estimated, average failure fractions,

Table 1.4-2

\begin{tabular}{clcc}
\hline Nuclide & Half life & Yield & $\begin{array}{c}\text { (R/B) } \\
\text { from fuel }\end{array}$ \\
\hline $\mathrm{I} 127$ & $\infty$ & 0.137 & $3.5 \times 10^{-5}$ \\
$\mathrm{I} 129$ & $1.6 \times 10^{7} \mathrm{yr}$ & 1.00 & $3.5 \times 10^{-5}$ \\
$\mathrm{I} 131$ & $8.04 \mathrm{~d}$ & 2.93 & $3.37 \times 10^{-6}$ \\
$\mathrm{I} 132$ & $2.29 \mathrm{~h}$ & 4.31 & $2.14 \times 10^{-7}$ \\
$\mathrm{I} 133$ & $2.08 \mathrm{~h}$ & 6.69 & $2.12 \times 10^{-7}$ \\
$\mathrm{I} 134$ & $52.6 \mathrm{~min}$ & 7.90 & $1.38 \times 10^{-7}$ \\
$\mathrm{I} 135$ & $6.59 \mathrm{~h}$ & 6.19 & $3.76 \times 10^{-7}$ \\
\hline
\end{tabular}

The Langmuir isotherm for isotope-i of an element with $\mathrm{N}$ isotopes is given by,

$$
S_{i}=\frac{L K P_{i}^{*}}{1+K \sum_{i} P_{i}^{*}}
$$

where

$$
\begin{aligned}
& S_{i}=\text { sorbed concentration of isotope } \mathrm{i}, \mathrm{mol} / \mathrm{m}^{2} \\
& P_{i}^{*}=\text { partial pressure of } i \text { in equilibrium with } S_{i}, P a \\
& L=\text { concentration of sorption sites, } \mathrm{mol} / \mathrm{m}^{2} \\
& K=\text { sorption equilibrium constant, } \mathrm{Pa}^{-1} \text {. }
\end{aligned}
$$

The term, $\sum_{\mathrm{i}} \mathrm{P}_{\mathrm{i}}^{*}$ is the element partial pressure summed for all isotopes. Therefore, whenever $\mathrm{K} \Sigma_{\mathrm{i}} \mathrm{P}_{\mathrm{i}}^{*}$, is signi ficant compared with unity, the sorbed concentration of isotope-i is coupled with sorbed concentrations of all other isotopes. In such case, the transport behavior of 1131, say, must be solved for simultaneously with all other iodine isotopes. Fortunately, it will be shown that for iodine in the MHTGR primary system,

$$
\mathrm{K} \sum_{\mathrm{i}} \mathrm{P}_{\mathrm{i}}^{*} \ll 1
$$

which results in the simplification,

$$
\mathrm{S}=\mathrm{LK} \mathrm{P}_{\mathrm{i}}^{*} \text {. }
$$

When Eq. (5.2-3) applies, (in the so-called Henrian regime) the coverage, $S_{i}$, is proportional to $P_{i}^{*}$ and independent of the sorption of other isotopes, which provides a considerable computational simplification. 
Isotherms for iodine sorption on low chromium content steel, typical of the lower temperature regime of the steam gencrator where the major portion of iodine chemisorption is expected, are shown in Fig. 5.2-1. The curves were drawn by Myers (1990) from data of Osborne et al. (1982). According to the form of the Langmuir isotherm, Eq. (5.2-1), the concentration of sorption sites, $\mathrm{L}$, is given by ordinate value at saturation exhibited at high partial pressure. Thus, for $400^{\circ} \mathrm{C}$, approximately the average metal surface temperature of the PS, the value of $\mathrm{L}$ is seen to be $2.7 \times 10^{-4} \mathrm{~mol} / \mathrm{m}^{2}\left(3.6 \mu \mathrm{g} / \mathrm{cm}^{2}\right.$ when filled with iodine atoms). As may be expected, the concentration of sorption sites is seen to decline with temperature. However the decline is modest, with the value of $\mathrm{L}$ at $800^{\circ} \mathrm{C}$ equaling $\sim 4 \times 10^{-5} \mathrm{~mol} / \mathrm{m}^{2}$ (i.e., $0.5 \mu \mathrm{g} / \mathrm{cm}^{2}$ of sorbed iodine).

The form of Eq. (5.2-1) dictates that the value of $\mathrm{K}$ be given by the reciprocal of the abscissa at the midpoint of the knee in the curve between the Henrian and saturation regimes. As shown in the figure, $\mathrm{K}$ for steel at $400^{\circ} \mathrm{C}$ takes a value of $\sim 10^{4} \mathrm{~Pa}^{-1}$. The constant, $\mathrm{K}$, as indicated by the derivation of the Langmuir isotherm, is the value of the equilibrium constant for the reaction of gaseous iodine with available sorption sites; that is, the equilibrium constant for the reaction,

$$
I(g)+l=I \text { (ads), }
$$

defined as

$$
\mathrm{K} \equiv \frac{\mathrm{S}}{\mathrm{LP}}
$$

where

$S=$ surface concentration of $I($ ads $)$,

$\mathbf{\imath}=$ available sorption sites,

$\mathrm{L}=$ concentration of $\mathrm{l}, \mathrm{mol} / \mathrm{m}^{2}$,

$\mathrm{P}_{\mathrm{I}}=$ iodine pressure, $\mathrm{Pa}$.

As expected and as seen in Fig 5.2-1, $\mathrm{K}$ diminishes rapidly with temperature, taking a value of $\sim 10 \mathrm{~Pa}$ at $800^{\circ} \mathrm{C}$ compared with $\sim 10^{4}$ at $400^{\circ} \mathrm{C}$, signifying a rapidly diminishing tendency for sorption at higher temperatures.

Summarizing for iodine chemisorption on steel in a strongly reducing environment, the Henrian simplification of the Langmuir isotherm, Eq. (5.2-3), is assumed valid (to be verified below) with constants,

$$
\begin{aligned}
& \mathrm{L}_{\mathrm{s}}=4 \times 10^{-5} \mathrm{~mol} / \mathrm{m}^{2}, \\
& \mathrm{~K}_{\mathrm{s}}=10^{4} \mathrm{~Pa}^{-1},
\end{aligned}
$$

estimated for the average PS temperature. The steel sorption surface area of the steam generator is given in the PSID (1986) as,

$$
A_{s}=5500 \mathrm{~m}^{2} .
$$


ORNL-DWG 90Z-3784 ETD

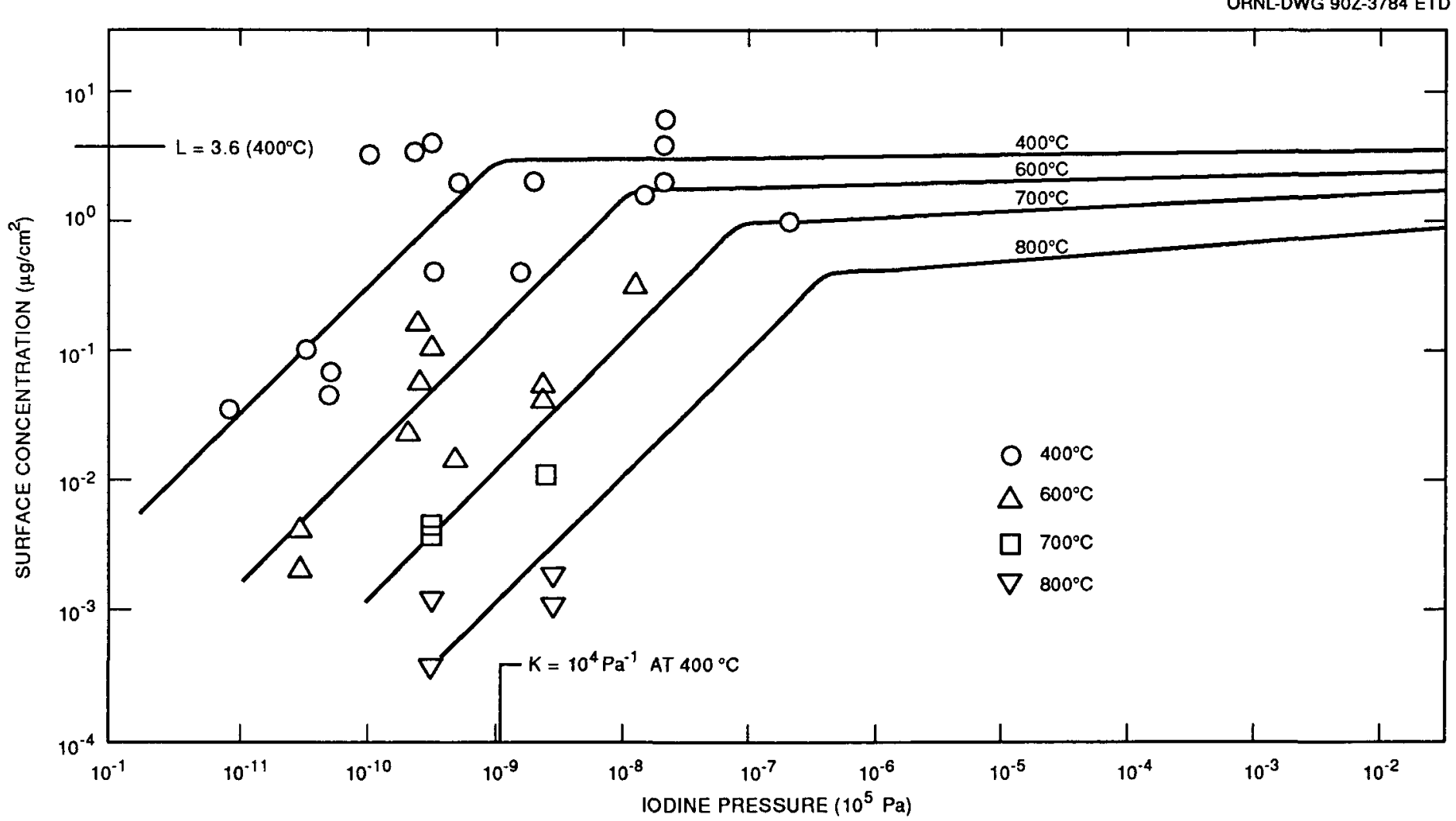

Fig. 5.2-1. Iodine sorption isotherms at low alloy steel (T-22). Drawn by Myers (1990) from data of Osbornc, et al. (1982). 


\subsubsection{Iodine Sorption on Graphite}

There are significantly fewer data for sorption on graphite than steel since it is generally not held to be a significant factor for iodine transport. Nevertheless some consideration is required in view of the enormous sorption surface presented by the interconnected porosity. An estimated graphite mass of $6.2 \times 10^{5} \mathrm{~kg}$ and a typical open, internal surface of H451 graphite of $1 \mathrm{~m}^{2} / \mathrm{g}$ yields a graphite sorption area of $6.2 \times 10^{8}, \sim 10^{5}$ greater than the steel surface.

It should be recognized that actual internal surface areas of H451 graphite can vary significantly from the assumed typical value of $1 \mathrm{~m}^{2} / \mathrm{g}$. Pore surface areas near the billet surface are generally lower due to a higher concentration of impregnant at these locations. In addition, pore areas generally increase with service life as graphite oxidation preferentially removes impregnant and opens internal pores.

The available graphite data at $400^{\circ} \mathrm{C}$ are summarized in Fig 5.2-2, adapted from Lorenz (1982). As for steel, the $400^{\circ} \mathrm{C}$ temperature is taken to be an average for the core graphite. (The actual space average is about $100^{\circ} \mathrm{C}$ higher, but in view of the data uncertainty, the available summary for $400^{\circ} \mathrm{C}$ suffices for a scoping estimate.)

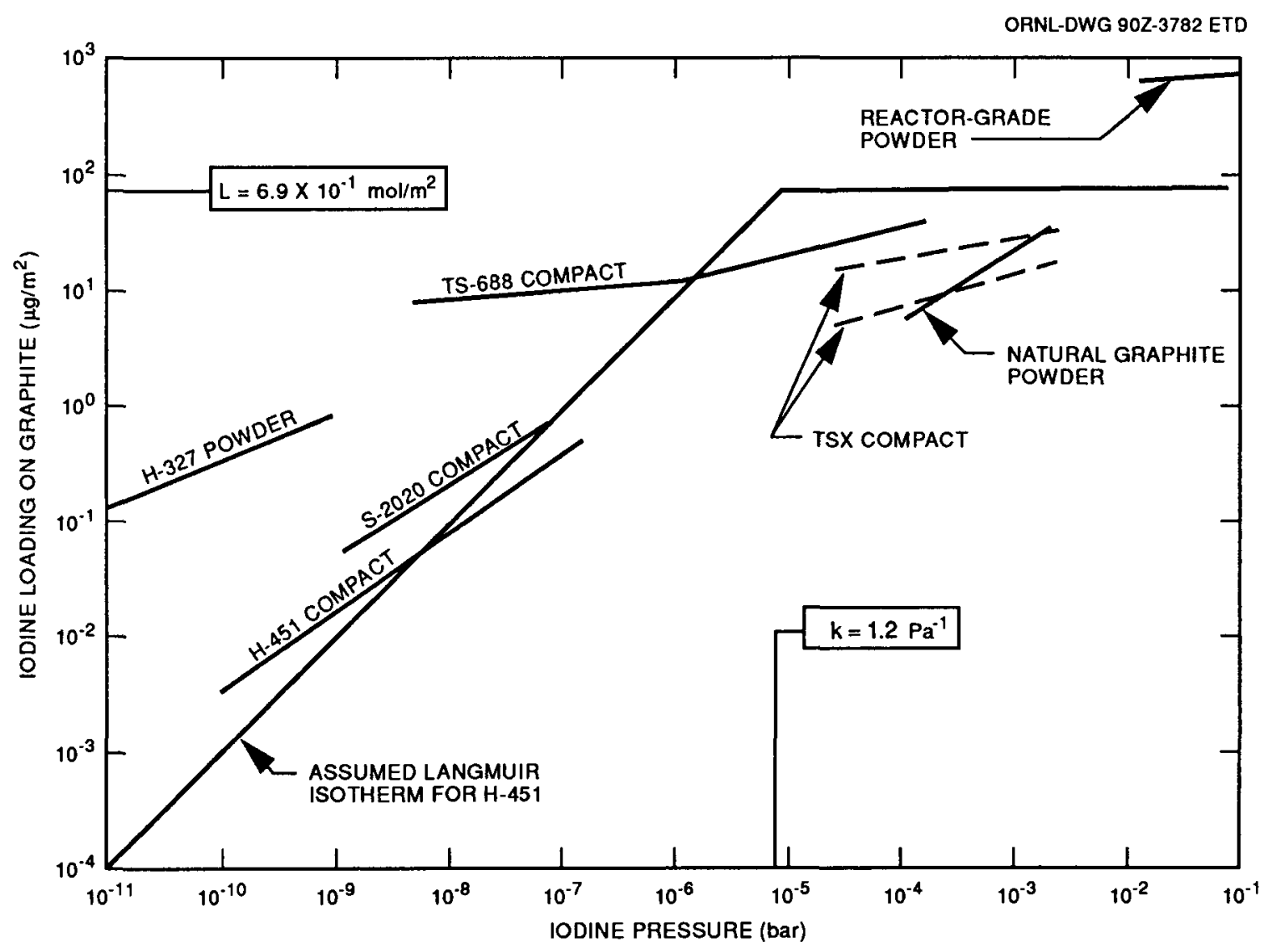

Fig. 5.2-2. Assumed Langmuir isotherm for iodine on $\mathrm{H} 451$ graphite at $400^{\circ} \mathrm{C}$, adapted from Lorenz, et al. (1982). 
Superimposed on the data review in Fig. 5.2-2 is an estimated Langmuir isotherm for $400^{\circ} \mathrm{C}$, reasonably drawn, with emphasis on the $\mathrm{H} 451$ compact data. As noted on the figure, the Langmuir sorption parameters, the available sorption site concentration, $\mathrm{L}_{\mathrm{G}}$, and sorption equilibrium constant are estimated to be,

$$
\begin{aligned}
& \mathrm{L}_{\mathrm{G}}=6.9 \times 10^{-7} \mathrm{~mol} / \mathrm{m}^{2} \\
& \mathrm{~K}_{\mathrm{G}}=1.2 \mathrm{~Pa}^{-1},
\end{aligned}
$$

with sorption surface,

$$
A_{G}=6.2 \times 10^{8} \mathrm{~m}^{2}
$$

\subsubsection{Sorption of Iodine on Dust}

No data exist for the sorption of iodine on dust, and indeed, no confident description exists for dust material compositions in prismatic HTGRs. Peach Bottom HTGR analyses (Sect. 3.1) indicate a wide range of materials contributing to the overall dust composition, much of which is not clearly identified. However, the sorptivity of iodine on "dust" in all likelihood is significantly lower than for steel, since metallic material, which exhibit the highest sorptive tendency for iodine, comprised only a small portion of the Peach Bottom dust. If it is assumed that MHTGR dust will consist primarily of "rust" flakes shed from the steam generator, we may roughly approximate a sorptive tendency by referring to the initial data of Osborne et al. (1982), taken under conditions that permitted oxidation of his steel specimen. In that environment, Osborne, et al. observed about a factor of 100 reduction in iodine sorptivity ${ }^{*}$ relative to the unoxidized surface as would occur by a factor of 10 reduction of both $L$ and K; i.e.,

$$
\begin{aligned}
& \mathrm{L}_{\mathrm{p}}=4 \times 10^{-6} \mathrm{~mol} / \mathrm{m}^{2} \\
& \mathrm{~K}_{\mathrm{p}}=10^{3} \mathrm{~Pa}^{-1} .
\end{aligned}
$$

However this is conjectural in view of the few available data for oxidized surfaces. If on the other hand, the carbonaceous constituent in dust is significant, an even lower sorptivity would result, based on the sorption parameters for graphite given in the previous section. Therefore, the dust sorptivity cited above could in fact, be an upper level estimate.

The quantity of dust and the associated surface area are also highly uncertain. In section 3.1, Peach Bottom coolant sampler data are cited which showed that circulating dust concentration ranged from $0.23 \mathrm{mg} / \mathrm{m}^{3}$ to $<3 \times 10^{-3} \mathrm{mg} / \mathrm{m}^{3}$ (Table $3.1-3$ ), for an average of 0.10 $\mathrm{mg} / \mathrm{m}^{3}$ over the life of core 2 . The MHTGR PS volume of $393 \mathrm{~m}^{3}$ would at this concentration contain $39 \mathrm{mg}$ of circulating dust. A highly speculative model was used to connect the measured circulating concentration with dust production rates and plateout concentrations. These estimates

*Defined as the coverage $\left(\mathrm{mol} / \mathrm{m}^{2}\right)$ per unit burden $(\mathrm{Pa})$. It is equal to the product of the Langmuir constants $L$ and $K$ in the Henrian sorption regime. 
showed (Table 3.1-3) that an average of $5.6 \mathrm{~kg}$ of dust was plated during Peach Bottom core 2 operation over an estimated metal area of $1925 \mathrm{~m}^{2}$ for an average deposit concentration of 2.9 $\mathrm{g} / \mathrm{m}^{2}$. This deposit over the $5500 \mathrm{~m}^{2}$ of MHGTR surface would yield a dust deposit of $16.0 \mathrm{~kg}$.

The effective sorptive surface associated with these quantities is problematical. Limited size distribution data, summarized in Sect. 3.1 taken from data in Dyer et al. (1977) indicate a relatively large average size of perhaps $1 \mu \mathrm{m}$. Large particulate sizes are consistent with formation mechanisms such as "rust" spallation, graphite abrasion or dust associated with construction debris and fuel fracture.

In contrast, condensation nuclei, such as may result form the carbon deposition end of the carbon transport cycle, would be expected to be much smaller, perhaps on the order of $0.1 \mu \mathrm{m}$ or less. Also possible "sooty" dust resulting from oil ingress may also have resulted in extremely small particles, if they formed in the gas phase. However the principal "sooty" dust was observed as plated material in the core and appeared to have grown in place. As noted in Sect. 3.1, there evidently was about $0.16 \mathrm{~kg}$ of such "sooty" deposit in the Peach Bottom core. Even when extrapolated to the larger MHTGR, the projected amount of the additional sooty deposit would be small compared with the estimated $16.0 \mathrm{~kg}$ of plated dust.

Due to these uncertainties, two dust characterizations will be assumed which may bracket the real range; namely that circulating and plated dust consists of (1) $0.1 \mu \mathrm{m}$ diameter spherical particles, (2) $1.0 \mu \mathrm{m}$ diameter particles. The assumed circulating and plated quantities, surface areas and sorptivities are summarized in Table 5.2-1.

Table 5.2-1. Assumed MHTGR dust levels extrapolated from Peach Bottom surveillance data (Sect. 3.1)

\begin{tabular}{ll}
\hline Circulating dust & \\
\hline Concentration $\left(\mathrm{mg} / \mathrm{m}^{3}\right)$ & 0.10 \\
Mass $(\mathrm{mg})$ & 39 \\
Surface area & \\
High $\left(\mathrm{m}^{2}\right)$ & 0.78 \\
Low $\left(\mathrm{m}^{2}\right)$ & 0.041 \\
Plated dust & \\
\hline Concentration $\left(\mathrm{g} / \mathrm{m}^{2}\right)$ & 2.9 \\
Mass $(\mathrm{kg})$ & 16.0 \\
Surface area & \\
High (m²) & $3.2 \times 10^{5}$ \\
Low $\left(\mathrm{m}^{2}\right)$ & $1.7 \times 10^{4}$ \\
\hline
\end{tabular}

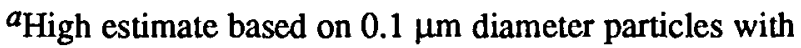
average density of 3.0.

Low estimate based on 1.0 diameter and particle density of 5.7 (rust). The surveillance data more closely match the low estimate. 


\subsection{IODINE DISTRIBUTION APPROXIMATIONS}

\subsubsection{Relative Amounts Sorbed on Steel, Graphite and Plated Dust}

The relative amounts of iodine plated in the three types of locations cited, namely as (1) chemisorbed on steel, (2) chemisorbed on graphite and (3) chemisorbed on plated dust, may be estimated from expressions in Sect. 5.2. If all three locations are dilutely covered, allowing use of the Henrian simplification to the sorption isotherm, then

$$
\begin{aligned}
& \begin{array}{c}
\text { fraction of } \\
\begin{array}{c}
\text { sorbed iodine } \\
\text { on steel }
\end{array}
\end{array}=\frac{L_{s} K_{s} A_{s}}{L_{s} K_{s} A_{s}+L_{G} K_{G} A_{G}+L_{p} K_{p} A_{p}} \\
& \begin{array}{c}
\text { fraction of } \\
\text { sorbed iodine } \\
\text { on graphite }
\end{array}=\frac{L_{G} K_{G} A_{G}}{L_{s} K_{s} A_{s}+L_{G} K_{G} A_{G}+L_{p} K_{p} A_{p}}
\end{aligned}
$$

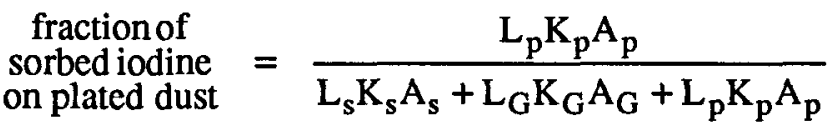

where the subscripts, s, G, and p refer to steel, graphite and dust particle, respectively. Implied in the above relationships is the assumption that all sorption locations are exposed to identical concentrations of gaseous iodine.

Applying the sorption parameters developed in Sect. 5.2 leads to the plated distributions listed in Table 5.3-1. As noted earlier, the low dust area estimate is more closely suggested by the Peach Bottom surveillance data. In such case, the major plated iodine form is clearly chemisorbed iodine on steel. If the Peach Bottom dust particles were typically far smaller than observed in samples, (i.e., $\sim 0.1 \mu \mathrm{m}$ versus $\sim 1.0 \mu \mathrm{m}$ ), the fraction of iodine associated with plated dust would increase significantly to $\sim 23 \%$.

Table 5.3-1. Plated iodine distribution in the primary system (speculative)

\begin{tabular}{lcc}
\hline \multicolumn{1}{c}{ Iodine form } & \multicolumn{2}{c}{$\begin{array}{c}\text { Percent of total } \\
\text { plated iodine }\end{array}$} \\
\cline { 3 - 4 } \cline { 3 - 3 } \multicolumn{1}{c}{ Plate iodine } & $\begin{array}{c}\text { High dust } \\
\text { area estimate }\end{array}$ & $\begin{array}{c}\text { Low dust } \\
\text { area estimate }\end{array}$ \\
\hline Chemisorbed on steel & 62.5 & 95 \\
Chemisorbed on graphite & 1.3 & 2 \\
Chemisorbed on plated dust & 36.3 & 2.9 \\
\hline
\end{tabular}

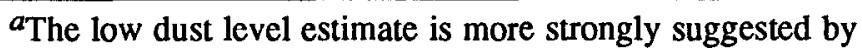
the Peach Bottom Core 2 surveillance data. 
As anticipated, the fraction sorbed on graphite is relatively small, due to its low sorptivity, regardless of the dust level, on the order of 1 to $2 \%$ of the total plated. However, the low sorptivity of graphite for iodine may be expected to lead to relatively higher fractional desorptions under depressurization conditions.

\subsubsection{Relative Amounts of Circulating Iodine-Gaseous Versus Sorbed on Dust}

If iodine sorption on dust may be characterized as being in the low-coverage (i.e., Henrian) regime, then the total amount of circulating iodine may be represented by

$$
\mathrm{n}_{\mathrm{I}}=(\mathrm{LKA})_{\mathrm{p}} \mathrm{P}_{\mathrm{I}}+\mathrm{P}_{\mathrm{I}} \frac{\mathrm{V}}{\mathrm{RT}}
$$

where

$$
\begin{aligned}
(\mathrm{LKA})_{\mathrm{p}} & =\text { sorption parameters for circulating dust, } \mathrm{mol} / \mathrm{Pa} \\
\mathrm{P}_{\mathrm{I}} & =\text { iodine partial pressure, } \mathrm{Pa} \\
\mathrm{V} & =\text { primary system volume, } \mathrm{m}^{2} \\
\mathrm{~T} & =\text { average primary system temperature, } \mathrm{K} .
\end{aligned}
$$

The first term on the RHS represents the quantity of iodine circulating as sorbed material on dust. The second term is the amount of gaseous iodine. Rearrangement of Eq. (5.4-2) leads to the following distribution estimates:

$$
\begin{aligned}
& \begin{array}{l}
\text { fraction of iodine } \\
\text { circulating as gas }
\end{array}=\frac{V / R T}{(V / R T)+(L K A)_{p}}, \\
& \begin{array}{l}
\text { fraction of iodine } \\
\text { circulating on dust }
\end{array}=\frac{(L K A)_{p}}{(V / R T)+(L K A)_{p}} .
\end{aligned}
$$

Application of the sorption parameter values developed in the previous section, for both high and low dust area estimates leads to the results shown in Table 5.3-2. Again, the low dust area case more closely matches Peach Bottom dust sample data, in which case only $\sim 3 \%$ of the

Table 5.3-2. Distribution of circulating iodine forms

\begin{tabular}{lcc}
\hline \multirow{2}{*}{$\begin{array}{c}\text { Circulating iodine } \\
\text { form }\end{array}$} & \multicolumn{2}{c}{$\begin{array}{c}\text { Percent of total } \\
\text { circulating iodine }\end{array}$} \\
\cline { 2 - 3 } & $\begin{array}{c}\text { High dust area } \\
\text { estimate }\end{array}$ & $\begin{array}{c}\text { Low dust area } \\
\text { estimate }\end{array}$ \\
\hline Gaseous iodine & 64 & 97 \\
Chemisorbed on dust & 36 & 2.8 \\
\hline
\end{tabular}

${ }^{a}$ More consistent with available data. 
circulating iodine would be associated with dust. For the high dust area assumption, the fraction rises to $36 \%$.

\subsubsection{Circulating Versus Sorbed Quantity of Iodine}

The fraction of the total iodine in the PS that is chemisorbed may be estimated using the assumptions that (1) sorption of steel dominates over graphite and plated dust, and (2) the circulating form is principally gaseous. Then using the ideal gas law with Eq. (5.3-3) yields for the total mols of isotope-i, in the PS,

$$
\mathrm{n}_{\mathrm{i}}=\mathrm{C}_{\mathrm{i}} \mathrm{V}+\mathrm{S}_{\mathrm{i}} \mathrm{A}
$$

Hence,

$$
\mathrm{n}_{\mathrm{i}}=\mathrm{C}_{\mathrm{i}} \mathrm{V}+\mathrm{LKRT} \cdot \mathrm{AC}_{\mathrm{i}}
$$

Rearranging these equations yields

$$
\begin{aligned}
& \text { fraction }-i \text { sorbed }=\frac{(\text { LKRTA })_{s}}{V+(\text { LKRTA })_{s}} \\
& \text { fraction }-i \text { gaseous }=\frac{V}{V+(\text { LKRTA })_{s}}
\end{aligned}
$$

Using parameters typical for an MHTGR PS (see Appendix D) yields,

$$
\begin{aligned}
& \text { fraction sorbed } \approx 1.0, \\
& \text { fraction circulating }=2.6 \times 10^{-6} .
\end{aligned}
$$

Thus as expected, the overwhelming portion of iodine in the PS exists as chemisorbed iodine. High circulating dust levels, much higher than the $0.077 \mathrm{mg} / \mathrm{m}^{3}$ concentration estimated in Sect. 5.3, can elevate the estimated circulating fraction of iodine from the above. However, unless dust levels are many orders of magnitude higher, sorbed iodine would still dominate.

\subsection{AMOUNT OF IODINE IN THE PS UNDER NORMAL OPERATING CONDITIONS}

In this subsection a simple model is used to estimate the quantities of the principal iodine isotopes in the primary system, using the isotopic release rates from the fuel cited in Sect. 5.1. Estimates developed in Sect. 5.3 are used as a guide; namely that (1) the amount sorbed on steel significantly exceeds the amount on graphite, and (2) sorbed iodine overwhelmingly dominates over circulating iodine. Although far less certain, the following development assumes the principle circulating form to be gascous iodine rather than circulating dust, also as suggested in Sect. 5.3. If this proves false, the effect would be to increase the estimated circulating level of iodine, but the total inventory in the PS should not be much affected. The model assumptions are: 
(1) Constant release rate to the primary system of isotope-i of $R_{i} \mathrm{~mol} / \mathrm{s}$,

(2) Constant purification flow rate, $\mathrm{Q} \mathrm{m} 3 / \mathrm{s}$ that is $100 \%$ effective in removing gasborne iodine;

(3) One region of sorption surface $\mathrm{A}$, and volume, $\mathrm{V}$, at average conditions of temperature and pressure;

(4) The sorbtivity of the surface is that of steel at some averaged PS temperature and is assumed to be in the Henrian sorption regime.

These assumptions lead to the following mass balance for circulating and sorbed species of isotope-i,

$$
\begin{aligned}
& V \frac{d C_{i}}{d t}=R_{i}-\lambda_{i} V C_{i}-Q C_{i}-h A\left(C_{i}-C_{i}^{*}\right) \\
& A \frac{d S_{i}}{d t}=h A\left(C_{i}-C_{i}^{*}\right)-\lambda_{i} A S_{i} .
\end{aligned}
$$

Together with the sorption isotherm,

$$
\mathrm{S}_{\mathrm{i}}=\mathrm{LKRT} \cdot \mathrm{C}_{\mathrm{i}}^{*} \text {, }
$$

these form a set of three equations with three unknowns which may readily be solved for $C_{i}, S_{i}$, and $C_{i}{ }^{*}$. The terminology used is as follows:

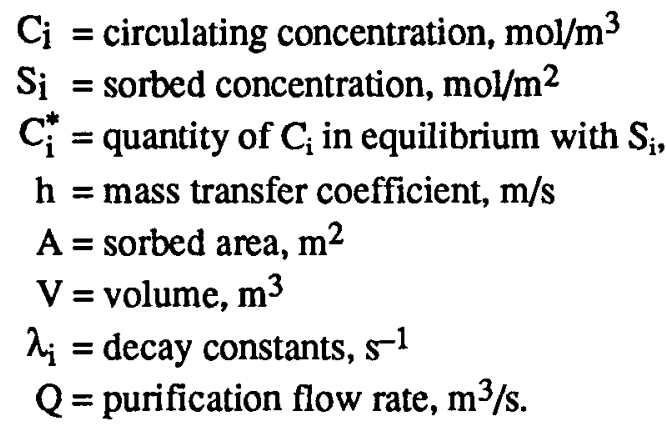

As indicated in Sect. 5.3, the simplified, Henrian form of the sorption isotherm decouples the mass balance for isotope-i from the other iodine isotopes. When the full form of the Langmuir isotherm Eq. (5.3-3) is required, i.e., when the degree of iodine sorption for all isotopes approaches the saturation value, $L$, the mass balances must be solved simultaneously for all isotopes. The validity of the simplified isotherm will be checked using the numerical results.

Although Eqs. (5.4-1) to (5.4-3) can be solved for the three unknowns, an accurate simplification is possible by assuming equilibrium between the bulk gas concentration, $\mathrm{C}_{\mathrm{i}}$, and the sorbed concentration, $S_{\mathrm{i}}$; i.e., by assuming,

$$
S_{i}=L K R T \cdot C_{i}
$$

In such case it is readily shown that Eqs. (5.4-1), (5.4-2) and (5.4-3) have the following solution:

$$
n_{i}(t)=\frac{R_{i}}{\lambda_{i}}\left(1-\exp \left(-\alpha_{i} t\right)\right)
$$




$$
\begin{aligned}
& \text { fraction sorbed }=\frac{\text { LKRTA }}{V+\text { LKRTA }} \\
& \text { fraction circulating }=\frac{V}{V+\text { LKRTA }}
\end{aligned}
$$

where,

$$
\begin{aligned}
& \mathrm{n}_{\mathrm{i}}=\text { total amount of } \mathrm{i} \text { isotope-in the PS, mol, } \\
& \alpha_{i}=\left[\lambda_{i}(V+\text { LKRTA })+Q\right] /(V+\text { LKRTA }), s^{-1} \\
& t=\text { continuous operating time; at EOL, } t=1.26 \times 10^{9} \mathrm{~s}(40 \mathrm{y}) .
\end{aligned}
$$

\begin{tabular}{|c|c|c|c|c|c|c|}
\hline \multirow{2}{*}{$\begin{array}{l}\text { Iodine } \\
\text { isotope }\end{array}$} & \multirow{2}{*}{$\begin{array}{c}\text { Half } \\
\text { life }\end{array}$} & \multirow{2}{*}{$\begin{array}{c}\text { Release rate } \\
(\mathrm{pmol} / \mathrm{s})^{a}\end{array}$} & \multicolumn{2}{|c|}{ Mass } & \multicolumn{2}{|c|}{ Activity } \\
\hline & & & $\begin{array}{c}\text { Circulating } \\
\text { (nmol) }\end{array}$ & $\begin{array}{l}\text { Sorbed } \\
\text { (nmol) }\end{array}$ & $\begin{array}{l}\text { Circulating } \\
(\mu \mathrm{Ci})\end{array}$ & $\begin{array}{l}\text { Sorbed } \\
\text { (Ci) }\end{array}$ \\
\hline 127 & $\infty$ & 0.27 & 0.78 & 0.31 & 0 & 0 \\
\hline 129 & $1.6 \times 10^{7} \mathrm{y}$ & 1.54 & 4.46 & 1.75 & $1.0 \times 10^{-4}$ & $3.9 \times 10^{-5}$ \\
\hline 131 & $8.04 \mathrm{~d}$ & 1.75 & $4.49 \times 10^{-3}$ & $1.75 \times 10^{-3}$ & 72.6 & 28.4 \\
\hline 132 & $2.29 \mathrm{~h}$ & 0.17 & $5.02 \times 10^{-6}$ & $1.96 \times 10^{-6}$ & 6.9 & 2.69 \\
\hline 133 & $2.08 \mathrm{~h}$ & 0.26 & $7.06 \times 10^{-5}$ & $2.77 \times 10^{-5}$ & 10.7 & 4.16 \\
\hline 134 & $52.6 \mathrm{~min}$ & 0.19 & $2.25 \times 10^{-6}$ & $8.78 \times 10^{-7}$ & 8.1 & 3.14 \\
\hline 135 & $6.58 \mathrm{~h}$ & 0.44 & $3.86 \times 10^{-5}$ & $1.53 \times 10^{-5}$ & 18.3 & 7.16 \\
\hline TOTALS & & 4.62 & 5.25 & 2.05 & 117 & 45.5 \\
\hline
\end{tabular}

Results are summarized in Table 5.4-1; parameter values used for the estimate are listed in Appendix D.

Table 5.4-1. Estimated sorbed and circulating amounts of the significant iodine isotopes in the primary system at EOL of the MHTGR

$a_{\mathrm{pmol}}=10^{-12} \mathrm{~mol} ; \mathrm{nmol}=10^{-9} \mathrm{~mol}, \mathrm{mmol}=10^{-3} \mathrm{~mol}, \mu \mathrm{Ci}=10^{-6} \mathrm{Ci}$.

It is necessary to check the validity of the Henrian sorption regime assumption [i.e., Eq. (5.2-3) in lieu of Eq. (5.2-1)]. We note that a total $2.05 \mathrm{mmol}$ of iodine are predicted to be sorbed over a steel surface area of $5500 \mathrm{~m}^{2}$, which represents $0.08 \%$ of the estimated saturation value of $4.5 \times 10^{-4} \mathrm{~mol} / \mathrm{m}^{2}$. The low coverage relative to the saturation value indicates that the Henrian assumption is valid in this case. Further confirmation is achieved by comparing the gas phase concentration, $5.25 \mathrm{mmol}$ in $393 \mathrm{~m}^{3}$ equivalent to a partial pressure of $8.28 \times 10^{-11} \mathrm{~Pa}$ with the value of $1 / \mathrm{K}$, which defines the transition pressure between the Henrian and saturation regimes. As noted earlier, the sorption equilibrium constant, $\mathrm{K}$ takes a value of about $10^{4} \mathrm{~Pa}^{-1}$ for steel at the average $P S$ temperature. Hence, $P_{I}$ « $1 / K$ further confirms the Henrian assumption.

Comparison of the removal rate constants, a, defined by Eq. (5.4-4) with radioactive decay constants for each isotope (Table 5.4-2) indicates that the principal removal mechanism is radioactive decay for isotope masses 131 through 135 . The purification flow has virtually no 
Table 5.4-2. Iodine removal rate constants from the primary systems

\begin{tabular}{clc}
\hline $\begin{array}{c}\text { Iodine } \\
\text { isotope }\end{array}$ & \multicolumn{1}{c}{$\begin{array}{c}\text { Decay } \\
\text { constant }\end{array}$} & $\begin{array}{c}\text { Removal rate } \\
\text { constant }\end{array}$ \\
\cline { 2 - 2 } & \multicolumn{1}{c}{$(1 / \mathrm{s})$} & $(1 / \mathrm{s})$ \\
\hline 127 & 0 & $1.69 \times 10^{-10}$ \\
129 & $1.37 \times 10^{-15}$ & $1.69 \times 10^{-10}$ \\
131 & $9.98 \times 10^{-7}$ & $9.98 \times 10^{-7}$ \\
132 & $8.41 \times 10^{-5}$ & $8.41 \times 10^{-5}$ \\
133 & $9.26 \times 10^{-6}$ & $9.26 \times 10^{-6}$ \\
134 & $2.20 \times 10^{-4}$ & $2.20 \times 10^{-4}$ \\
135 & $2.93 \times 10^{-5}$ & $2.93 \times 10^{-5}$ \\
\hline aParameter $\alpha$ of Eq.
\end{tabular}

effect on PS levels of these isotopes. These isotopes equilibrate fairly rapidly (approximately a few months for 1131). In contrast, the removal rate for the stable and near stable mass numbers 127 and 129 by means of the purification flow, is so low that these are not yet equilibrated in 40 operating years $\left(1.26 \times 10^{9} \mathrm{~s}\right)$. These features appear because most of the iodine chemisorbs; only the small fraction, $2.56 \times 10^{-6}$ [from Eq. (5.5-4) and Table 5.4-1] is circulating and thus is subject to removal by the purification flow.

Also noteworthy in Table 5.4-1 is the estimated activity of sorbed iodines on PS steel of $45.5 \mathrm{Ci}$ compared with the estimated total circulating activity of $\sim 117 \mu \mathrm{Ci}$. It is further noted that the major share of the iodine activity is contributed by $I 131(62.4 \%)$.

\subsection{QUANTITY OF IODINE IN PRIMARY SYSTEM LOCATIONS}

The circulating and plated iodine levels given in Table 5.4-1 can now be distributed among the three principal sorbed forms (i.e., sorbed on steel, sorbed on graphite, and sorbed on plated dust) and two principal circulating forms i.e., gaseous iodine and sorbed on circulating dust) using the approximation developed in Sect. 5.4. These distributions are listed in Table 5.5-1 for the "low dust" and "high dust" level cases, summed for the seven principal isotopes. As noted earlier, Peach Bottom surveillance data for core 2 more closely support the "low dust" distribution case.

According to Table 5.5-1, 45.5 $\mathrm{Ci}$ of iodine are plated and $1.17 \times 10^{-4} \mathrm{Ci}$ circulating in the PS. The dust level does not effect the total quantity of iodine in the system, only its distribution. (The only mechanism by which dust may alter total iodine level in the PS is via an increased purification rate as a result of higher circulating concentrations. However, the effect is insignificant at dust levels assumed here.)

The principal mass is contributed by the stable isotopes (127 and 129). The principal activity is contributed by 1131 (see Table 5.3-1). 
Table 5.5-1. Estimated iodine levels in the MHTGR primary system at EOL

\begin{tabular}{|c|c|c|c|c|}
\hline & \multicolumn{2}{|c|}{ High dust area } & \multicolumn{2}{|c|}{ Low dust area ${ }^{a}$} \\
\hline & $\begin{array}{c}\operatorname{Mass}_{(\mathrm{mol})}^{b} \\
\text { (1) }\end{array}$ & $\begin{array}{l}\text { Activity } b \\
\text { (Ci) }\end{array}$ & $\underset{(\mathrm{mol})}{\operatorname{Mass}^{b}}$ & $\begin{array}{l}\text { Activity } \\
\text { (Ci) }\end{array}$ \\
\hline \multicolumn{5}{|l|}{ Circulating } \\
\hline As gas & $3.36 \times 10^{-12}$ & $7.49 \times 10^{-5}$ & $5.09 \times 10^{-12}$ & $1.13 \times 10^{-4}$ \\
\hline Sorbed on dust & $1.89 \times 10^{-12}$ & $4.21 \times 10^{-5}$ & $1.43 \times 10^{-13}$ & $3.28 \times 10^{-6}$ \\
\hline Total & $5.25 \times 10^{-12}$ & $1.17 \times 10^{-4}$ & $5.25 \times 10^{-12}$ & $1.17 \times 10^{-4}$ \\
\hline \multicolumn{5}{|l|}{ Plated } \\
\hline$\overline{\text { Sorbed }}$ on steel & $1.28 \times 10^{-3}$ & 28.4 & $1.95 \times 10^{-3}$ & 43.2 \\
\hline Sorbed on graphite & $2.7 \times 10^{-5}$ & 0.59 & $4.1 \times 10^{-5}$ & 0.91 \\
\hline Sorbed on plated dust & $7.44 \times 10^{-4}$ & 16.5 & $6.0 \times 10^{-5}$ & 1.3 \\
\hline Total & $2.05 \times 10^{-3}$ & $\overline{45.5}$ & $2.05 \times 10^{-3}$ & $\overline{45.5}$ \\
\hline
\end{tabular}

${ }^{a}$ Low dust level estimate more closely matches Peach Bottom Core 2 surveillance data.

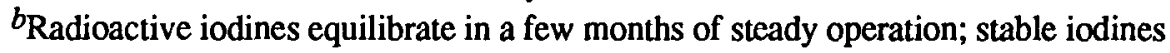
(including I129) increase steadily for $>40 \mathrm{y}$.

It is interesting to compare these predictions with observed levels taken during Peach Bottom core 2 surveillance (see Table 5.5-2). The total circulating iodine estimates for the MHTGR given in Table 5.5-1 yield circulating 1131 concentrations of $6.7 \times 10^{-2}$ and $5.2 \times 10^{-3}$ $\left(\mu \mathrm{Ci} / \mathrm{m}^{3}\right)$ for the "high" and "low" dust level cases, respectively, based on a primary system volume of $393 \mathrm{~m}^{3}$ and 1131 activity fraction listed in Table 5.5-1. In comparison, Peach Bottom core 2 surveillance data suggest a circulating iodine concentration of $1.6 \times 10^{-3}\left(\mu \mathrm{Ci} / \mathrm{m}^{3}\right)$, based on two measurements averaging $0.016\left(\mu \mathrm{Ci} / \mathrm{m}^{3}\right)$ dust, and an average dust concentration of $0.099 \mathrm{mg} / \mathrm{m}^{3}$. The close relationship of the "low dust" estimate to the surveillance data confirms

Table 5.5-2. Comparison of predicted MHTGR circulating I131 concentration on dust with Peach Bottom surveillance data

\begin{tabular}{|c|c|}
\hline & $\frac{\begin{array}{c}\text { Circulating } \\
\text { iodine on dust }\end{array}}{\frac{\mu \mathrm{Ci} \mathrm{I131}}{\mathrm{m}^{3}}}$ \\
\hline $\begin{array}{l}\text { High dust estimate, }{ }^{a} \text { MHTGR } \\
\text { Low dust estimate, }{ }^{a} \text { MHTGR } \\
\text { Peach Bottom surveillance data }{ }^{b}\end{array}$ & $\begin{array}{l}6.7 \times 10^{-2} \\
5.2 \times 10^{-3} \\
1.6 \times 10^{-3}\end{array}$ \\
\hline $\begin{array}{l}a_{\text {Using estimates in Tables } 5.4-1} \\
\text { system volume is } 393 \mathrm{~m}^{3} \text {. } \\
b_{\text {Average of two } 1131 \text { dust measur }} \\
\text { dust concentration measurement, [D } \\
\text { See Sect. } 3.1 \text { ]. }\end{array}$ & $\begin{array}{l}.5 .1 . \text { Primary } \\
\text { ts and average } \\
\text { al., (1977). }\end{array}$ \\
\hline
\end{tabular}


lower dust sorptivity for iodine based on an observed relatively large size $(\sim 1 \mu \mathrm{m})$ and low sorptivity typical of an iron oxide.

\subsection{RELEASE OF IODINE DUE TO DEPRESSURIZATION}

\subsubsection{Chemical Desorption from Steel Surfaces}

A large advantage in the use of the Langmuir sorption expression when the Henrian regime applies, is that it allows simple approximation of quantities desorbed due to depressurization. Referring to the derivation in Appendix D, the following expression approximates the fraction of iodine originally in the primary system, both sorbed and gaseous, that is removed by depressurization,

$$
F_{I}=1-\exp \left(\frac{-4.16 V}{\text { KLRTA }+V}\right)
$$

The above refers to a single region of volume, $\mathrm{V}$, and a single sorption surface, $\mathrm{A}$, characterized by an average temperature, $T$. The product $K L$ defines the Langmuir sorptivity of the surface for the representative temperature. The multiplier, 4.16 , is the natural $\log$ of the initial to final pressure, and takes this value for a nominal MHTGR PS depressurizing to 1 atmosphere.

Applying the sorption constants and areas given in Sect. 5.3 for steel, graphite, and plated dust leads to the results in Table 5.6-1. As shown, the degree of chemical desorption is predicted to be quite small. As noted, a total of about $1.4 \times 10^{-3} \mathrm{Ci}$ of iodine are expected to be desorbed corresponding to $0.0031 \%$ of the original sorbed amount, approximately equally distributed from the three principal sorption surfaces.

Table 5.6-1. Quantities of iodine chemically desorbed due to depressurization

\begin{tabular}{|c|c|c|c|c|}
\hline & $\begin{array}{l}\text { Fraction of } \\
\text { iodine } \\
\text { desorbed }^{a}\end{array}$ & $\begin{array}{c}\text { Initial } \\
\text { amount }^{b} \\
\text { (Ci) }\end{array}$ & $\begin{array}{l}\text { Amount } \\
\text { desorbed } \\
\text { (Ci) }\end{array}$ & $\begin{array}{c}\text { Percent of } \\
\text { total desorbed } \\
(\%)\end{array}$ \\
\hline From steel & $1.1 \times 10^{-5}$ & 43.2 & $4.8 \times 10^{-4}$ & $1.1 \times 10^{-3}$ \\
\hline From graphite & $5.1 \times 10^{-4}$ & 0.91 & $4.6 \times 10^{-4}$ & $1.0 \times 10^{-3}$ \\
\hline \multirow[t]{2}{*}{ From dust } & $6.7 \times 10^{-4}$ & 1.3 & $8.7 \times 10^{-4}$ & $1.9 \times 10^{-3}$ \\
\hline & & 45.5 & $1.8 \times 10^{-3}$ & $4.0 \times 10^{-3}$ \\
\hline
\end{tabular}

${ }^{a}$ Eq. 5.6.1.

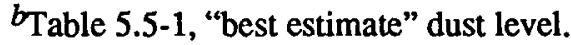

The predicted activity desorbed, $1.4 \times 10^{-3} \mathrm{Ci}$, is seen to be significantly greater than the estimated circulating level of $1.2 \times 10^{-4} \mathrm{Ci}$, which of course, also accompanies the blowdown flow. 


\subsubsection{Estimated Iodine Liftoff with Dust}

A portion of the estimated $0.68 \mathrm{Ci}$ of iodine associated with plated dust $(\sim 1.5 \%$ of the total amount of "plated" iodine) will be removed with the dust lifted off by flow forces. A speculative estimate of the degree of dust liftoff may be made using the method suggested in Sect. 4.6,

$$
F_{L O}=1-\exp \left(\int_{0}^{t} \beta(S R(t)) d t\right)
$$

where,

$$
\begin{aligned}
\mathrm{F}_{\mathrm{LO}}(\mathrm{t}) & =\text { cumulative fractional dust liftoff to time, } t, \\
\beta & =\text { liftoff rate parameter, } \mathrm{s}^{-1} \\
\mathrm{t} & =\text { time from start of depressurization, } s, \\
\mathrm{SR} & =\text { shear ratio. }
\end{aligned}
$$

The dependence of $\beta$ on the shear ratio is presumed to take the following form,

$$
\beta(S R)=\beta_{0} \exp (\operatorname{SR}(t)-1),
$$

where $\beta_{\mathrm{o}}$ is the equilibrium value of the liftoff rate parameter for predepressurization conditions. No evaluation of $\beta_{\mathrm{o}}$ under MHTGR primary loop conditions has been made; however, Wen and Kasper (1989) report that for a series of five, long term aerosol liftoff tests an initially high value of $\beta$ trended downward to an average value of $1.3 \times 10^{-5} \mathrm{~s}^{-1}\left(0.048 \mathrm{~h}^{-1}\right)$ after 10 to $100 \mathrm{~h}$. Therefore, for this speculative illustration, the value of $\beta_{o}$, typical for nominal MHTGR primary loop conditions will be assumed to be $1.3 \times 10^{-5} \mathrm{~s}^{-1}$.

The flow rate and shear ratio history in the MHTGR steam generator following a depressurization has been estimated for two cases (Kroeger, 1990) using the RATSAM code: (1) the "base case", in which the pressure relief valve located in the steam generator vessel downstream from the main circulator fails open, and (2) the "large break blowdown" which presumes a major failure of the cold duct pressure boundary. The mass flow rate and shear ratio histories of these two case are shown in Fig. 5.6-1.

The curves labeled "economizer" refer to tube bundle zone predicted by RATSAM to contain the highest shear ratios for these two blowdown cases. As shown for the base case, shear ratios of about unity are predicted in the economizer for $\sim 50 \mathrm{~s}$ followed by a sharp drop. Thus, Force Ratio or Shear Ratio methods would predict zero liftoff from the steam generator tubing for base case depressurization.

The liftoff parameter method described above would predict a small degree of liftoff as would normally occur for unity shear ratio for $50 \mathrm{~s}$ duration; i.e., according to Eqs. (5.6-3) and $(5.6-4)$

$$
\int_{0}^{t} \beta(t) d t \approx\left(1.3 \times 10^{-5}\right)(50)=6.5 \times 10^{-4} .
$$

Hence,

$$
F_{\text {LO }}=6.5 \times 10^{-4}
$$




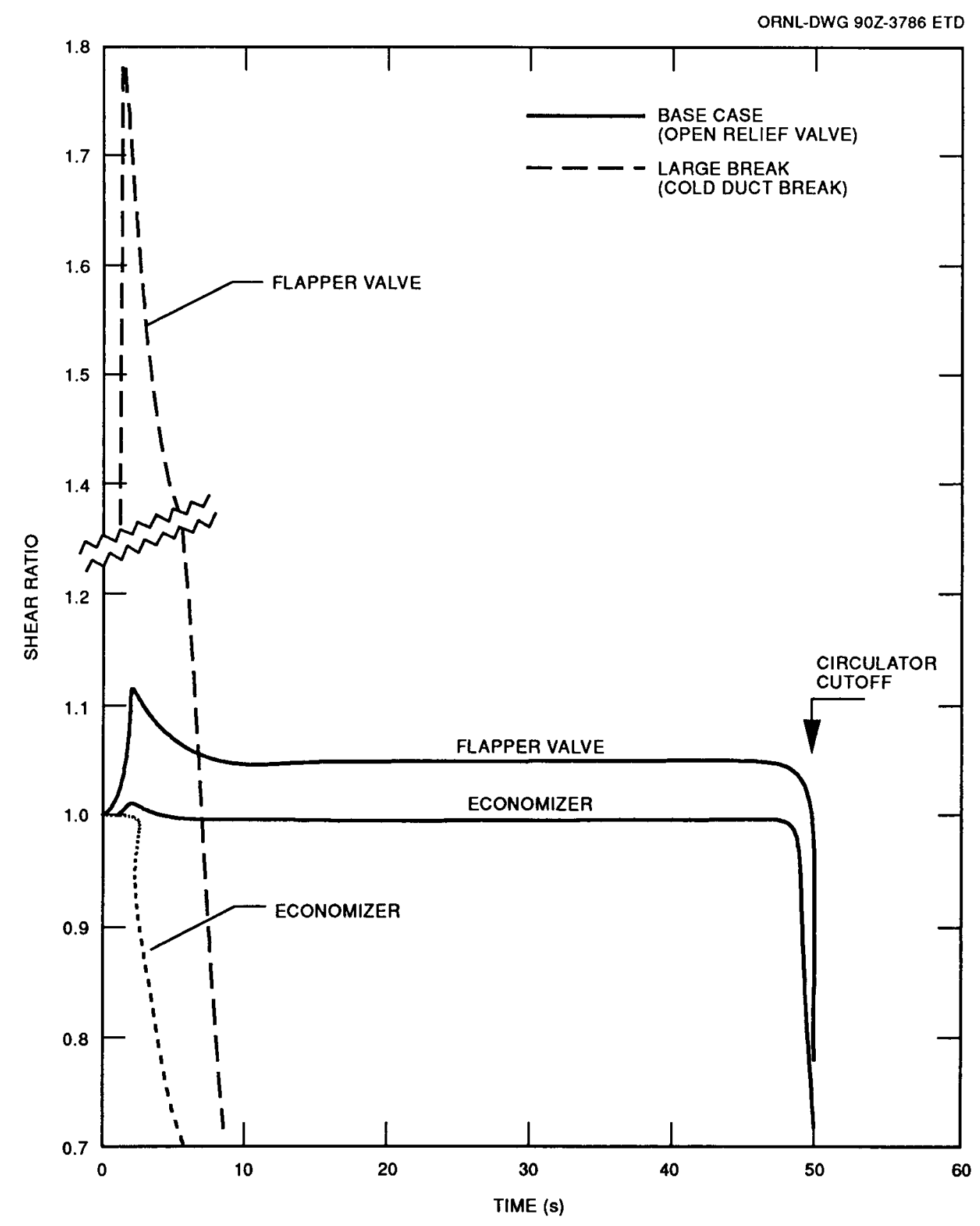

Fig. 5.6-1. Shear ratios in the SG predicted by RATSAM (Kroeger, 1990).

That is, for base case blowdown a total fractional dust liftoff fraction of $6.5 \times 10^{-4}$ is predicted for the economizer, and correspondingly lower fractional liftoffs are predicted for the rest of the tube bundle where shear ratios are predicted to be smaller.

Flows and shear ratios at the flapper valve, actually downstream from the tube bundle, are predicted to be higher due to their location beyond the circulator, and closer to the presumed 
failure location at the relief valve. Numerical integration of $\int \beta(t) d t$ for the flapper valve location yields (for the base case) only slightly higher fractional liftoffs; i.e.,

$$
\mathrm{F}_{\mathrm{LO}}=7.0 \times 10^{-4}
$$

Somewhat surprisingly, quite low shear ratios are predicted by RATSAM in the tube bundle for a postulated major break in the cold duct, as seen in Fig. 5.6-1 by the dashed curve labeled "economizer". Moreover, shear ratios of only unity are terminated within $4 \mathrm{~s}$. By means of numerical integration, the liftoff parameter method predicts $5.2 \times 10^{-5}$ fractional liftoff in the economizer for the postulated large break conditions and correspondingly lower liftoffs in the other SG regions subjected to lower predicted shear ratios. The Shear Ratio or Force Ratio method would predict zero liftoff for this case.

Shear conditions at the flapper valve for the large break case are of the type that could lead to significantly different predictions between the shear ratio and liftoff parameter methods. Here high shear ratios of $\sim 1.8$ are imposed for an extremely short duration, apparently less than 1 sccond. The shear (or force) ratio approach would define the liftoff to result from the high momentary value with no account taken for its brevity. In contrast, the result using the liftoff parameter method depends on the integral of the liftoff parameter for the time period. Carrying out the integral numerically for the large break blowdown at the flapper valve yields,

$$
\mathrm{F}_{\mathrm{LO}}=1.7 \times 10^{-4}
$$

That is, a significantly lower blowdown is predicted at this location compared with the base case due to the brevity of the imposed high shear.

Dust liftoff results are summarized in Table 5.6-2. In subsequent summary tables, the fractional dust liftoff of $6.5 \times 10^{-4}$ will be assumed for discussion purposes, the value corresponding to base case blowdown for the economizer tubing region.

The significance of these RATSAM results is that the SG tubing region appears effectively shielded from high depressurization shears, evidently by the circulator, when the pressure boundary failure is located between the SG and the core. In such case, the direction of the

\begin{tabular}{l}
$\begin{array}{c}\text { Table 5.6-2. Predicted degrees of dust } \\
\text { liftoff for two locations in the } \\
\text { MHTGR steam generator }\end{array}$ \\
\hline $\begin{array}{c}\text { Dust liftoffa } \\
(\%)\end{array}$ \\
\hline $\begin{array}{l}\text { Base case } \\
\text { Economizer }\end{array}$ \\
Flapper valve \\
$\begin{array}{l}\text { Large break case } \\
\text { Economizer }\end{array}$ \\
Flapper valve \\
\hline
\end{tabular}

aspeculative estimates; see text. 
depressurization flow is from the SG and through the core. The direct leakage path from the SG is effectively blocked by the circulator, which permits a throughflow of only that indicated by its characteristic curve while it is circulating, and effectively no flow after power cutoff.

\subsection{SUMMARY OF IODINE "LIFTOFF”}

In this section a complete set of estimates are presented as required for determining iodine release from the PS due to a dry depressurization. The motive is to clearly identify all the factors involved in the determination and to select the most critically uncertain areas.

It is important to recognize that the basis for the estimate is a general knowledge of how iodine behaves in the PS based on its chemical characteristics. There are only a few, simple gaseous forms, and iodine interaction with all available solids under dilute, high temperature conditions is predominantly surface sorption. There is negligible compound formation (as would occur with cesium and strontium) and negligible diffusion into solids (as may occur with cesium and silver). Thus iodine release estimate must proceed through the following steps:

(1) Determination of release rates from fuel during normal operation. This in tum depends on the amount of exposed fuel kernels, the degree of uranium contamination outside the fuel particle, and the transport delay from the source to the fuel element exterior. For iodine, with relative short-live nuclides, the transport delay allows a high degree of radioactive decay. The correlation used Eq. (5.1-1) predicts $99.8 \%$ decay of 1131 during transport within exposed kernels and about $80 \%$ decay from contamination. Clearly, small errors in the transport delay estimate, especially from exposed kernels, can cause large errors in the quantity of radioactive iodine in the PS. Because of the large degree of decay predicted from exposed kernels, the predominant source of radioactive iodine in the PS is uranium contamination.

(2) Determination of the amount of iodine in the PS available for loss by dry depressurization. This entails balancing the iodine sources with losses, here exclusively radioactive decay and removal by the purification stream. Since surface sorption is overwhelmingly the principal iodine form in the PS, the small purification flow (relative to decay rate) has essentially no impact on the radioactive species. Hence, the amount of radioactive iodine potentially available for loss by depressurization is essentially fixed by step 1 .

(3) Distribution of iodine in the PS. The principal inventory locations are (a) circulating as gas, (b) circulating as sorbed iodine on dust, (c) sorbed on steel, (d) sorbed on graphite, and (e) sorbed on plated dust. The iodine distribution between these inventory locations is determined by the product of each sorptivity (i.e., mols I sorbed per unit area and iodine partial pressure, $\mathrm{mol} / \mathrm{m}^{2} \mathrm{~Pa}$ ) and available surface area. For dilute coverages (as appears the case) the sorptivity is defined by the product of the Langmuir isotherm constants, LK. Best estimate distributions in the PS are summarized below:

\begin{tabular}{|c|c|}
\hline Circulating & Curies \\
\hline gaseous & $1.1 \times 10^{-4}$ \\
\hline on dust & $3.3 \times 10^{-6}$ \\
\hline & $1.2 \times 10^{-4}$ \\
\hline
\end{tabular}




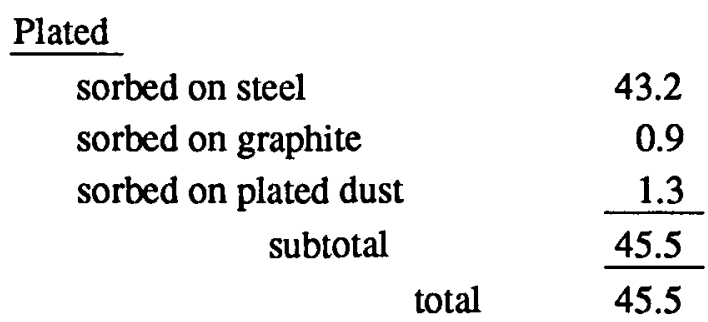

The high sorptivity of steel and its surface area are well established values. The fact that graphite has a much lower sorptivity (about $10^{-6}$ lower) is also well known, but neither an accurate estimate of graphite sorptivity nor its effective, large, surface for sorption are well known. Therefore, there is a significant uncertainty (at least a factor of 10 ) in the amount of iodine held on graphite.

Similarly, the amount of iodine circulating on plated dust is highly uncertain. The best estimate values given above are based on (1) measured values of the circulating dust concentration from the Peach Bottom Surveillance Program (described in Sect. 3), (2) a model evaluation relating the circulating and plated dust levels, using a speculative value of the liftoff rate parameter, $\beta,(3)$ iodine sorption constants for dust, assuming it to be largely rust, and (4) an estimate of the surface area per unit mass of dust, based upon particle sizes observed at Peach Bottom. Some internal consistency in the estimate is demonstrated by the favorable comparison of best estimate predictions of sorbed iodine per unit mass of dust with two available Peach Bottom measurements. As noted, best estimate values of both circulating and plated iodine on dust are each small compared with the total.

(4) Estimated release due to depressurization. This estimate consists of two parts, one dealing with chemical desorption (Sect. 5.6.1) the second with dust liftoff (Sect. 5.6.2). Results from these two subsections are summarized below:

\begin{tabular}{|c|c|c|c|c|}
\hline & $\begin{array}{c}\text { Initial Iodine } \\
\text { Activity } \\
\text { (Ci) }\end{array}$ & $\begin{array}{c}\text { Chemical } \\
\text { Desorption } \\
\text { (Ci) }\end{array}$ & $\begin{array}{c}\text { Dust } \\
\text { Liftoff } \\
(\mathrm{Ci}) \\
\end{array}$ & $\begin{array}{l}\text { Total } \\
\text { Loss } \\
(\mathrm{Ci})\end{array}$ \\
\hline Circulating & $1.2 \times 10^{-4}$ & & & $1.2 \times 10^{-4}$ \\
\hline \multicolumn{5}{|l|}{ Plated } \\
\hline sorbed on steel & 43.2 & $4.8 \times 10^{-4}$ & & $4.8 \times 10^{-4}$ \\
\hline sorbed on graphite & 0.91 & $4.6 \times 10^{-4}$ & & $4.6 \times 10^{-4}$ \\
\hline on plated dust & 1.3 & $8.7 \times 10^{-4}$ & $3.8 \times 10^{-4}$ & $12.5 \times 10^{-4}$ \\
\hline Total & 45.4 & & Total & $2.2 \times 10^{-3}$ \\
\hline
\end{tabular}

The above refers to the base case depressurization and best estimates dust levels.

It is noteworthy that the degree of chemical desorption is about equal for the three main chemisorption areas. The reason for this is that regions of high sorptivity (like steel) tend both to accumulate a large portion of the iodine by virtue of their high sorbitivity, but for the same reason, tend to hold onto the sorbed material on depressurization. If the chemisorption constants 
are known and the coverage is low (as is the case), estimates for chemical desorption are fairly straightforward.

In contrast, the dust liftoff estimates relies on the highly uncertain value of the liftoff parameter, $\beta$, and its variation with flow rate during a depressurization. Beyond the degree of dust liftoff, all the other uncertainties regarding plated dust mass, surface area and dust sorptivity also play into the above liftoff estimate rendering it highly uncertain. While it is not the purpose of this study to develop source term estimates, it nevertheless is important to note that the liftoff component of depressurization release is quit low. The liftoff estimate is low for several reasons, which taken as a group compels one to believe this to be the case. (1) Low shear ratio in the SG. Whatever dust liftoff model is used, it is difficult to visualize much liftoff from SG surfaces, where most of the dust is, resulting from the low shear ratios predicted for the base case depressurization. As shown in Fig. 5.6-1, maximum shear ratio in the SG (actually in the upflow annulus near the relief value) generally are only about 1.04 , and then for a period of only $\sim 50 \mathrm{~s}$. Considering that the dust would have been plated by exposure to perhaps years of flow at high velocity, it is hard to believe any significant removal would occur by $50 \mathrm{~s}$ exposure to such low shears. Moreover, other portions of the SG, i.e., essentially all of the tube bundle, are predicted to experience even lower shear ratios. (2) Low sorptivity for iodine, defined as mols adsorbed per unit area and partial pressure. While the actual value is uncertain, it is clearly much lower than for steel. Therefore, any iodine distribution estimate for the PS would very likely place the major portion of "plated" iodine as being sorbed on steel, hence not subject to liftoff. 


\section{CESIUM, STRONTIUM AND SILVER PLATEOUT AND LIFTOFF: QUALITATIVE EVALUATION}

\subsection{CESIUM PLATEOUT AND LIFTOFF}

\subsubsection{Cesium Release from Fuel}

Determination of the cesium inventory in the PS differs from iodine with respect to the number of fuel defects effective for release, and the fractional decay expected during the release process. Since cesium readily diffuses through pyrocarbon, fuel particles with defective SiC layers will release cesium in addition to those with exposed kernels. Referring to Table 1.4-2, the average failure fraction for release of cesium expected by DOE is $9 \times 10^{-5}$, compared with $3.5 \times$ $10^{-5}$ for release of iodine.

An additional difference relative to iodine is the extent of radioactive decay of key isotopes in the process of being released from failed fuel. Due to short half-lives, the iodine isotopes mostly decay prior to release from failed fuel. For example, release models indicate that $99.8 \%$ of the I131 born in exposed kernels and $80 \%$ born in contamination decays prior to release from fuel. The principal cesium isotopes differ in several respects. Cesium-137, with a 30.2 y half-life would experience essentially no decay loss in transit from failed particles. Moreover, the formation diagram in Appendix A indicates that both Cs134 and Cs136 are activation products of stable Cs133 and Cs135, respectively. As noted in Sect. 1.4, the effective "half lives" of these precursors in a neutron flux representative of an MHTGR are $\sim 3$ and $\sim 13$ years, respectively. As a consequence, a great deal of the precursor material for the radionuclides Cs134 and Cs136 may be expected to be released from failed fuel prior to absorbing a neutron. Hence, the Cs134 and Cs136 production rates may be substantially lower than usually estimated.

A final consideration is the possibility of some degree of cesium release from intact particles, at least those in the highest temperature regions in the core and towards the end of the fueling interval.

\subsubsection{Gaseous Cesium Forms}

Thermodynamic prediction of the nature of cesium gaseous species was performed by Feber et al. (1976). Three impurity levels were assumed, which are listed in Table 6.1-1, with a range of oxygen and carbon potentials. The compositions were selected from analyses performed at the indicated HTGR reactors. An attempt was made to account for surface sorption in the analysis, but the results must be considered preliminary in nature. In each case it was assumed that the total gaseous cesium concentration was $10^{-16}$ volume fraction and that no free carbon was present.

The results, summarized in Table 6.1-2, indicate that the principal gaseous form of cesium in the high temperature zone of the PS is atomic Cs when the $\mathrm{H}_{2} / \mathrm{H}_{2} \mathrm{O}$ ratio exceeds about twenty. For the somewhat higher oxygen potential at the AVR, evidently both Cs and CsOH gases exist in the high temperature region. In all three cases, the equilibrium shifts to $\mathrm{CsOH}$ gas in the low temperature region. Secondary gaseous cesium species are principally $\mathrm{CsH}$ and $\mathrm{Cs}_{2}(\mathrm{OH})_{2}$. 
Table 6.1-1. Typical impurity compositions ${ }^{a}$ for determination of gaseous cesium species (Feber, et.al., 1976)

\begin{tabular}{lclllll}
\hline Reactor & $\begin{array}{c}\text { Pressure } \\
(\mathrm{kPa})\end{array}$ & $\mathrm{H}_{2} \mathrm{O}$ & $\mathrm{CO}_{2}$ & $\mathrm{H}_{2}$ & $\mathrm{CO}$ & $\mathrm{CH}_{4}$ \\
\hline $\begin{array}{l}\text { Peach } \\
\text { Bottom }\end{array}$ & 2296 & $<0.5$ & & 9 & 0.5 & 0.6 \\
AVR & 965 & 3 & 10 & 30 & 30 & \\
Dragon & 2068 & 0.05 & $<0.02$ & 1.0 & 0.6 & 0.1 \\
\hline
\end{tabular}

$a_{\text {In }}$ parts per million by volume; balance is helium.

Table 6.1-2. Gaseous cesium species predicted for compositions in Table 6.1-1a (Feber, et al., 1976)

\begin{tabular}{llll}
\hline \multirow{2}{*}{ Composition } & & \multicolumn{2}{c}{ Gaseous species } \\
\cline { 3 - 4 } & & Principal & \multicolumn{1}{c}{ Secondary } \\
\hline Peach Bottom & High T & $\mathrm{Cs}$ & $\mathrm{CsH}, \mathrm{CsOh}$ \\
& Low T & $\mathrm{CsOH}$ & $\mathrm{Cs}, \mathrm{Cs}_{2}(\mathrm{OH})_{2}, \mathrm{CsH}$ \\
AVR & High T & $\mathrm{Cs}, \mathrm{CsOH}$ & $\mathrm{CsH}$ \\
& Low T & $\mathrm{CsOH}$ & $\mathrm{Cs}, \mathrm{Cs}_{2}(\mathrm{OH})_{2}, \mathrm{CSH}$ \\
Dragon & High T & $\mathrm{Cs}$ & $\mathrm{CsOH}, \mathrm{CsH}$ \\
& Low T & $\mathrm{CsOH}$ & $\mathrm{Cs}, \mathrm{Cs}_{2}(\mathrm{OH})_{2}, \mathrm{CSH}$ \\
\hline
\end{tabular}

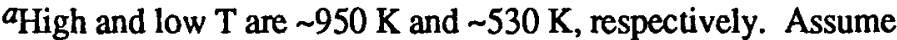
total cesium concentration is $10^{-16}$ vol fraction. No free carbon present.

\subsubsection{Cesium Plateout Characteristics}

The distinctive feature of cesium plateout is its strong tendency to react with many oxides to form stable compounds of the form $\mathrm{Cs}_{\mathrm{x}} \mathrm{MOy}$, where $\mathrm{M}$ may be chromium, iron, molybdenum, aluminum, silicon and other metals. For example, data shown by Woolley (1981) indicate that such stable oxides form on carbon steel, stainless steel and titanium surfaces, generally above $\sim 573 \mathrm{~K}\left(-300^{\circ} \mathrm{C}\right)$ in either HTGR or AGR $\left(\mathrm{CO}_{2}\right.$ coolant) atmospheres. Woolley observed distinctly different types of cesium plateout above and below $\sim 573 \mathrm{~K}\left(\sim 300^{\circ} \mathrm{C}\right)$. This is roughly consistent with the observations of Clark (1979), who found cesium deposits on Peach Bottom SG tubing heaviest in the superheater region [T $\left.>723 \mathrm{~K}\left(450^{\circ} \mathrm{C}\right)\right]$. Such high temperature cesium deposits were susceptible to removal only by heating to above $1273 \mathrm{~K}$.

There are indications that the most stable reaction products of cesium and metal oxides are more complex than indicated above and, in fact, occur with combinations of oxides. Therefore, it is not clear if sufficient thermodynamic data are available for predicting the net result of competitive reactions for cesium between dust particles and surface oxides of various compositions. Data of Woolley (1981) indicate further that cesium compounds tend to diffuse 
into the oxide to an extent typically depending on temperature and the square root of the exposure time.

Cesium also chemisorbs on steel, oxide and graphite surfaces. Since cesium may react with the surface oxides of steel and can also form carbides with graphite at low temperatures, we may expect a strong chemisorption tendency for cesium on these surfaces. Woolley (1981) observed that chemisorption is the predominant deposit form on steel below $\sim 573 \mathrm{~K}\left(300^{\circ} \mathrm{C}\right)$. Milstead and Zumwalt (1967) observed, at least for high cesium partial pressure $(0.1$ to $0.001 \mathrm{~Pa})$ and $\sim 1000$ $\mathrm{K}$, that the sorption is reversible but extremely slowly, i.e., on the order of days.

\subsubsection{Cesium Liftoff Determination}

The initial step for a cesium "liftoff" evaluation is determination of the distribution between the various plateout forms. The main point of departure from iodine, is the chemical reactivity of cesium with dust and surface oxides. The distribution of cesium between the deposit forms probably cannot now be fully predicted due to a dearth of dust composition and concentration data. A lack of sufficient thermodynamic and diffusion coefficient data for prediction of the relative association between surface oxide and dust also inhibits the prediction.

A qualitative point of departure from iodine is the higher sorptivity of cesium on graphite. Cesium chemisorption equilibria and kinetics on graphite surfaces are therefore comparatively more significant.

Some data are available in Clark (1979) on the chemical desorption of cesium from Peach Bottom HTGR SG tubing. Clark found that the desorption behavior generally depends on the temperature of deposition. Sorption on economizer tubing $(500$ to $600 \mathrm{~K})$ were volatilized at $850 \mathrm{~K}$, whereas deposits on superheater tubing (720 to $850 \mathrm{~K}$ ) remained fixed up to $\sim 1270 \mathrm{~K}$.

\subsection{SILVER PLATEOUT AND LIFTOFF}

\subsubsection{Silver Release from Fuel}

The above comments for cesium release from failed fuel particles also apply generally to silver. Since silver diffuses readily through pyrocarbon, particles with defective SiC layers release silver, as well as those with exposed kernels. The DOE-projected average failure fraction releasing silver is $9 \times 10^{-5}$, of which $1 \times 10^{-5}$ consists of contamination (Table 1.4-2).

The principal silver nuclides for MHTGR safety are the $250 \mathrm{~d}$ half-life activation product, Ag110m and the $7.47 \mathrm{~d}$ half-life fission product, $\mathrm{Ag} 111$ (see formation diagrams, Fig. A.4). As for the cases of the cesium activation products, Cs134 and Cs136, the production rate of $\mathrm{Ag} 110 \mathrm{~m}$ depends to a degree on the escape rate of $\mathrm{Ag} 109$ from failed fuel relative to the production rate by neutron absorption. The total capture cross-section (thermal plus epithermal) of Ag 109 is 93.5 barns leads to an estimated "half-life" of $456 \mathrm{~d}$ in a flux of $1.9 \times 10^{14}$ neutrons $/ \mathrm{cm}^{2} \mathrm{~s}$. Therefore, much of the Ag109 may be expected to move from failed fuel as Ag109 into lower flux zones, thereby diminishing the production rate of $\mathrm{Ag} 110 \mathrm{~m}$.

The release rate of the relatively short-lived fission product, $\mathrm{Ag} 111$, from failed fuel depends upon the holdup time of silver in uranium grains and uranium contamination sources. It 
should be noted that the iodine FP of comparable half-life, I131, largely decays during transport from exposed kernels and contamination. Comparatively, Ag111 decay should be much less due to the high diffusivity of silver relative to iodine.

As noted earlier (Sect. 1.4), there is a reasonable chance for some silver diffusion source from intact particles in high temperature regions of the core. Since isotope Ag109 likely diffuses from failed fuel prior to its conversion to $\mathrm{Ag} 110 \mathrm{~m}$ by neutron absorption, a primary source for $\mathrm{Ag} 110 \mathrm{~m}$ in the PS may be intact fuel particles.

\subsubsection{Silver Plateout Characteristics}

The unique behavior of silver in the PS relates to its chemical inertness and extremely high diffusivity in graphite. ${ }^{*}$ Therefore, silver will spread rapidly through graphitic systems and tend to exist as a distinct macroscopic phase. Even though the vapor pressure of silver is quite low $\left(\sim 1.16 \times 10^{-5} \mathrm{~Pa}\right.$ at $\left.1000 \mathrm{~K}\right)$, the relative vapor pressures between high and low temperature locations of the PS may, over the long term, cause an accumulation of silver in low temperature regions. In any case, the high melting point of silver at $1234 \mathrm{~K}$ indicates that the deposit would be solid.

An additional property of silver that may impact its deposition characteristics is its small but possibly significant solubility in nickel, a constituent of alloy $800 \mathrm{H}$ comprising the superheater tubes of the SG. The solubility is estimated to be 1 atom $\%$ at $1073 \mathrm{~K}$ (Massalski, 1986).

It was also noted that Ag110m has been observed in Peach Bottom HTGR dust samples, probably as a condensed phase. Activities on circulating dust samples (Table 3.1-1) ranged from $1.3 \times 10^{-3}$ to $5 \times 10^{-3} \mu \mathrm{Ci} / \mathrm{mg}$, and were fairly steady throughout Core 2 operation. Somewhat higher levels were observed on the carbonaceous filamentary "dust" acquired form the surface of fuel elements (Table 3.1-2). An activity level of $0.034 \mu \mathrm{Ci} / \mathrm{mg}$ of dust was observed on an end-of-life fuel element.

While silver does not chemisorb on internal graphite surfaces to a significant degree, some may be expected to condense and freeze in place in the course of its transit through graphite. For example, a total of $0.47 \mathrm{Ci}$ of $\mathrm{Ag} 110 \mathrm{~m}$ was found in the graphite parts of Peach Bottom fuel element E0101 (Wichner, et.al., 1978), which was one of 804 driver elements unloaded at the end of Core 2 operation. (The cited surveillance report also provides axial distribution data on $\mathrm{Ag} 110 \mathrm{~m}$ within the fuel element.)

\subsubsection{Silver Liftoff}

According to the above view, plated silver deposits may be expected as condensed (probably solidified) silver within graphite, on dust and as other macroscopic accumulations. In

*The mechanism for the high diffusivity has not been clearly established. However, review comments by Myers state that silver diffusivity depends on total pressure, indicative of gas phase transport through connected porosity. In contrast, cesium and iodine diffusivities are not pressure dependent, which together with their affinities for graphite indicates surface diffusion. Thus the high diffusivity of silver may be caused by its inertness, leading to a lack of wetting in graphite. 
addition, some accumulation as dissolved material in alloy $800 \mathrm{H}$ superheater tube is a possibility. Of these plateout forms, only that associated with plated dust would be amenable to liftoff in a dry depressurization. Peach Bottom HTGR data indicate a somewhat greater deposit on dust associated with the core than other dust samples possibly due to silver condensing in close proximity to the source.

Therefore silver liftoff determination would entail (1) determination of the birth rate of the $\mathrm{Ag} 110 \mathrm{~m}$ activation product in failed fuel (the release rate is expected to be equal to the birth rate in failed fuel), and estimation of the R/B for intact fuel to determine the PS inventory, (2) a mass transport analysis to determine the fraction of silver in the PS associated with plated and circulating dust, (3) a dust liftoff analysis.

\subsection{STRONTIUM PLATEOUT AND LIFTOFF}

The principal strontium isotopes are the $50.5 \mathrm{~d}$ half-life $\mathrm{Sr} 89$ and the $28.6 \mathrm{y}$ half-life Sr90/Y90 pair. All are weak $\beta$-emitters. The principal safety concern relates to the high dose conversion factor to the bone for the Sr $90 / \mathrm{Y} 90$ fission product pair.

At low concentrations and high temperatures within a graphite environment, strontium exists as the metal and hence exhibits transport characteristics similar to cesium and other metals, namely high diffusivity through pyrocarbon and graphite and high chemical sorptivity on graphite (relative to iodine). Therefore, the same sorts of fuel particle failures which release cesium and silver also apply to strontium.

However as noted in Sect. 1.4, strontium is strongly retained in the design UCO kernels due to $\mathrm{O} / \mathrm{C}$ ratios being $>1.7$. It is not clear how this effects strontium release from failed fuel. Two possible effects are (1) significant decay of Sr89 to stable yttrium prior to release, (2) the principal mode of release shifting to the short-lived precursors Kr89 and Rb89.

Strontium behavior departs significantly from cesium in its higher chemical reactivity with both carbon and oxygen, tending to form high melting, low vapor pressure carbides or oxides. Within graphite, in zones of minimal oxygen penetration, strontium carbide $\left(\mathrm{SrC}_{2}\right)$ with a formation free energy of about $-80 \mathrm{~kJ} / \mathrm{mol}$ forms when sufficient concentration levels permit. When $\mathrm{SrC}_{2}$ does form, its high melting temperature (in excess of $2000 \mathrm{~K}$ ) indicates an extremely low mobility for strontium from that point.

In common with other alkaline earths, strontium exhibits a strong tendency for oxide formation, the formation free energy of SrO being approximately $-600 \mathrm{~kJ} / \mathrm{mol}$ at typical PS temperatures. Thus in zones of quite small oxygen penetration, perhaps even within graphite porosity, $\mathrm{SrC}_{2}$ or metallic strontium directly, converts to the highly refractory SrO with a melting temperature of $2733 \mathrm{~K}$. Highly stable SrO is not likely to exhibit any significant mobility via diffusive or evaporative means.

Hence plateout and liftoff evaluation for strontium requires principally determination of locations for $\mathrm{SrC}_{2}$ and $\mathrm{SrO}$ formation. That fraction of strontium compound forming on dust (likely SrO) would be subject to liftoff by flow forces. 


\section{DOE PLATEOUT AND LIFTOFF PROGRAM}

Research and development activities bcaring on depressurization effects are being supported by the DOE under the auspices of both the New Production Reactor (NPR) and the MHTGR Technology programs. Generic items are incorporated within the NPR program. Issues specific to the commercial reactor and university and foreign activities are included in the MHTGR Technology program. The basic descriptive document is MHTGR-DOE (1987) which, because of its early date, includes both commercial and NPR elements. The equivalent NPR plan exists at this time as an early draft (NPR-DOE, 1989).

The important issues relating to the depressurization effects of a commercial MHTGR may be classed as follows:

1. Establishment of the ex-fuel inventory of the important FP elements, principally iodine, cesium, strontium and silver, defining the quantities available for depressurization release. This objective requires the following elements:

a. Determination of the as-manufactured fuel particle quality, specifically the initial fraction of exposed kemels, defective $\mathrm{SiC}$ layers and uranium contamination.

b. Determination of the rate of fuel failure during normal operation. Parts (a) and (b) define the average fuel failure fraction during a fuel cycle effective for fission gas and fission metal release.

c. Determination of the release rate of fission products from failed fuel, critical for the iodine isotopes because of their relatively short half-lives.

d. Some further resolution may be required regarding diffusive release of silver and cesium from intact fuel particles in high temperature regions of the core.

e. Determination of the true production rate of important activation products Cs134, Cs136, and Ag110m may lower currently predicted ex-fuel levels.

2. Establishment of the type and general location of the ex-fuel, deposit for each FP element. A small portion will be in some circulating form and hence available for quick release. The major portion will exist as deposits of various sorts, the nature of which determines its response to depressurization conditions. This objective requires,

a. Determination of the chemical forms of the FP elements in the PS.

b. Association with dust may be a significant aspect of depressurization release. If so, determination of the amount and characteristics of dust in the PS is required. This difficult objective could perhaps be best achieved by identification of the dust production mechanisms and laboratory scale experimentation.

c. Determination of the deposit locations and types from the above information and by means of a mass transport analysis.

3. Determination of depressurization conditions. This appears largely available from the RATSAM code.

4. Determination of the response of each type of deposit to the predicted depressurization conditions.

a. Determination of the degree of chemical desorption from solid surfaces.

b. Determination of the degree of dust liftoff due to flow forces during depressurization. 
The DOE program relating to the above requirements for depressurization effects evaluation consists of the following elements:

Fuel Material Development. The program activities in this area include the following:

a. Fuel particle tests using the Irradiated Microsphere Gamma Analysis facility (IMGA),

b. Fuel manufacturing development,

c. Development of fuel $\mathrm{QC}$ procedures,

d. Development of a QA plan,

e. In-pile capsule tests,

f. Severe accident behavior tests.

The IMGA facility is designed for rapid radioactivity measurement of large numbers of irradiated fuel particles. A determination of the fraction of particles with damaged $\mathrm{SiC}$ layers is obtained by monitoring the ratio of Cs137, which is released from particles with failed SiC coatings, to that of Ce144, remains within the UCO kemel. Such determination would also include failures of the type which expose kernels; however, it would be difficult to distinguish between the two types of failures. At present, the IMGA facility has been used to verify the low failure fractions of German-made fuel.

In-pile capsule tests HRB-17 and -18 were designed principally for determination of hydrolysis effects on failed fuel particles. Capsule series HRB-21, -19 , and -20 , in that order, are planned for validating fuel particle failure models for irradiation conditions at $975^{\circ} \mathrm{C}, 1250^{\circ} \mathrm{C}$, and $1180^{\circ} \mathrm{C}$, respectively. HRB-21 will be the first capsule using US-made, high quality fuel. The irradiation will be conducted in the HFIR and carried out to full burnup. The main purpose of these tests will be validation of fuel failure models. Continuous monitoring of $\mathrm{Kr}$ and $\mathrm{Xe}$ fission gases should provide important data on holdup decay within exposed kernels and uranium contamination.

Fission Product Transport Tests. Bench scale, once-through, flow tests are being conducted to measure the degree of "lift-off" (predominantly chemical desorption) from low alloy steel. A realistic gaseous environment is being used, which contains a representative composition of $\mathrm{CO}, \mathrm{H}_{2} \mathrm{O}, \mathrm{H}_{2}$, and $\mathrm{CO}_{2}$ impurities. Preliminary results for iodine seem to indicate some effect of the impurities, leading to some differences from earlier data, which were obtained generally with pure helium. A general trend seems to indicate more rapid and extensive desorption as a result of the impurities. In addition, tests with high moisture levels are included in the scope, and future tests with $\mathrm{Cs}$ and $\mathrm{Sr}$ are planned.

Dust formation rates, due to spallation of oxide films from SG tubing are being investigated on a laboratory scale. Currently, specimens of low alloy steel are being thermal cycled in a representative atmosphere with oxide growth and spallation rates being periodically monitored. Tests such as these could be extremely helpful in predicting the contribution to reactor dust levels from this source. In addition, dust samples taken from a FSV circulator surface are being characterized. Related studies deal with attempting to identify the nature and degree of chemical association with dust materials. Initial chemical evaluations are dealing with iodine association with dust. 
FP transport tests are planned at MIT using a circulating system termed the DABLE loop. A unique feature of this facility is ceramic impeller capable of operation up to $700^{\circ} \mathrm{C}$. Consequently, the complex and costly business of cooling and heating the circulating flow is not needed. The test section consists of a 1 -inch diameter, 1-inch long tube of either alloy $800 \mathrm{H}$ or low alloy steel. Initial tests will be conducted using an iodine source. A preliminary project plan has been written (GA-Dable, 1988) indicating the general goals of this facility, however, the precise nature of future test programs has not been fixed.

A major effort in the area of testing to determine depressurization releases is planned for the Comedie in-pile loop using CEA facilities at Grenoble. The plan for the initial test series, termed BD-1, is described by Acharya (1988), which also contains a general description of this fairly complex experiment. Three test series are planned, each of which includes about four subelements, such that a total of twelve test runs would be completed at the planned termination. The first test series (BD-1) will be conducted using nominally clean surfaces and reference PS conditions; that is, no dust or moisture will be added. Plans call for adding dust in the second test series (BD-2). The means for doing so, total amount and type of dust is currently being developed. The third test series will be devoted to determination of the effects of moisture on liftoff. 


\section{SUMMARY AND CONCLUSIONS}

\subsection{SUMMARY}

(1) A review is presented of the technical status of "plateout" and "liftoff" modeling as it relates to a dry depressurization event of an MHTGR primary system. These terms appear in quotation marks to signify that they each represent a number of chemical and physical processes which follow different rules of behavior. Moreover, the behavioral rules differ significantly between fission product elements due to major differences in chemical affinities and physical properties. This report covers the plateout and liftoff characteristics of the fission product elements iodine, cesium, strontium and silver. Iodine is treated in a relatively complete fashion. The unique features of plateout and liftoff behavior of the other three elements are qualitatively summarized.

(2) Section 1 deals with several preliminary topics bearing on the amount, locations and chemical forms of fission products in the PS. The large subject of FP release from failed fuel particles and the expected degree of fuel failures is briefly reviewed. It is noted that iodine is rcleased from defective fuel of the type which expose the kernel and from uranium contamination outside of particles. An expression for steady-state release rates from these types of failures is cited. It is noteworthy that the controlling release mechanism from exposed kemels, diffusion within the grain to its surface, is predicted to be so slow that radioactive iodine species largely decay in transit. Only about $0.2 \%$ of the 1131 (the dominant iodine isotope) is predicted to survive the duration between birth in an exposed kernel and diffusive release from the $\mathrm{UO}_{2}$ grain. The significances of this observation are (1) small variation in fuel kemel structure which affect its size and diffusivity can have a large effect on iodine release from exposed kernels, (2) the principal source of iodine in the PS is thus predicted to be uranium contamination, which is associated with a significantly shorter transport delay, allowing about $20 \%$ of the I131 (at $\sim 1100 \mathrm{~K}$ ) to survive for release.

(3) The principal observations regarding release of fission metals from fuel are the following: (a) A larger category of particle failures types allows fission metal release; i.e., particles with failed SiC but intact PyC may release metals but retain gases (including iodine). Anticipated failure fractions of each type are summarized in Table 1.4-2. (b) Fission metals with high oxygen affinity, such as strontium (and the rare earths) are strongly held in UCO kernels of standard composition. Releases of such metals are expected to result predominantly from uranium contamination. (c) Cesium, and to a greater extent, silver are expected to be readily released from particles with failed SiC layers. Silver has an especially high diffusion coefficient in UCO and PyC. (d) Some significant cesium release is possible, and significant silver release likely from intact particles located in high temperature regions. Therefore, the PS inventory of cesium and especially silver may be larger than indicated by the failed fuel fraction alone.

(4) It is noted that the quantity of important activation products, Cs134, Cs136 and $\mathrm{Ag} 110 \mathrm{~m}$ in the PS (ex-fuel), may be significantly less than usually estimated. The reason is that the predicted "lifetimes" of the stable precursors are sufficiently long such that each will largely leak from failed fuel prior to absorbing a neutron. 
(5) The various possible modes of FP deposition in the PS are described in Sect. 1.5. Because of the relative simplicity of iodine chemistry under these conditions, the principal inventory locations of iodine can be cited with a good degree of certainty. These are (a) circulating as a gas, (b) chemisorbed on circulating dust, (c) chemisorbed on metal surfaces (d) chemisorbed on the extensive graphite surface which forms the open, connected porosity, (e) chemisorbed on plated dust. The test calculation in section 5 indicates that by far the principal deposition mode of iodine is as chemisorbed material on PS steel.

(6) The deposition modes of cesium, strontium and silver are more briefly discussed. Because of the relatively complex chemistry of cesium under PS conditions, its principal plateout modes (and hence also its response to depressurization conditions) require careful evaluation. The principal characteristic of cesium is its tendency for reacting with many oxides to form stable compounds of the form $\mathrm{Cs}_{\mathrm{x}} \mathrm{MO}_{\mathrm{y}}$. For example, cesium chromate readily forms, either in dust or in the adherent oxide coating on steel. Obviously, the liftoff characteristics of these two modes are vastly different. In addition, there is indication of cesium diffusion into oxide coatings on steel, which further enhances the opportunity for permanent, immobile repository for cesium in the PS. Though complex, the chemistry of cesium may be sufficiently known to allow prediction of its principal deposition modes. However, adequate characterization of dust quantity and type is required. An additional feature of cesium is its relatively high sorptivity in graphite. Therefore, the cooler graphite regions may be a significant inventory location for cesium.

(7) The principal deposition (hence liftoff) features of strontium relate to its high oxygen affinity. Strontium will form the refractory oxide even under the strong reducing conditions in the PS. Because of the high melting point and extremely low vapor pressure of the oxide, SrO will very likely permanently deposit where it forms, on dust or on structure and perhaps even within graphite. The liftoff behavior of strontium depends heavily on determining where the oxide forms. In addition, similar to cesium, graphite has a significant sorptivity for strontium.

(8) Since silver is essentially chemically inert under PS conditions, its deposition and liftoff behavior depend on the effects of its physical properties. A low vapor pressure and high melting point $(1234 \mathrm{~K})$ signify that silver will freeze permanently upon any opportune surface. It is very likely that silver condensed on fixed surfaces will not liftoff. If the vapor pressure of silver in higher temperature areas is sufficient, thermal transport will gradually move condensed deposits to low temperature regions where it would collect as a distinct phase. In addition, Peach Bottom HTGR data indicate that there is some association of silver with dust. A feature of silver is its small solubility in nickel, a constituent of alloy $800 \mathrm{H}$ comprising the superheater portion of the SG. The possibility of dissolved silver in alloy $800 \mathrm{H}$ as a permanent repository location needs to be evaluated. Unlike cesium and strontium, the silver content of graphite by means of chemisorption is expected to be extremely small.

(9) Some features of the chemical environment in the primary system are described in Sect. 2. The environment is dominated by the presence of graphite, which imposes reducing conditions throughout, and is modified by highly unpredictable ingress rates of oxidants from various sources, e.g., minute leaks from the steam generator, graphite outgassing, and maintenance operations. The oxidants react principally with graphite to form mainly $\mathrm{CO}$ and $\mathrm{H}_{2}$, which exist in equilibrium with the oxidants $\mathrm{CO}_{2}$ and $\mathrm{H}_{2} \mathrm{O}$, the ratio being indicative of the oxygen potential of the system. Thus the oxygen potential of the PS is determined by the various 
oxygen potential of the system. Thus the oxygen potential of the PS is determined by the various impurity in leakages, the rates of which are unknown and which may be highly variable between even identical reactors. The oxygen potential controls the oxidation rates of graphite and steel, and is therefore a factor affecting dust production. In addition to affecting the dust level and possibly the nature of the metal surfaces, the chemical environment also affects the chemical speciation of fission products in the primary system, particularly that of cesium.

(10) In Sect. 3, the available information on reactor dust characterization and dust plateout modeling are reviewed. Reactor dust data are available from the Peach Bottom surveillance program for Core 2 and the AVR pebble bed reactor, the latter currently only in preliminary form. The Peach Bottom HTGR surveillance data are by far the most complete dust data set for a nonpebble bed HTGR. The AVR dust data indicate that a significantly different mixture of dust is produced in pebble bed reactors due to a much higher degree of graphite abrasion.

(11) Heavy reliance is placed on Peach Bottom surveillance data in this evaluation as an indication of expected circulating dust concentrations and for types and sizes of dust particles. The data set includes the following information on dust: (a) circulating concentrations determined by isokinetic samplers, (b) circulating concentrations determined from amounts collected by means of a cyclone separator in a bypass stream, (c) size distribution from impactor plates in the samplers, (d) elemental compositions, (e) some data on molecular and crystallographic makeup, (f) some data on fission product activity on sampler dust. The negative aspects of using this data set are that the reactor was not of the prismatic type (although closer to prismatic than pebble bed) and lubricating oil leakages into the helium influenced the dust level. However, the latter influence does not appear to be significant. Instead, the process of replacing Core 1 with Core 2 appears to have been the principal dust producing "mechanism" during Core 2 operation.

(12) The principal dust types found in the Peach Bottom samples were (a) graphite particles from abrasion, (b) "rust" flakes, however frequently containing materials other than expected and occasionally composed of carbides, (c) carbon filamentary material from surfaces evidently growing from catalytic sites, (d) debris from maintenance or core replacement activity, (e) much other, unidentified material usually containing silica. Generally, the dust samples contained significant cesium activity, especially at EOL. Some iodine, strontium and silver was also observed associated with dust.

(13) Measured circulating concentrations of dust averaged $0.09 \mathrm{mg} / \mathrm{m}^{3}$ during Peach Bottom Core 2 operation. A simple dust balance model was used to estimate dust production rates and plateout concentrations from the circulating concentration data. These estimates indicate an average dust production rate of $\sim 0.25 \mathrm{~kg} / \mathrm{y}$ and a total plateout amount of $\sim 5.6 \mathrm{~kg}$ in the Peach Bottom PS. (The latter value is highly speculative).

(14) The status of dust plateout modeling is reviewed in Sect. 3.2 and applied to sample conditions in the MHTGR heat exchanger in Sect. 3.3. Although some weaknesses exist, dust plateout modeling is in a fairly advanced state compared with dust liftoff estimation. The weaknesses lie with predictions relating to crossflow exterior to tightly packed tubes, the typical SG condition. Application of available plateout models to such a flow configuration is highly 
uncertain. An additional uncertainty relates to predicting plateout of large particles (i.e., $>1 \mu \mathrm{m}$ ) where the net deposition rate is affected by a fractional bounce-off.

(15) An order-of-magnitude evaluation of dust deposition in the SG is reported in Sect. 3.3. Dust plateout models predict the SG to be a perfect sink for particles $>0.5 \mu \mathrm{m}$ due to turbulent-inertial and impaction deposition mechanisms. Likewise, very small particles, i.e., $<0.003 \mu \mathrm{m}$ are expected to completely deposit due to the effectiveness of particle diffusion for these small sizes. Thermophoresis is predicted to be significant dust deposition mechanism for sizes $<0.5 \mu \mathrm{m}$. It is noted that thermophoresis works against dust deposition in the core where the gas temperature increases toward the surface.

(16) The status of dust liftoff modeling is reviewed in Sect. 4. In general, dust liftoff models fall into two categories which may be termed either "force ratio" or "turbulent burst" models. The shear ratio concept falls in the first category, although it is strictly not a model in the sense of providing an expression for liftoff prediction. "Force ratio" models postulate that liftoff occurs when drag or lift forces exceed the force of attraction. "Turbulent burst" models postulate that liftoff results from the penetration of the laminar sublayer by bursts of turbulence from the turbulent zone. The framework for a liftoff model may be developed from either postulate, however, most recent developments are based on the "turbulent burst" concept. Physical reality appears to favor the turbulent burst mechanism for particle liftoff. An important implication of the "turbulent burst" approach is that the liftoff process occurs continuously, even at steady state (i.e., at shear ratios of unity) at which time deposition and liftoff rates are in equilibrium. Thus, during depressurization some liftoff is predicted for shear ratios of unity and below.

(17) A liftoff model based on the "force ratio" concept is outlined in Sect. 4.3. Most models of this type presume the particle-substrate attractive force to be proportional to its radius, which is unlikely to be completely true and which cannot be directly tested for particles $<5 \mu \mathrm{m}$. A second basic assumption is that liftoff forces are transmitted to the particle by viscosity acting through a classical, laminar sublayer. Expressions for such flow forces are available only for the most ideal configurations, e.g., a sphere on a smooth plate.

(18) Sections 4.5-4.7 outline recent liftoff modeling developments based on "turbulent burst" concepts. The most convenient expressions of this concept defines a liftoff rate parameter, $\beta$, (defined in Sect. 4.6) which is a function of the force ratio, $F$, (i.e., the ratio of the attractive to the flow liftoff force). When it is assumed that

$$
\beta=A \exp (-F) \text {, }
$$

which may have some technical basis, a model results which is consistent with observed, time dependent liftoff data. Reported values of $\beta$ (effectively the fractional liftoff rate) range from $\sim 10 \mathrm{hr}^{-1}$ for loosely held particles to $\sim 0.05 \mathrm{hr}^{-1}$ for strongly adherent particles.

(19) A sample calculation of iodine plateout and liftoff is presented in Sect. 5 which attempts to integrate the numerous influential factors. The motivation is to place these factors in a proper perspective. The estimation assumes iodine to exist in the PS in five forms: circulating as gas, sorbed on circulating dust, and chemisorbed on steel, graphite and on plated dust in the 
SG. Simple models are used to estimate (1) the total iodine inventory in the PS, (2) its distribution among the five forms, (3) the amount chemically desorbed due to depressurization and (4) the amount removed with the liftoff of dust. A detailed summary of this calculation is presented in Sect. 5.7. The numerical results are summarized below:

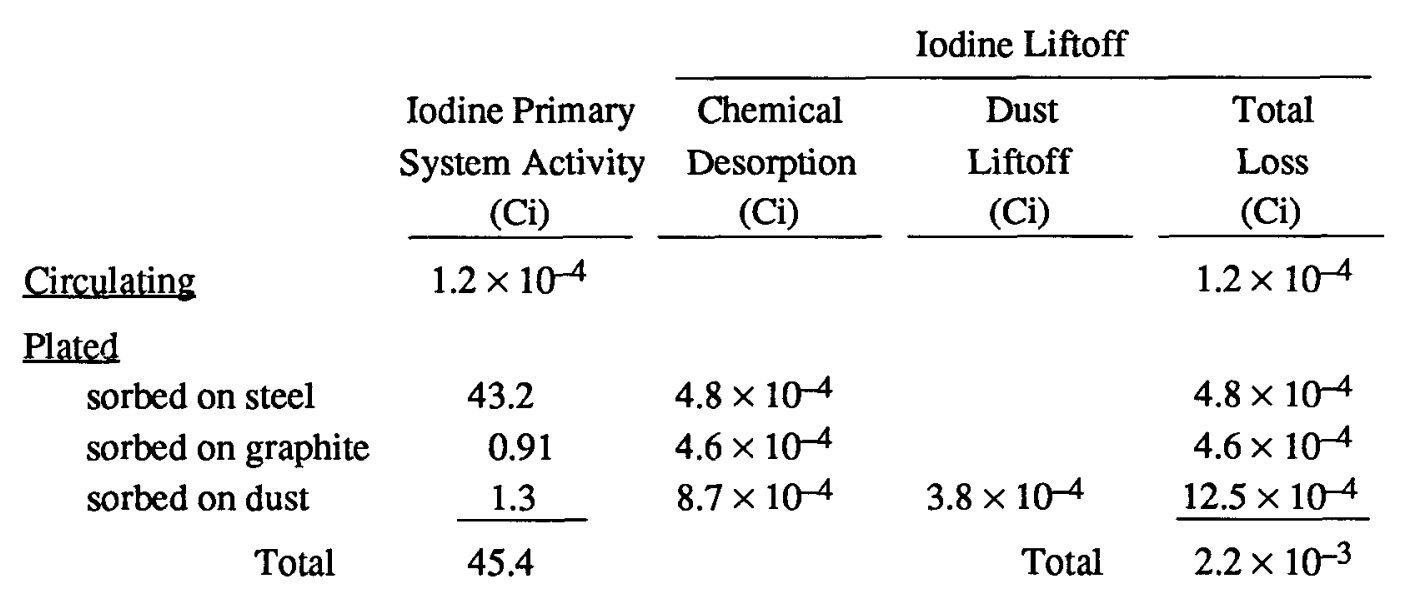

(20) Some general conclusions resulting from the sample calculation for iodine liftoff are the following: (a) There is some degree of uncertainty in the estimated PS inventory, i.e., the 45.4 Ci value, the main cause being the nature of the iodine release mechanism from failed fuel particles, including HM contamination. Data indicate lengthy holdup times of iodine within grains of $\mathrm{UO}_{2}$ in exposed kernels, such that the overwhelming portion of radioactive iodine in failed fuel particles is predicted to decay prior to release. One result is that small errors in the estimated decay in transport can cause significant changes in the predicted R/B. Furthermore, the transport delay of iodine in $\mathrm{UO}_{2}$ grains may be a function of burn-up and fuel manufacturing method. (b) The dust liftoff effect is predicted to be quite small, the primary reason being that only small and brief increase in shear ratio is predicted by RATSAM in the SG tubing (see Fig. 5.6-1). The evident reason is that the tubing region is protected from high shears by the large flow resistance afforded by the circulator, which is situated between the break (i.e., the open relief valve) and the tubing. If true, the depressurization flow is such that the SG tubing region is at least partially a dead zone. Regardless of which liftoff model is used in such case, only extremely small dust liftoffs would be predicted from the SG. Future estimations should therefore select other PS regions which are subjected to higher shears than predicted for the SG. However because its large surface area, the effectiveness of thermophoretic deposition, and the nature of the crossflow geometry causing multiple impactions, the major repository for plated dust is predicted to be the SG. (c) A second reason for the small effect of dust liftoff is that only $\sim 2.9 \%$ of the iodine inventory is predicted to be associated with plated dust. The bases for this estimate are the observed circulating dust levels in the Peach Bottom HTGR, a model relating these measurements to a quantity plated (the most speculative aspect of the estimate), and an approximate factor of 100 lower iodine sorptivity for "dust" relative to steel. (d) A possibly surprising result is that chemical desorption from graphite and from plated dust is about as significant as from steel, despite significantly lower inventories. The reason is that weak chemisorbers like graphite, which capture only about $2 \%$ of the PS iodine despite its enormous surface, 
therefore also more readily desorb iodine under depressurization conditions for the same reason. (e) The net result is a predicted $0.005 \%$ iodine release from the PS due to a base case dry depressurization. The estimate would increase somewhat by including higher shear zones (e.g., the core) in addition to the SG.

\subsection{CONCLUSIONS}

(1) Despite occasional success in computationally matching observed plateout distributions, a sufficient technical basis for "plateout" and "liftoff" modeling, does not exist or has not been applied. An acceptable modeling approach should properly account for all significant phenomena contributing to the deposition process. In particular plateout and liftoff mechanisms are expected to depend significantly on the unique chemical and physical properties of the individual FP elements. Computational models should reflect these differences.

(2) This review indicates that radioactive iodine release from the primary system as a result of a dry depressurization is likely to be quite small, perhaps on the order of $0.01 \%$ of the ex-fuel inventory, equivalent to a few millicuries. Several factors contribute to this conclusion. (a) The preponderant portion of iodine within the PS is likely to exist as chemically sorbed material on steel. It can be shown that the "liftoff" of this material due to chemical desorption is quite small. (b) The degree of dust liftoff due to shear forces during depressurization also appears to be small, due to negligible increases in shear ratio predicted by RATSAM for the SG, the principal dust repository. This observation is reinforced for iodine by noting that only a relatively weak interaction between iodine and the dust material is likely.

(3) Several considerations indicate that depressurization releases of cesium, strontium, and silver would likewise be extremely low. An unknown, but possibly major share of the cesium in the PS is expected to be permanently incorporated within the oxide coating of metal surfaces. As such, it would be unaffected by a depressurization event. Strontium will exist in the PS primarily as the highly refractory $\mathrm{SrO}$, or perhaps as $\mathrm{SrC}_{2}$ within graphite. In either case, such deposit forms would be solidified in place, and, except for the portion associated with dust, be unaffected by dry depressurization. The same may be said of silver, which is expected to exist principally as solidified deposits. Finally, a favorable situation may exist with respect to dust liftoff in that the principal dust repository, the SG, may be protected from high shear forces by the adjacent circulator. If current RATSAM results prove correct, depressurization flows resulting from failure of the relief valve (the most likely accident initiator) would be directed preferentially through the core. As a consequence, the SG experiences only small increases of shear ratio, on the order of a few percent and only for very brief periods.

(4) A part of the basis for mechanistic modeling rests on predicting chemical interactions of the principal FP elements. The required chemical understanding may be largely available but has not yet been applied. The chemical behavior of iodine under dry plateout and liftoff is relatively straightforward and essentially known. Modeling iodine behavior may perhaps proceed along lines outlined in Sect. 5. The essential chemical behavior of strontium and silver seems also to be adequately understood. In contrast, the chemical behavior of cesium is significantly 
more complex and thus presents a more difficult modeling challenge. Nevertheless, even for cesium, the known chemical tendencies of the element must be recognized as a modeling basis.

(5) If dust transport effects prove to be a significant factor in the degree of depressurization release, predictive efforts run into several formidable obstacles. The principal obstacle in modeling dust transport effects lies in predicting the quantity, size and chemical makeup of the dust. Identification of dust forming mechanisms, qualification of each on a laboratory scale, and comparison with existing Peach Bottom HTGR data, appears to be the best approach to this difficult problem. In contrast, dust additions to loop experiments will always be questionable unless they can be more firmly based on sound material and modeling principles. Also, dust data from pebble bed reactors are not likely to be helpful in view of significantly different dust formation mechanisms leading different dust levels and types.

(6) Improvement of dust liftoff modeling should be considered using recently reintroduced concepts based on turbulent eddy penetrations of the laminar sublayer. A potential advantage over the shear ratio concept as currently applied is that it provides a natural way for including time dependence in the liftoff process. The duration of the shear, which is a significant liftoff variable, could thereby be accounted for. In addition, physical reality appears to favor the turbulent burst mechanism for detaching plated particles relative to force ratio treatments. 


\section{REFERENCES}

Alberstein, D. et al. (1975), "Metallic FP Release from the HTGR Core," GA-A13258.

Acharya, R. (1988), "Specifications for Comedie Test BD-1", DOE-HTGR-87095, Rev. A, September 1988.

Brockman, J. E. (1985), "Resuspension of FP's During Containment Depressurization," Appendix G in SAND84-0410.

Bullock, R. E. (1983), “FP Release During Post-Irradiation Anneals of Several Types of Coated Fuel Particles," GA-A17046.

Busch, D. D. et al., 1972, "Particulate Matter in the Peach Bottm HTGR Primary System," Gulf, GA. B10034.

Clark, M. J. (1979), "The Desorption of Cesium from Peach Bottom HTGR Steam Generator Tubes," AERE-R8949.

Cleaver, J. W. and Yates, (1973), "Mechanism of Detachment of Colloidal Particles form a Flat Substrate in a Turbulent Flow," J. of Colloid and Interface Sci. 44, 464-474.

Conklin, J. C., R. J. Krane (1989), "Thermophonectic Transport of Particles with Volumetric Heating in Natural Convection," ORNL-6573.

Corn, M. (1966), “Adhesion of Particles," in Aerosol Science, Academic Press.

Craig, G. T. (1975), "The Behavior of Particulates in HTGR's," GA-A.13402.

Dennis, R. (1976) Editor, “Handbook on Aerosols,” TID-26608.

Dyer, F. F., et al., 1977, "Distribution of Radionuclides in the Peach Bottom HTGR Primary Circuit during Core 2 Operation," ORNL-5188.

Everett, M. R. (1967), et al., “Carbon Transport Studies for Helium Cooled HTRs,” DPR-491.

Feber, R. C. et al. (1976), "Application of Code QUIL to Cesium-Impurity Equilibria in the Primary System of HTGR's," LA-NUREG-6373.

Fromentin, A. (1989), "Particle Resuspension from a Multi-Layer Deposit by Turbulent Flow," Paul Scherrer Institute, Report-38.

Fuchs, N. (1964), "The Mechanics of Aerosols," Pergamon Press.

GA-DABLE (1988), "DABLE Project Test Plan," DOE HTGR-88396, Rev. 0.

GA Staff, 1978, "Metallurigical Examination of Primary Circuit Components from the Peach Bottom HTGR," GA-A14506.

Gainey, B. W. (1977), “An Evaluation of Carbon Deposition and Possible Consequences in the HTGR," GA-A13982.

Glissmeyer, J. A. (1983), "Review of Models Applicable to Accident Aerosols," NUREG/CR-2835. 
Groos, E. et al. (1977), "FP Release From Coated Particles Imbedded in Spherical Fuel Elements for HTGR's," Nuc. Tech. 35, 509-515.

Haire, M. J., (1979), "Evaluation of Sr-90 Concentration Profiles in Peach Bottom Fuel Elements," ORNL/TM-6209.

Helmbold, M. and Allelein, H. J. (1983), “Comparison of FP Release Calculations for PB-HTR's of Different Fueling," in Transport of FP's in Matrix and Graphite, HMI-B372.

Lipimski, R. J., et al. (1985), “Uncertainty in Radionuclide Release under Specific LWR Accident Conditions," SAND84-0410.

Lorenz, R. A., et al. (1982), "Sorption/Desorption Behavior of Iodine on Graphite," ORNL/TM8284.

Marple, V. A. and K. Willeke, 1976, "Inertial Impactors: Theory, Design and Use," in Fine Particles, B.Y.H. LIU (Ed), Academic Press.

Massalski, T. B., Editor (1986), “Binary Alloy Phase Diagrams,” ASM.

Milstead, C. E., Zumwalt, L. R. (1967), “Cesium Deposition on Stainless Steel," Nuc. Appl. 3, 495-499.

Moorman, R. and Verfondern, K. (1986), "Probabilistic Safety Analyses Methods for Selected HTR Concepts," Vol 3: Fission Product Release, Jülich Special Report 388/Vol. 3.

Myers, B. F. et al. (1977), “The Behavior of FG's in HTGR Fuel Material," GA-A13723.

Myers, B. F. (1986), “Analysis of FG Release from HM Contamination,” GA document 907657.

Nabielek, H. and Myers, B. F. (1982), "FP Retention in HTR Fuel," in Gas-Cooled Reactors Today, Proc. Conf. Bristol, 20-24, 1982.

Nabielek, H. et al. (1977), "Silver Release from Coated Fuel Particles," Nuc. Tech. 35, 483-493.

NPR-DOE (1989), “Five-Year Engineering Development Plan,” Rev. 0, September 1989.

Osborne, M. F., et al. (1982), "Iodine Sorption on Low Chromium Alloy Steel," ORNL/TM7755.

Plumlee, D. E. (1984), "HTGRIT: Computer Prediction of the Impurity Effects in an HTGR Primary Loop: Preliminary Results," GE Doc. XL-848-850040.

Pointud, M. L. and Chenebault, P. (1977), "Emission of FG's by Failed Coated Oxide Fuel Particles," Nuc. Tech., 35, 494-500.

PSID (1986), "Preliminary Safety Information Document for the Standard MHTGR."

Reeks, M. W. et al. (1988), "On the Resuspension of Small Particles by a Turbulent Flow," J. Appl. Phys. D, 21, 574-589.

Roberts, D. L., et al. 1984, “Aerosol Retention in Nuclear Reactor Components," NP-3705.

Saffman, P. G. (1968), "Lift on a Small Sphere in Slow Shear Flow," J. Fluid Mech. 22, 385-400.

Schneider, A., et al., 1989, “A Study of Dust Formation in HTGR's,” Project E25-661. 
Stansfield, O. M. et al. (1983), "Fuel Performance Models for the HTGR Systems," GA-10073.

Tiegs, T. N. et al. (1981), "FP Behavior in $\mathrm{UC}_{\mathrm{x}} \mathrm{O}_{\mathrm{y}}$ Fissile Particles made from WAR's," J. Nuc. Mat. 99 (1981) 222-234.

USNRC (1989), “Severe Accident Risks,” NUREG-1150, Vol. 1.

Vanslager, F. E., et al. (1970), "Fission Product Transport in HTGR Systems," GA-10073.

Vatistas, N. (1989), "The Effect of Adhesion Time on Particle Deposition," Chem. Eng. Sci. 44, 1603-1608.

Wen, H. Y. and Kasper, G. (1989), "On the Kinetics of Particle Reentrainment," J. Aero. Sci. 20, 483-498.

Wichner, R. P., et al., (1978), "Distribution of Fission Products in Peach Bottom HTGR Fuel Element E0101," ORNL/TM-6343.

Wichner, R. P. and F. F. Dyer (1979), "Distribution and Transport of Titanium in the Peach Bottom HTGR," ORNL-5497.

Wichner, R. P. and F. F. Dyer (1980), "Carbon-14 Production in the Peach Bottom HTGR Core," ORNL-5597.

Williams, P. T., et al. (1989), “Draft Preapplication SER for the MHTGR,” NUREG-1338.

Woolley, R. L. (1981), "The Desorption of Cesium from Peach Bottom HTGR Steam Generator Tubes," AERE-R8949.

Wright, A. L., 1988, "Aerosol and I-Vapor Deposition Relevant to TVA Radiation monitor Sampling Lines," ORNL-6461.

Yamano, N. and J. E. Brockmann, 1989, “Aerosol Sampling and Transport Efficiency (ASTEC) with Application to the Surtsey Aerosol Samplers," NUREG/CR-5252.

Zumwalt, L. R. (1983), "Review of Sorption of Metallic FP's on Graphite," in Transport of FP's in Matrix and Graphite, HMI-B372. 


\section{Appendix A}

\section{FORMATION DIAGRAMS FOR THE PRINCIPAL IODINE, CESIUM, STRONTIUM, AND SILVER NUCLIDES}

The formation diagrams shown in Fig. A.1 through A.4, adapted from Voigt (1976), are based on data for thermal fission of U235. Some simplifications have been made which are probably insignificant for the purpose of evaluating precursor effects on fission product transport. The vertical arrows in each figure signify the atomic number at birth for each mass number. Yields are given beneath each arrow as mols produced per 100 mols of fission. The yields denoted with a prefix " $t$ " indicate an incremental yield for the higher atomic numbers. Stable or near-stable nuclides are highlighted by the rectangular border. 


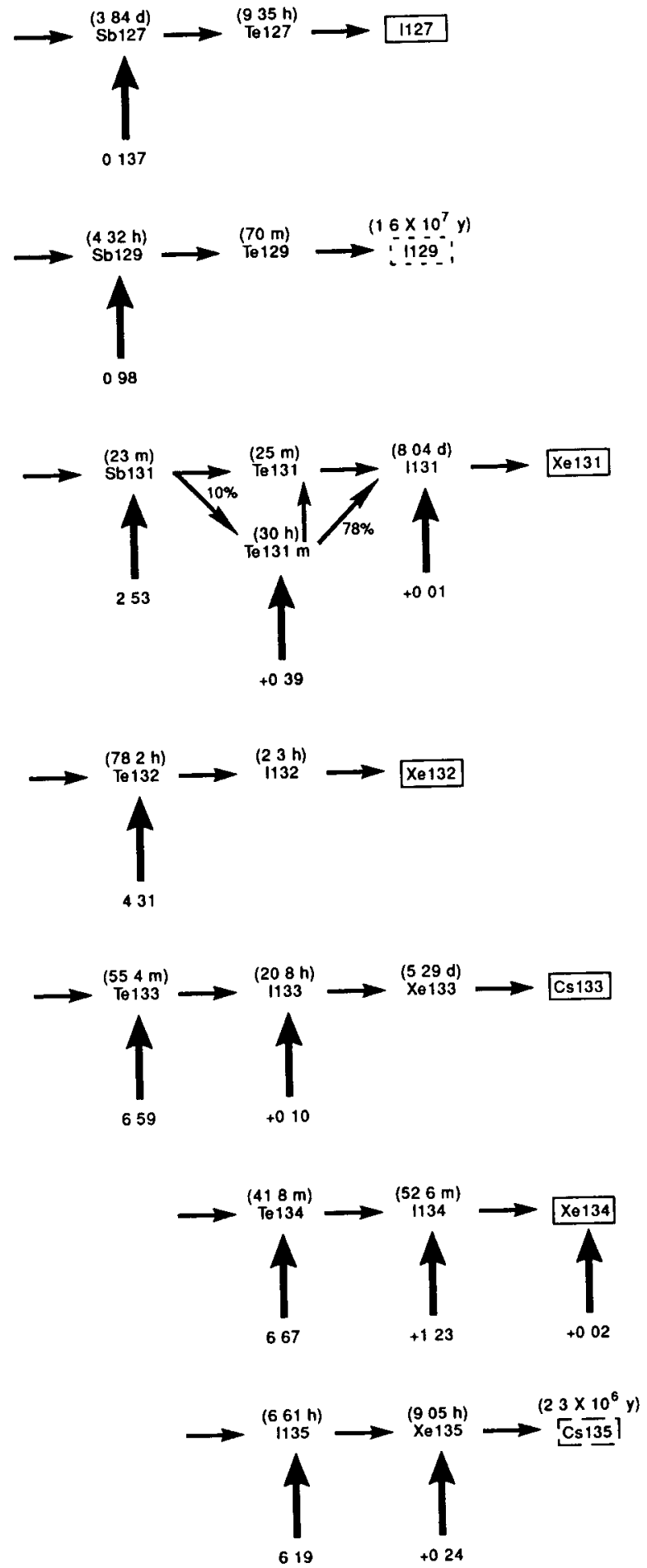

Fig. A.1. Formation of iodine nuclides. 

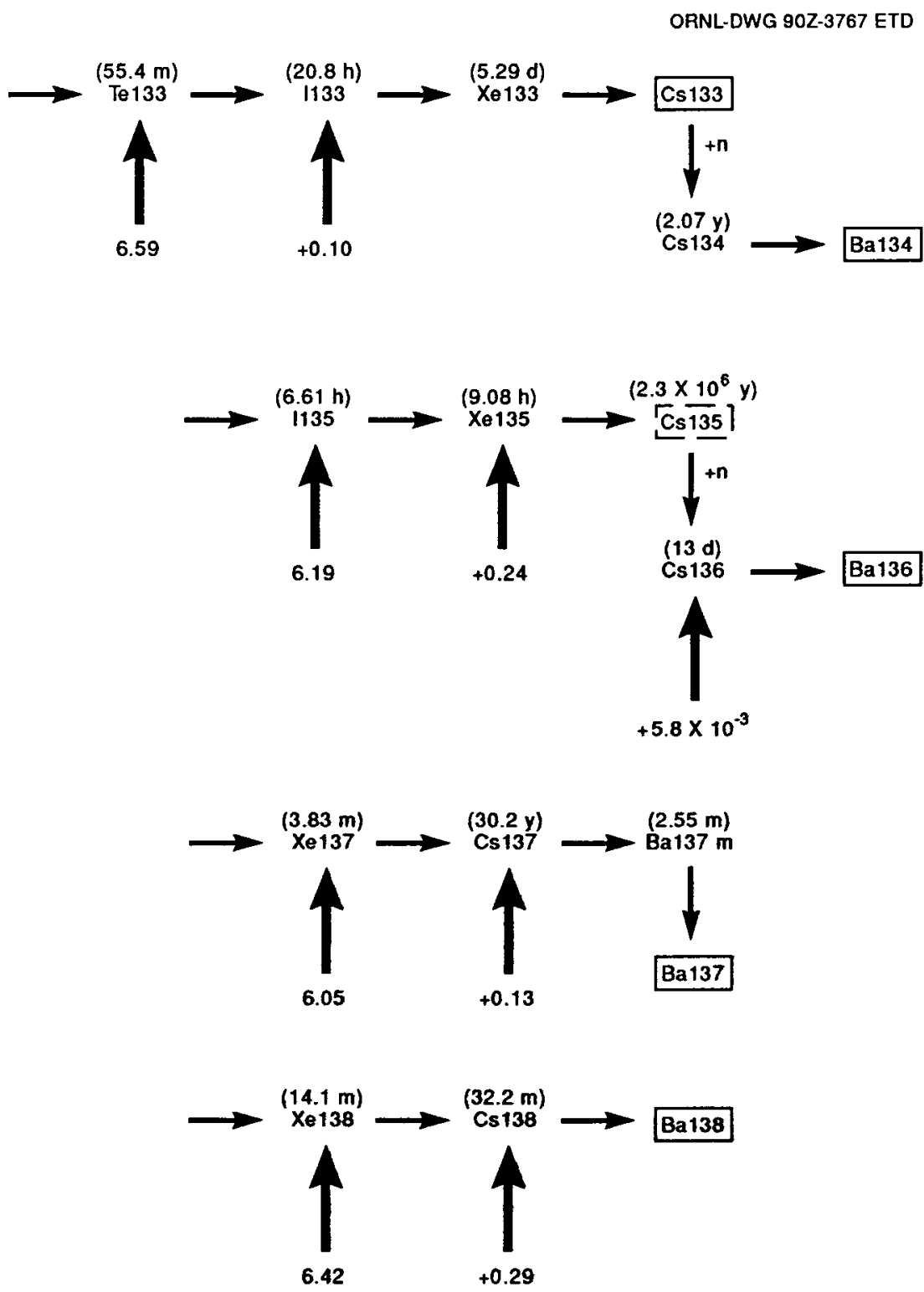

Fig. A.2. Formation of cesium nuclides. 
ORNL-DWG 90Z-3766 ETD

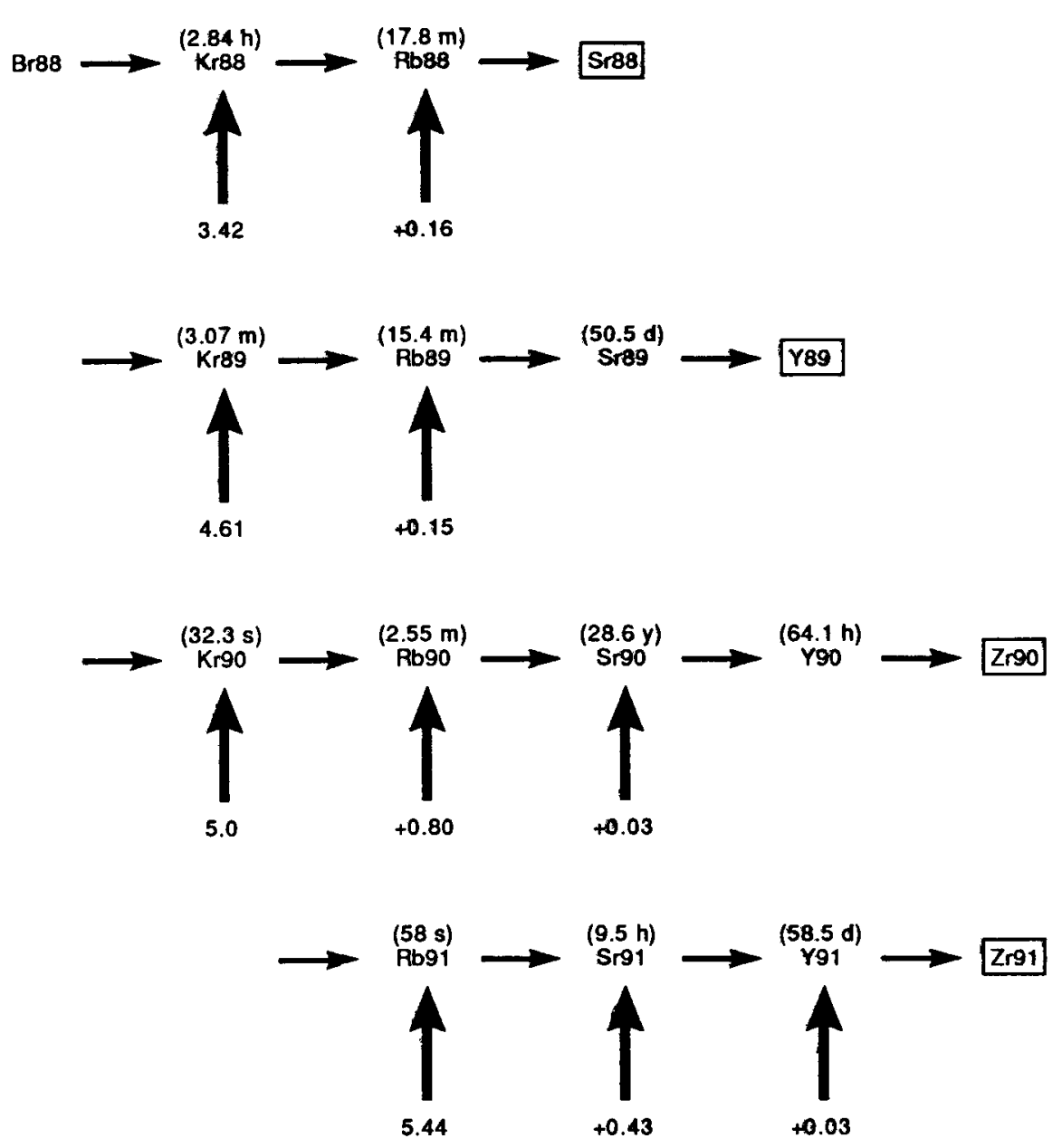

Fig. A.3. Formation of strontium nuclides. 


\section{$103 / 104$}

ORNL-DWG 90Z-3770 ETD

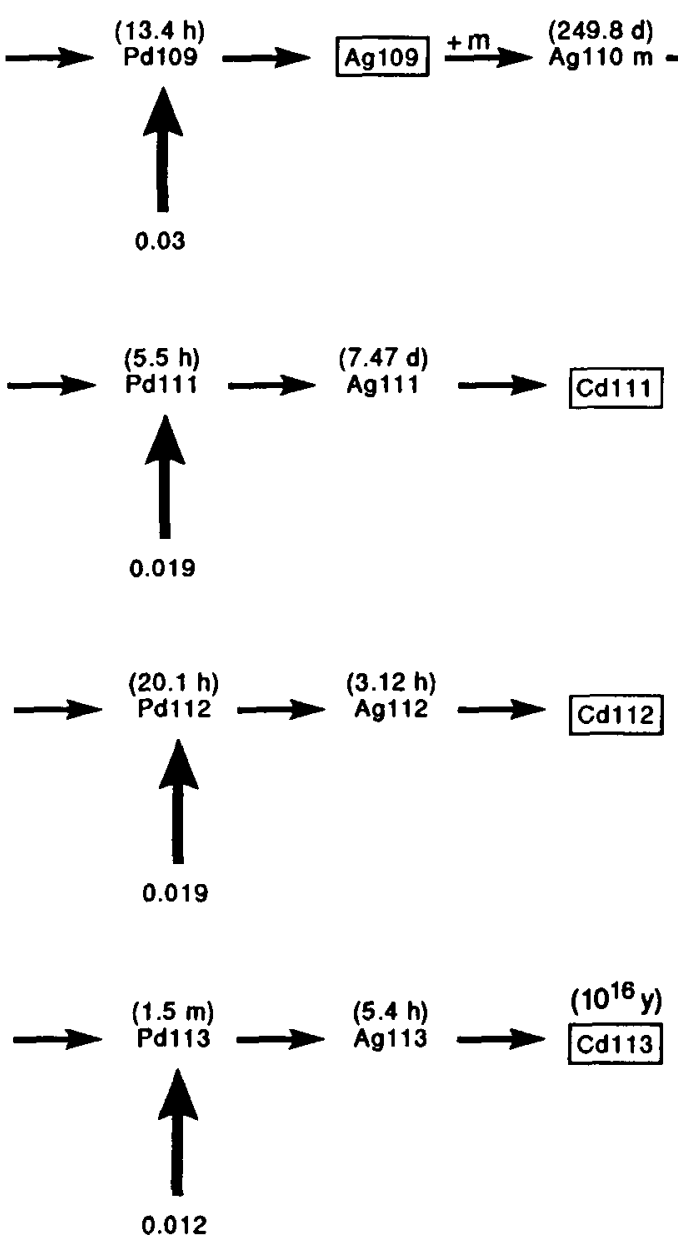

Fig. A.4. Formation of silver nuclides. 



\section{Appendix B}

\section{DUST PLATEOUT CONDITIONS AND CALCULATIONAL METHOD}

\section{B.1 DEPOSITION MECHANISMS (see Sect. 3.3 for references)}

1. Diffusion across the laminar sublayer (lsl) from a turbulent central region of flow (core) in which particles are uniformly distributed.

2. Thermophoresis across a lsl from a turbulent core.

3. Turbulent impaction across a lsl from a turbulent core.

4. Inertial impaction to a cylinder in cross-flow. Since a theoretical expression is used, a multiplicative bounce-off factor is used with this correlation.

\section{B.2 ASSUMED FLOW CONDITIONS IN THE SG AND PARTICLE PROPERTIES}

\begin{tabular}{|c|c|c|c|}
\hline Property & Symbol & Value & Unit \\
\hline pressure & $\mathbf{P}$ & 6.38 & $\mathrm{MPa}$ \\
\hline temperature & $\mathrm{T}$ & 746 & $\mathbf{K}$ \\
\hline gas density & $\rho_{g}$ & 4.12 & $\mathrm{~kg} / \mathrm{m}^{3}$ \\
\hline viscosity & $\mu$ & $3.71 \times 10^{-5}$ & $\mathrm{~Pa} \cdot \mathrm{s}$ \\
\hline gas thermal conductivity & $\mathrm{k}_{\mathrm{g}}$ & 0.293 & $\mathrm{~W} / \mathrm{m} \cdot \mathrm{k}$ \\
\hline mean velocity & $\mathrm{U}$ & 160 & $\mathrm{~m} / \mathrm{s}$ \\
\hline volume flow rate & $Q$ & 38.2 & $\mathrm{~m}^{3} / \mathrm{s}$ \\
\hline tube diameter & $d_{t}$ & 0.022 & m \\
\hline number of impactions (est) & $\mathrm{N}_{\mathrm{b}}$ & 100 & \\
\hline SG surface area & $\mathrm{A}_{\mathrm{s}}$ & 4020 & $\mathrm{~m}^{2}$ \\
\hline mean free path in $\mathrm{He}$ & $\lambda$ & $3.8 \times 10^{-8}$ & \\
\hline Reynolds no. based on tube & $\mathrm{R}_{\mathrm{et}}$ & $3.91 \times 10^{5}$ & \\
\hline friction factor, $\tau_{w} / \rho U^{2}$ & f & 0.002 & \\
\hline friction velocity & $\mathrm{U}^{*}$ & 7.12 & $\mathrm{~m} / \mathrm{s}$ \\
\hline particle diameter & $d_{p}$ & $10^{-3}-10$ & $\mu \mathrm{m}$ \\
\hline particle density & $\rho_{p}$ & & \\
\hline soot & & 1000 & $\mathrm{~kg} / \mathrm{M}^{3}$ \\
\hline rust & & 5200 & \\
\hline particle thermal conductance & $k_{p}$ & & \\
\hline soot & & 60 & $\mathrm{~W} / \mathrm{m} \cdot \mathrm{k}$ \\
\hline rust & & 20 & \\
\hline $\begin{array}{l}\text { particle diffusion coefficient } \\
\text { deposition velocity }\end{array}$ & $\mathrm{D}_{\mathrm{p}}$ & & $\mathrm{m}^{2} / \mathrm{s}$ \\
\hline diffusion & $\mathrm{V}_{\mathrm{D}}$ & & $\mathrm{m} / \mathrm{s}$ \\
\hline thermophoresis & $V_{\text {th }}$ & & \\
\hline turb. impaction & $V_{t}$ & & \\
\hline
\end{tabular}




\begin{tabular}{|c|c|c|c|}
\hline Property & Symbol & Value & Unit \\
\hline \multicolumn{3}{|l|}{ deposition efficiency } & \\
\hline diffusion & $E_{D}$ & & \\
\hline thermophoresis & $E_{t h}$ & & \\
\hline turb. impaction & $E_{t}$ & & \\
\hline inertial & $\mathrm{E}_{\mathbf{i}}$ & & \\
\hline sublayer thickness & $\Delta y$ & & \\
\hline Knudsen no. & $\mathrm{Kn}$ & & \\
\hline slip factor & $\mathrm{C}$ & & \\
\hline Stanton no. (particle) & St & & \\
\hline sticking fraction & sf & & \\
\hline fraction of strikes per tube & $\mathrm{N}_{\mathbf{i}}$ & & \\
\hline fraction sticking per tube & $\mathrm{N}_{\mathrm{si}}$ & & \\
\hline fraction transmitted, total & $\mathrm{E}$ & & \\
\hline
\end{tabular}

\section{B.3 DIFFUSION ACROSS $\ell$ sl}

$$
\begin{aligned}
\mathrm{D}_{\mathrm{p}} & =\frac{\kappa \mathrm{TC}}{\pi \mu \mathrm{d}_{\mathrm{p}}} \\
\mathrm{V}_{\mathrm{D}} & =\mathrm{D}_{\mathrm{p}} / \Delta \mathrm{y} \\
\Delta \mathrm{y} & =\mathrm{y}^{+} \mu / \rho \mathrm{U}^{*}=12.4 \mu \mathrm{m} \text { for } \mathrm{y}^{+}=10 \\
\mathrm{U}^{*} & =\mathrm{U} \sqrt{\mathrm{f}} \\
\mathrm{Kn} & =2 \lambda / \mathrm{dp} \\
\mathrm{C} & =1+\mathrm{Kn}[1.257+4 \exp (-1.1 / \mathrm{Kn})] \\
\mathrm{E}_{\mathrm{D}} & =\exp \left(-\mathrm{V}_{\mathrm{D}} \mathrm{A}_{\mathrm{D}} / \mathrm{Q}\right)
\end{aligned}
$$

\section{B.4 TURBULENT IMPACTION ACROSS $\ell$ s}

$$
\begin{aligned}
\mathrm{V}_{\mathrm{t}} & =6 \times 10^{-4} \tau_{+}^{2} \mathrm{U}^{*}, \text { for } \tau_{+}<12.9 \\
& =0.1 \mathrm{U}^{*}, \text { for } \tau_{+}>12.9 \\
\tau_{+} & =\rho_{p} \rho_{\mathrm{g}} \mathrm{d}_{\mathrm{p}}^{2}\left(\mathrm{U}^{*}\right)^{2} \mathrm{C} /\left(18 \mu^{2}\right) \\
\mathrm{E}_{+} & =\exp \left(-\mathrm{V}_{\mathrm{t}} \mathrm{A}_{\mathrm{p}} / \mathrm{Q}\right)
\end{aligned}
$$

\section{B.5 THERMOPHORESIS ACROSS $\ell s \ell$}

The treatment follows that of Wright (1988) using property data from C.1. A temperature driving force of $50 \mathrm{~K}$ is assumed across the wall-effected layer. 


\section{$107 / 108$}

B.6 INERTIAL IMPACTION (following method of Wright (1988)

$$
\begin{aligned}
\mathrm{N}_{\mathrm{i}} & \cong 1-\exp (-0.1 \cdot \mathrm{St} \cdot \mathrm{C}) \\
\mathrm{N}_{\mathrm{si}} & =\mathrm{sf} \mathrm{N}_{\mathrm{i}} \\
\mathrm{E}_{\mathrm{I}} & =\left[1-\mathrm{N}_{\mathrm{si}}\right]^{\mathrm{N}_{\mathrm{b}}}
\end{aligned}
$$

\section{B.7 TOTAL TRANSPORT EFFICIENCY}

$$
E=E_{D} \cdot E_{t h} \cdot E_{t} \cdot E_{I}
$$





\section{Appendix C}

\section{DERIVATION OF THE FORCE RATIO LIFTOFF CRITERION (SECTION 4.3)}

Model assumptions are presented in Sect. 4.3. A nomenclature list is provided in this appendix.

Velocity profile and particle Reynolds No.

$$
\begin{aligned}
& u^{+}=y \\
& u(y)=\frac{y U^{2} \rho f}{\mu} \\
& u_{p}=\frac{d_{p} U^{2} \rho f}{2 \mu} \\
& \operatorname{Re}_{p}=\frac{d_{p} u_{p} \rho}{\mu} \\
& \operatorname{Re}_{p}=\frac{f}{2} \frac{d_{p} \rho U}{\mu}
\end{aligned}
$$

\section{Drag force}

$$
\begin{aligned}
& F_{D}=\frac{1}{2} \rho u_{p}^{2} A_{p} C_{D} \\
& A_{p}=\frac{1}{4} \pi d_{p}^{2}
\end{aligned}
$$

Substituting (C.1) and definition of Ap into C.4 yields,

$$
F_{D}=0.0982 \frac{d_{p}^{4} U^{4} \rho^{3} f^{2} C_{D}}{\mu^{2}}
$$

Adhesive force assumption

$$
F_{A}=A^{\prime} d_{p}
$$




\section{Liftoff criterion}

$$
\frac{F_{D}}{F_{A}} \geq 1
$$

Combining (C.5), (C.6) yields

$$
\frac{F_{D}}{F_{A}}=\frac{0.0982 d_{p}^{3} U^{4} p^{3} f^{2} C_{D}}{A^{\prime} \mu^{2}}
$$

For $\operatorname{Re}_{\mathrm{p}}<1$, which is the usual case for $d_{p}<1 \mu \mathrm{m}$ plated within the laminar sublayer,

$$
C_{D}=\frac{24}{\operatorname{Re}_{p}}
$$

Combining (C.2), (C.7), (C.8), (C.9) and solving for $U$, yields the liftoff velocity, $\mathrm{U}_{\mathrm{LO}}$

$$
\mathrm{U}_{\mathrm{LO}}>\frac{\overline{0.212 \mathrm{~A}^{\prime}}}{\mathrm{d}_{\mathrm{p}} \rho \mathrm{f}}
$$

\section{Typical MHTGR Values}

$$
\begin{aligned}
\rho & =4.12 \mathrm{~kg} / \mathrm{m}^{3} \\
\operatorname{Re} & =1.8 \times 10^{5} \\
\mathrm{f} & =0.0019 \\
\mathrm{~A}^{\prime}(\max ) & =1.1 \times 10^{-2} \mathrm{~N} / \mathrm{m} \\
\mathrm{A}^{\prime}(\min ) & =1.5 \times 10^{-5} \mathrm{~N} / \mathrm{m}
\end{aligned}
$$

Substituting into the liftoff velocity criterion, (C.9) yields for typical SG conditions,

$$
\mathrm{U}_{\mathrm{LO}}>5.20 \frac{\mathrm{A}^{\prime}}{\mathrm{d}_{\mathrm{p}}},
$$

using units of $N / m$ for $A^{\prime}$ and meters for $d_{p}$.

\section{Alternate expression for $\mathrm{F}_{\mathrm{D}}$}

Substituting (C.1), (C.2), (C.9) into (C.4),

$$
\mathrm{F}_{\mathrm{D}}=4.71 \mathrm{~d}_{\mathrm{p}}^{2} \tau_{\mathrm{w}}
$$


$111 / 12$

Nomenclature for Appendix C

$\begin{array}{ll}u^{+} & u / U^{*} \\ y^{+} & y \rho U^{*} / \mu \\ u & \text { local mean velocity } \\ u_{p} & \text { local velocity at } y=d_{p} / 2 \\ U & \text { space-average mean velocity } \\ U^{*} & \text { friction velocity }=\sqrt{\tau_{w} / \rho} \\ \tau_{w} & \text { wall shear stress } \\ \rho & \text { helium density } \\ y & \text { distance from wall } \\ d_{p} & \text { particle diameter } \\ f & \tau_{w} / \rho U^{2} \\ \mu & \text { helium viscosity } \\ F_{D} & \text { drag force } \\ F_{A} & \text { adhesive force } \\ A^{\prime} & \text { adhesion constant }=F_{A} / d_{p} \\ C_{D} & \text { drag coefficient } \\ R_{p} & d_{p} \rho u_{p} / \mu \\ R e & \text { D } \rho U / \mu \\ D & \text { conduit dimension } \\ A_{p} & \text { cross-sectional area of particle }\end{array}$





\section{Appendix D}

\section{MODEL FOR CHEMISORPTIVE DESORPTION}

Referring to Fig. D.1, the model assumes one region of volume, V, surface area, A, initial pressure, $P_{1}$, and uniform surface material at temperature, $T$. At time zero, a depressurization is initiated causing a blowdown flow rate of $\mathrm{Q}(\mathrm{t})$. The following terminology is adopted:

$\mathrm{C}(\mathrm{t})=$ iodine concentration in gas, $\mathrm{mol} / \mathrm{m}^{3}$,

$\mathrm{C}_{2}=$ final value of $\mathrm{C}(\mathrm{t}), \mathrm{mol} / \mathrm{m}^{3}$,

$\mathrm{S}(\mathrm{t})=$ iodine surface concentration, $\mathrm{mol} / \mathrm{m}^{2}$,

$\mathrm{V}=$ volume, $\mathrm{m}^{3}$,

$A=$ surface area, $\mathrm{m}^{2}$,

$Q(t)=$ blowdown flow rate, $\mathrm{m}^{3} / \mathrm{s}$,

$\mathrm{P}_{1}, \mathrm{P}_{2}=$ initial and final pressures, $\mathrm{Pa}$,

$\mathrm{KL}=$ Langmuir sorptivity, $\mathrm{mol} / \mathrm{m}^{2} \cdot \mathrm{Pa}$,

$n(t)=$ total iodine in system, mol,

$n_{1}, n_{2}=$ initial and final values of $n, m o l$,

$\mathrm{n}_{\mathrm{He}}(\mathrm{t})=$ quantity helium in system, mol,

$P_{I}=$ iodine partial pressure, $P a$.

The rate of iodine loss from the system is given by,

$$
\frac{d n}{d t}=-Q(t) C(t)
$$

ORNL-DWG 90Z-3785 ETD

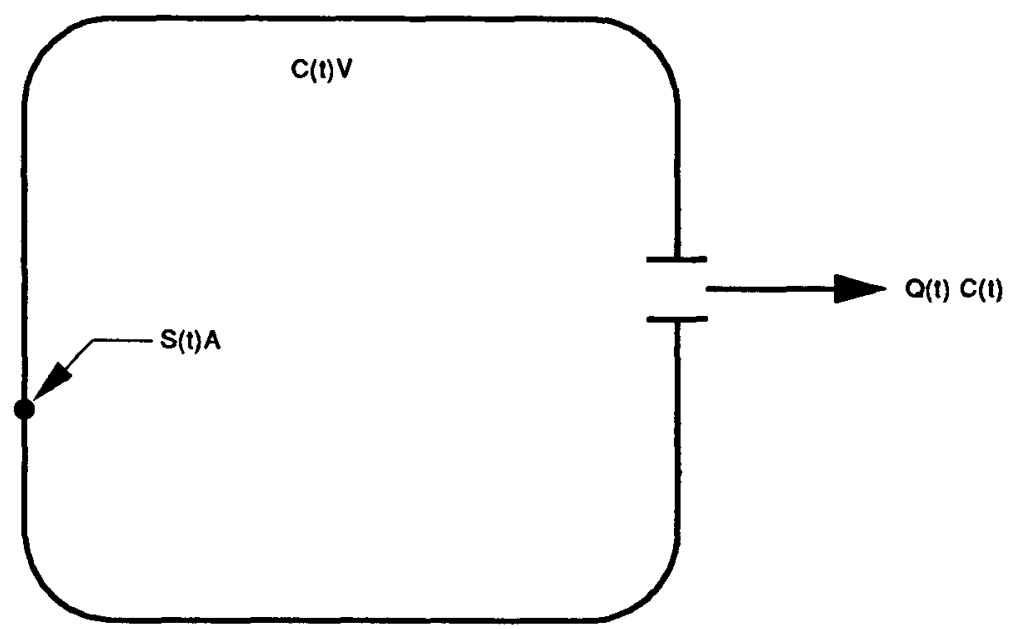

Fig. D.1. Situation assumed for chemical desorption model. 
The total mols in the volume $\mathrm{n}$ is related to $\mathrm{C}$ by the following, assuming chemisorption in the Henrian regime:

$$
n(t)=S(t) A+C(t) V
$$

Since $S(t)$ may be approximated at low coverage by,

$$
\mathrm{S}(\mathrm{t}) \equiv \mathrm{KLP}_{\mathbf{I}}
$$

using the ideal gas law for the iodine partial pressure leads to,

$$
S(t)=\operatorname{KLRT} C(t)
$$

Therefore,

$$
n(t)=C(t)[K L R T A+V]
$$

Substituting (D.4) into (D.1) and rearranging,

$$
\frac{d C}{C}=-\frac{Q(t) d t}{K L R T A+V}
$$

The integral of the RHS of Eq. (D.5) may be evaluated by noting,

$$
Q(t)=\frac{\operatorname{dn}_{H e}}{d t} \frac{R T}{P(t)}
$$

and

$$
\mathrm{n}_{\mathrm{He}}=\frac{\mathrm{P}(\mathrm{t}) \mathrm{V}}{\mathrm{RT}} \text {, }
$$

which leads to,

$$
\mathrm{Q}(\mathrm{t}) \mathrm{dt}=\frac{\mathrm{VdP}}{\mathrm{P}}
$$

Substituting Eq. (D.6) into (D.5) and integrating,

$$
\ln \frac{C(t)}{C(0)}=\frac{V}{K L R T A+V} \ln \frac{P(t)}{P_{1}} .
$$

Since $\mathrm{P}_{1}=6.38 \mathrm{MPa}$, then at the end of the blowdown when $\mathrm{P}_{2} \cong 0.1 \mathrm{MPa}$,

$$
C(\text { final })=C(0) \exp \left(\frac{-4.16 V}{K L R T A+V}\right)
$$

The fraction of iodine originally in the volume (both gaseous and plated) that is released by the blowdown, $F_{I}$, is defined by,

$$
F_{\mathrm{I}}=\frac{\mathrm{n}(0)-\mathrm{n}_{2}}{\mathrm{n}(0)}
$$


Substitution of Eq. (D.4) into (D.9) yields,

$$
\mathrm{F}_{\mathrm{I}}=1-\frac{\mathrm{C}_{2}}{\mathrm{C}(0)}
$$

applying Eq.(D.8),

$$
F_{I}=1-\exp \left(\frac{-4.16 V}{K L R T A+V}\right)
$$




\section{INTERNAL DISTRIBUTION}

1-2. S. J. Ball

3. Wolfgang Barthold

4. E. C. Beahm

5. S. H. Buechler

6. J. C. Cleveland

7. J. C. Conklin

8. S. R. Greene

9. F. J. Homan

10-11. Henry Jones

12. J. E. Jones Jr.

13-14. M. J. Kania

15. P. R. Kasten

16. T. S. Kress

17. R. A. Lorenz

18. J. C. Mailen

19. R. N. Morris
20. D. L. Moses

21. B. F. Myers

22. C. E. Pugh

23. J. P. Sanders

24. R. M. Schilling

25. O. M. Stansfield

26. D. B. Trauger

27-31. R. P. Wichner

32. A. L. Wright

33. A. Zucker

34. ORNL Patent Section

35. Central Research Library

36. Document Reference Section

37-38. Laboratory Records Department

39. Laboratory Record (RC)

\section{EXTERNAL DISTRIBUTION}

40. Director, Division of Regulatory Applications, Office of Nuclear Regulatory Research, U.S. Nuclear Regulatory Commission, Washington, DC 20555

41. Dr. Peter G. Kroeger, Brookhaven National Laboratory, Upton, NY 11973

42. Dr. Peter M. Williams, Division of Regulatory Applications, Office of Nuclear Regulatory Research, U.S. Nuclear Regulatory Commission, NL/S-169, Washington, DC 20555

43. Office of Assistant Manager for Energy Research and Development, Department of Energy, Oak Ridge Operations, Oak Ridge, TN 37831

44-45. Office of Scientific and Technical Information, P.O. Box 62, Oak Ridge, TN 37831

46-270. Given distribution as shown in categories R1, R7, and R8

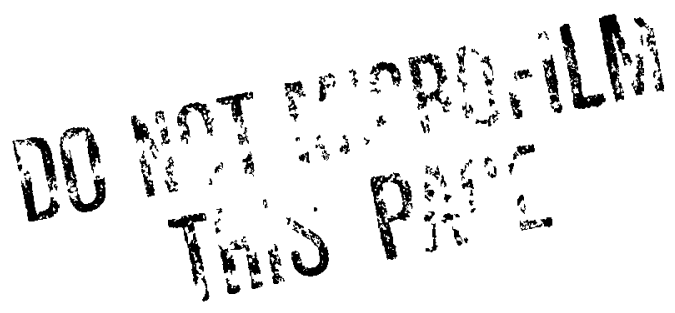




\begin{tabular}{|c|c|}
\hline 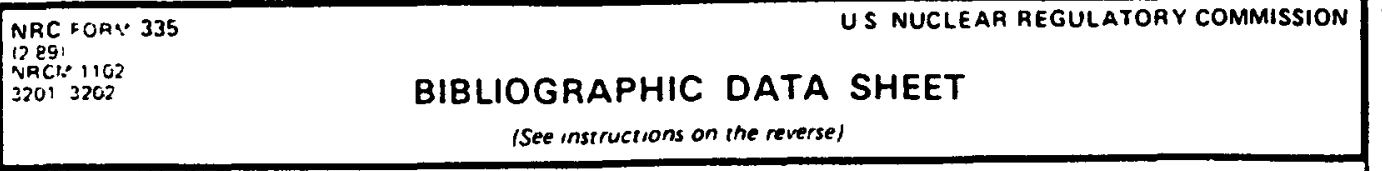 & 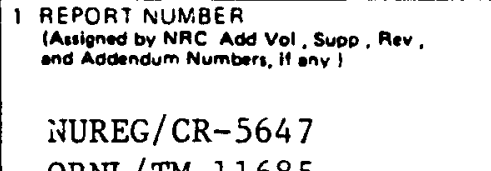 \\
\hline 2 TITLE AND SUBTITLE & ORNL/TM-11685 \\
\hline 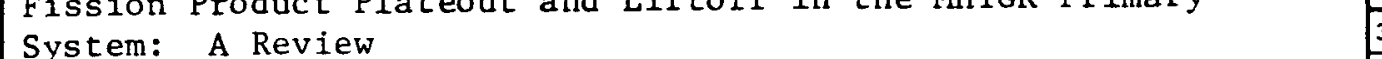 & DATE REPORT PUBLISHED \\
\hline & \begin{tabular}{l|c} 
MONTH & YEAA \\
April & 1991
\end{tabular} \\
\hline & $\begin{array}{l}4 \text { FIN OR GAANT NUMBER } \\
\text { A9477 }\end{array}$ \\
\hline $\begin{array}{l}5 \text { AUTHOR(S) } \\
\text { R. P. Wichner }\end{array}$ & $\begin{array}{c}6 \text { TYPE OF REPORT } \\
\text { Technical }\end{array}$ \\
\hline & 7. PERIOD COVERED /1nclusive Dates' \\
\hline $\begin{array}{l}8 \text { PERFOAMING ORGANIZATION - NAME AND ADORESS (II NRC, provide } \\
\text { neme dnd miling odoress. } \\
\text { Oak Ridge National Laboratory } \\
\text { Oak Ridge, TN } 37831-6285\end{array}$ & mission, ond moting edodress, al controcior, provide \\
\hline 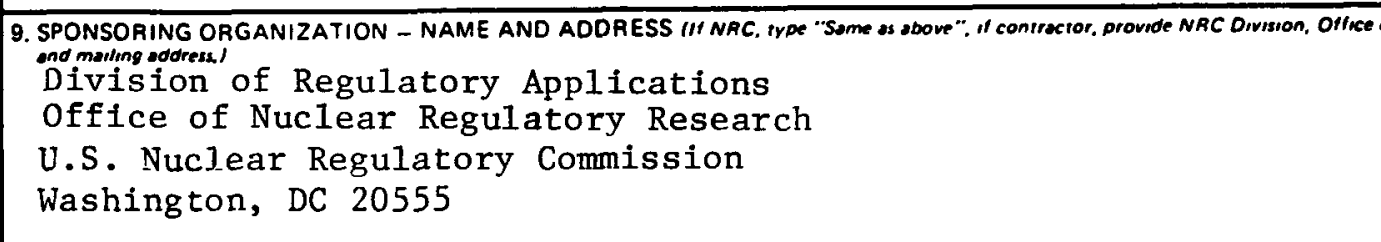 & Fegron. US. Nucker Regulatory Commisson. \\
\hline 10 SUPPLEMENTARY NOTES & \\
\hline $\begin{array}{l}\text { 11. ABSTRACT } 1200 \text { words or lest } \\
\text { A review is presented of methods for predicting radioactivity } \\
\text { depressurization of an MHTGR primary system. The various types o } \\
\text { effective for iodine, cesium, strontium, and silver are discussed in } \\
\text { characteristics and the nature of the materials in the primary sys } \\
\text { to iodine behavior, including the quantity available for release, } \\
\text { locations, and the effect of dust on distribution and release. } \\
\text { products cesium, strontium, and silver in such accidents is presen } \\
\text { A major part of the review deals with expected dust levels } \\
\text { Available information on the level and nature of dust in the } \\
\text { reviewed. A summary is presented of dust deposition and liftoff } \\
\text { This study concludes that lodine releases from dry depressuri } \\
\text { to be extremely low, due to low degrees of chemical desorptio } \\
\text { involvement of iodine with dust. Mechanisms controlling the dist } \\
\text { fission product material in the primary system, depend strongly on } \\
\text { the individual elements. Therefore, both plateout and liftoff mode } \\
\text { unique chemical and physical properties. }\end{array}$ & $\begin{array}{l}\text { y release resulting from } \\
\text { of deposition mechanisms } \\
\text { n terms of their chemical } \\
\text { stem. Emphasis is given } \\
\text { the types of "plateout" } \\
\text { The behavior of fission } \\
\text { nted qualitatively. } \\
\text { types, and transport. } \\
\text { HTGR primary system is } \\
\text { mechanisms. } \\
\text { zation events are likely } \\
\text { on, liftoff, and a low } \\
\text { tibution and liftoff of } \\
n \text { the chemical nature of } \\
\text { els should reflect those }\end{array}$ \\
\hline 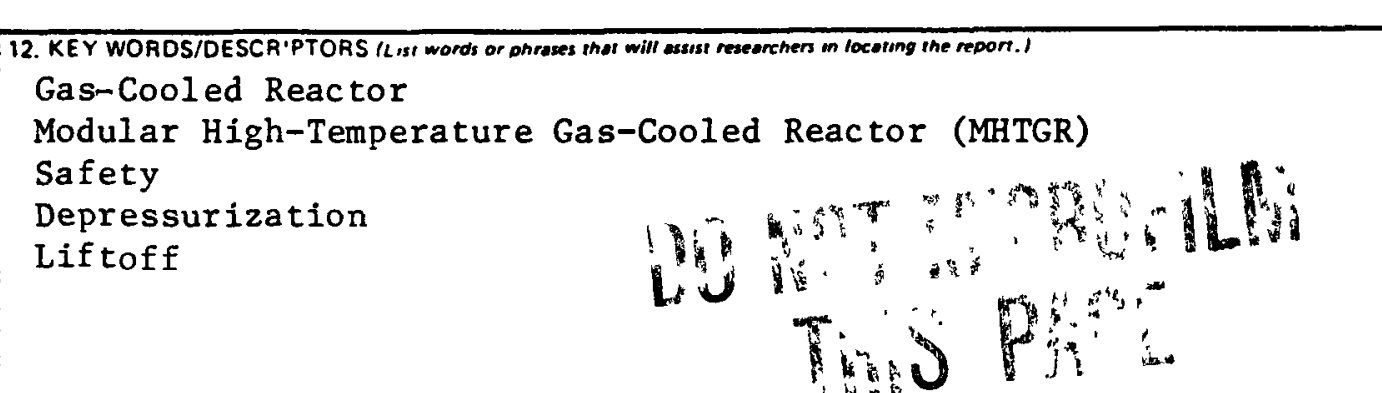 & 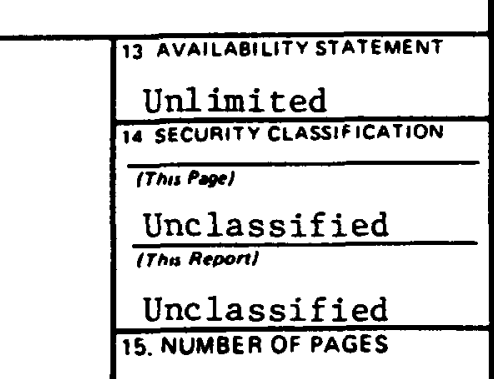 \\
\hline & 16 PRICE \\
\hline
\end{tabular}

